IZA DP No. 9814

Good Jobs, Bad Jobs:

What's Trade Got To Do With It?

James Lake

Daniel L. Millimet

March 2016 


\title{
Good Jobs, Bad Jobs: What's Trade Got To Do With It?
}

\author{
James Lake \\ Southern Methodist University \\ Daniel L. Millimet \\ Southern Methodist University \\ and IZA
}

\section{Discussion Paper No. 9814 \\ March 2016}

\author{
IZA \\ P.O. Box 7240 \\ 53072 Bonn \\ Germany \\ Phone: +49-228-3894-0 \\ Fax: +49-228-3894-180 \\ E-mail: iza@iza.org
}

\begin{abstract}
Any opinions expressed here are those of the author(s) and not those of IZA. Research published in this series may include views on policy, but the institute itself takes no institutional policy positions. The IZA research network is committed to the IZA Guiding Principles of Research Integrity.

The Institute for the Study of Labor (IZA) in Bonn is a local and virtual international research center and a place of communication between science, politics and business. IZA is an independent nonprofit organization supported by Deutsche Post Foundation. The center is associated with the University of Bonn and offers a stimulating research environment through its international network, workshops and conferences, data service, project support, research visits and doctoral program. IZA engages in (i) original and internationally competitive research in all fields of labor economics, (ii) development of policy concepts, and (iii) dissemination of research results and concepts to the interested public.
\end{abstract}

IZA Discussion Papers often represent preliminary work and are circulated to encourage discussion. Citation of such a paper should account for its provisional character. A revised version may be available directly from the author. 


\section{ABSTRACT}

\section{Good Jobs, Bad Jobs: What's Trade Got To Do With It?*}

Using US local labor markets between 1990 and 2010, we analyze the heterogeneous impact of rising trade exposure on employment growth of 'good' and 'bad' jobs. Three salient findings emerge. First, rising local exposure to import competition, via falling US tariffs or rising Chinese import penetration, reduces (increases) employment growth of bad (good) jobs. Conversely, improved local access to export markets, via falling foreign tariffs, increases (reduces) employment growth of bad (good) jobs. Second, falling US tariff protection is substantially more important, economically and statistically, than rising Chinese import penetration. Third, globalization generates occupational polarization but not job polarization.

JEL Classification: F13, J21, J31

Keywords: $\quad$ trade liberalization, China, local labor markets, job polarization, occupational polarization

Corresponding author:

James Lake

Department of Economics

Southern Methodist University

Box 0496

Dallas, TX 75275-0496

USA

E-mail: jlake@smu.edu

\footnotetext{
* We are grateful to Douglass Campbell, Maggie Chen, Martin Davies, Mina Kim, Bill Powers, Erick Sager and Beyza Ural for useful comments and discussion as well as many seminar and conference participants at the DC Junior Trade Study Group, Fall 2015 Midwest Trade Meetings, STATA Camp Econometrics 2015, George Washington University, University of Nevada Las Vegas, University of Richmond, USITC, and Washington and Lee University.
} 


\section{Introduction}

Recent years have witnessed a renewed interest in two issues concerning the US labor market. The first issue is the impact of trade on labor market outcomes, receiving significant public attention due to the increased economic and political clout of China and the potential for trade deals of unprecedented size (e.g., the Trans-Pacific Partnership and the Transatlantic Trade and Investment Partnership). In turn, new research has emerged which, unlike the earlier literature that found only modest labor market impacts of trade, documents substantial labor market impacts of China's rapid evolution in international markets since 1990.

The second issue is the disappearance of middle class jobs. Together with the relative rise in employment of low-skill and high-skill jobs, this has been labelled the 'dumbbell' or 'hourglass' economy in the popular press and job polarization in academia (Goos and Manning (2007); Samuel (2013)). Acemoglu and Autor (2011, p.1046) review the literature, stating that US and European Union labor markets have undergone "systematic, non-monotonic shifts in the composition of employment across occupations" resulting in "rapid simultaneous growth of both high education, high wage occupations and low education, low wage occupations." In the language of Goos and Manning (2007), there has been simultaneous growth in "lousy" jobs and "lovely" jobs and a decline in "middling" jobs.

Despite substantial evidence of job polarization across the developed world, a broad conclusion of this literature is that trade and/or offshoring are not responsible for job polarization. ${ }^{1,2}$ Nevertheless, the liberalization of trade policy and China's rapid rise in international markets suggests globalization still impacts the allocation of workers across jobs.

In this paper, we investigate the impact of rising trade exposure on the allocation of workers across jobs in the US. To this end, we merge central insights from the two aforementioned literatures. From the recent trade and labor literature, we borrow the insight that local labor markets offer an appropriate setting to investigate the impacts of trade exposure. From the job polarization literature, we borrow the insight that employment growth can vary in interesting ways across the distribution of job quality (where job 'quality' is a function of wages and education). ${ }^{3}$ Specifically,

\footnotetext{
${ }^{1}$ Countries include the US (Autor et al. $(2006) ;$ Autor and Dorn $\left.(2013)\right)$, the EU (Goos and Manning (2007); Goos et al. (2014)), Germany (Spitz-Oener (2006)), Denmark (Keller and Utar (2015)), and a set of eleven OECD countries (Michaels et al. (2014)).

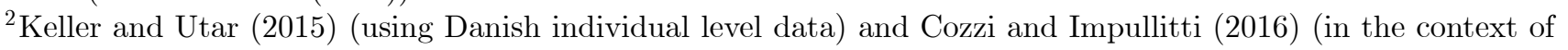
global technological convergence) represent exceptions to this broad conclusion.

${ }^{3}$ The notion of job quality is not intended to carry any normative connotations, but is rather a convenient way to describe a job's position in the distribution of wages and/or education.
} 
we analyze the heterogenous effects of trade exposure on employment growth between 1990 and 2010 across the job quality distribution. By defining jobs at a very disaggregate level, we assess how trade exposure differentially affects local employment growth of 'good' versus 'bad' jobs. As such, our research question, while related to the recent trade literature, differs in that we do not focus explicitly on the impacts of trade exposure on manufacturing or overall employment growth.

Our results are striking. Broadly, two salient findings emerge regarding the impact of trade exposure on the allocation of workers across jobs. First, and foremost, the impact of trade exposure on the employment growth of a job exhibits substantial heterogeneity according to a job's initial quality. ${ }^{4}$ Moreover, the qualitative nature of these effects differs dramatically depending on the mode of trade exposure. Rising local exposure to import competition - via declining US tariffs or rising Chinese import penetration - reduces employment growth of bad jobs but raises employment growth of good jobs. Conversely, rising local access to export markets - via falling foreign tariffs imposed on US exports - raises employment growth of bad jobs but reduces employment growth of good jobs.

Second, while we find a pattern of job polarization at the US local labor market level (consistent with Autor and Dorn (2013)) when holding local trade exposure constant at 1990 levels, we find that rising local trade exposure between 1990 and 2010 did not exacerbate job polarization. ${ }^{5}$ This confirms the broad conclusion of the job polarization literature that globalization has not exacerbated job polarization in the US. Rather, despite opposing effects of changes in import competition and foreign market access, the relative magnitudes indicate that globalization - resulting in a simultaneous rise in local import competition and local access to foreign markets - reallocates workers upwards in the distribution of job quality.

Our finding of substantial heterogeneity in the effects of trade exposure on the employment growth of jobs of different initial quality is not easily reconciled with standard trade theory. ${ }^{6}$ For concreteness, consider a two-sector full-employment model with two types of perfectly mobile labor, high skill and low skill. The two types of labor and two sectors create four 'jobs.' In the initial period

\footnotetext{
${ }^{4} \mathrm{As}$ is standard in the job polarization literature, we always use a time invariant measure of job quality to avoid confounding changes in the quality of a given job (the phenomena of intrest in the wage polarization literature) with a reallocation of workers across jobs of different quality.

5 Autor and Dorn (2013) document local labor market job polarization via a reallocation of low-skill workers into the broad occupational category of low-skill services. In contrast, our local labor market analysis documents a reallocation of workers among 1444 different jobs.

${ }^{6}$ As we discuss in Section 2, our baseline time invariant measure of job quality is based on the national distrubution of education and wages in 1990. However, we explore other time invariant measures in the sensitivity analyses that (i) only depend on wages, (ii) are computed separately for different regions, and (iii) are based on the year 2010 rather than 1990 .
} 
(denoted 0), low skill workers are paid a lower wage than high skill workers, $w_{L, 0}<w_{H, 0}$, and wages are equalized across sectors for each worker type. Using these initial wages to represent job quality, the distribution of employment across job quality has a mass of high (low) skill workers at $w_{H, 0}$ $\left(w_{L, 0}\right)$. Naturally, an increase in trade exposure may reallocate workers across sectors and change wages. However, changes in trade exposure have no effect on the distribution of employment across initial job quality; the distribution still has the mass of high (low) skill workers at $w_{H, 0}\left(w_{L, 0}\right)$.

Three assumptions appear crucial for this theoretical prediction. First, labor mobility eliminates wage dispersion across sectors for a given worker type. Otherwise, trade-induced resource reallocation can affect the distribution of workers across jobs of different initial quality (e.g., by changing the matching of low skill workers across jobs with different low skill wages). ${ }^{7}$ Second, there is a fixed one to one mapping between a worker's skill type and the jobs they can obtain. If workers of a given type choose the type of job they hold, trade-induced resource reallocation can affect the distribution of workers across jobs of different initial quality. In a more complex model, workers may be endowed with bundles of skills and select into jobs based on job-specific skills and the economy-wide distribution of returns to skills. ${ }^{8}$ Third, the distribution of factor endowments is fixed. If changes in trade exposure cause agents to alter the skills they possess, trade-induced resource reallocation can affect the distribution of workers across jobs of different initial quality. ${ }^{9}$ Our empirical results suggest theoretical models relaxing these assumptions are a fruitful avenue for future research by helping understand the link between trade exposure and the dynamic matching of workers to jobs of different quality.

We also obtain a number of other results pertinent to future studies of the local labor market effects of trade. First, falling US tariffs matter substantially more than rising Chinese import penetration. Studies investigating the impact of import competition on local labor market outcomes in

7 Davis and Harrigan (2011) offer an example. The authors merge the Shapiro and Stiglitz (1984) model of efficiency wages and the trade model of Melitz (2003) with firm-specific monitoring ability to create wage dispersion for workers of a given productivity. Falling foreign tariffs can then destroy good jobs and create bad jobs, consistent with our empirical results, by reallocating workers from high-wage unprofitable firms (i.e., where workers enjoy large rents) to low-wage profitable firms.

${ }^{8}$ The models in Acemoglu and Autor (2011), Autor and Dorn (2013) and Cozzi and Impullitti (2016) are three examples along these lines. The endogenous screening model of Helpman et al. (2010) is another example. In their model, more profitable firms (i) hire more workers, (ii) endogenously set higher ability thresholds when screening, and hence (iii) pay higher wages. To the extent that we think of falling foreign tariffs as increasing the profitability of export firms and falling US tariffs as reducing the profitability of import competing firms, this logic could help explain why falling foreign tariffs appear to push workers downward in the (time invariant) job quality distribution, but falling US tariffs have the opposite effect.

${ }^{9}$ In our empirical analysis, we control for the initial level of, as well as changes in, the educational composition of local labor markets. 
developed countries have typically focused on import penetration rather than trade policy Goldberg and Pavcnik (2016)). This is typified by the surge of recent papers, following the seminal work in Autor et al. (2013), analyzing the impact of Chinese import penetration. Autor et al. (2013) find substantial negative effects of Chinese import penetration on local labor market outcomes, including manufacturing employment. ${ }^{10}$ We also find a substantial negative effect of Chinese import penetration when omitting tariff policy from the empirical model, but we find the effect of Chinese import penetration is significantly attenuated once US and foreign tariffs are included. Thus, our results strongly complement McLaren and Hakobyan (2016) in that US tariffs, and trade policy more generally, are important determinants of US local labor market outcomes. ${ }^{11,12}$

Second, the impact of trade exposure on jobs of a given quality exhibits important heterogeneity depending on the job's sector. Specifically, while we find that jobs within the tradable goods sector are most affected, we also find economically significant effects of trade exposure on the distribution of workers across jobs in the tradable services and non-tradable sectors. The effects in these latter sectors arise even though our measures of trade exposure are solely based on tariffs and imports in the goods sector. Thus, we find non-trivial spillover effects in sectors not directly affected by goods-based trade and trade policy.

In the tradable services sector, where the US has a sizable trade surplus, we find employment growth partially offsets (accommodates) labor flows out of (into) tradable goods sector. Although they find little supporting empirical evidence, this is consistent with the reallocation mechanism between exposed and non-exposed tradable industries laid out in Acemoglu et al. (2015) that revolves around a tendency towards balanced trade. Nevertheless, the imprecision of our estimates imply our result should be treated cautiously. In the non-tradable sector, we find trade exposure has economically and statistically significant effects on the distribution of workers across jobs. Our results support recent empirical evidence of Keynesian-type aggregate demand spillovers where employment changes in the non-tradable sector magnify the impacts of trade exposure in the tradable goods sector (e.g., Mian and Sufi (2014); Acemoglu et al. (2015); McLaren and Hakobyan (2016)).

Third, our analysis highlights a subtle but important point regarding the relationship between

\footnotetext{
${ }^{10}$ Similar results have been found for Norway (Balsvik et al. (2015)), Germany (Dauth et al. (2014)), and Spain (Donoso et al. (2015)).

${ }^{11}$ Our results also complement the results in Shen and Silva (2014) who find a nuanced economic impact of rising local exposure to value added Chinese import penetration. Specifically, the authors obtain negative employment effects only when value added imports are measured as value added final good imports (as opposed to a measure including final and intermediate goods).

${ }^{12}$ Section 2 further discusses the literature on the local labor market impacts of trade exposure, including the closely related study by McLaren and Hakobyan (2016).
} 
occupational polarization and job polarization. As already discussed, we find that globalization and job polarization are not linked; overall, globalization reallocates workers from bad jobs to good jobs. However, classifying jobs into three standard occupational groups - non-routine, routine, and abstract - we find that an increase in any of the three measures of local trade exposure exacerbates occupational polarization, defined as stronger employment growth in non-routine and abstract occupations relative to employment growth in routine occupations (Autor et al. (2015)).

Our occupational polarization result is important for two reasons. First, it complements Autor et al. (2015) who, extending their analysis in Autor et al. (2013), show that rising local exposure to Chinese import penetration generates occupational polarization (and overall negative employment growth). We show these results hold for a broader class of measures capturing local trade exposure (i.e., US and foreign tariffs also). Second, our analysis highlights that occupational polarization and job polarization are not synonymous: our results suggest trade-induced occupational polarization but do not suggest trade-induced job polarization. Indeed, understanding how results concerning impacts on occupational polarization translate into effects on job polarization depends on both the marginal effects being estimated and the distribution of job quality within each occupational category.

Next, Section 2 describes the empirical methodology and data. Section 3 presents the baseline results. Section 4 discusses numerous sensitivity analyses. Section 5 investigates the relationship between occupational polarization and job polarization. Section 6 concludes.

\section{Empirics}

\subsection{Empirical model}

We assess the effects of trade exposure on employment growth across the job quality distribution in US local labor markets between 1990 and 2010. To do so, we build upon insights from the literatures on job polarization and the local labor market effects of trade exposure. Our baseline specification is

$$
\Delta n_{j c}=\beta_{0}+\beta_{1} q_{j}+\beta_{2} q_{j}^{2}+\Delta T_{c} \theta_{1}+q_{j} \Delta T_{c} \theta_{2}+x_{j c} \delta_{1}+\Delta x_{j c} \delta_{2}+\varepsilon_{j c}
$$

where $\Delta n_{j c}$ is the change in the employment share of job $j$ in US local labor market $c$ between 1990 and $2010, q_{j}$ measures the quality of job $j$ in 1990, $\Delta T_{c}$ represents a vector of changes in 
local trade exposure between 1990 and $2010, x_{j c}$ is a vector of controls, and $\varepsilon_{j c}$ is a mean zero error term. Henceforth, we slightly abuse terminology by using the term "employment growth" to describe $\Delta n_{j c}$. While detailed discussion of the data is relegated to the next section, we note that $x_{j c}$ includes economic and demographic attributes of locations, as well as state and industry fixed effects. $^{13}$

Our specification in (1) differs from the existing trade and local labor markets literature in two main ways. First, (1) assesses the impact of local trade exposure on the distribution of local employment across narrowly defined job types and allows heterogenous impacts with respect to the initial quality of a job, $q_{j}$. Note, including $q_{j}, q_{j}^{2}, x_{j c}$, and $\Delta x_{j c}$ controls for other determinants of employment growth: $q_{j}$ and $q_{j}^{2}$ allow changes in local job polarization arising for non-trade reasons and $x_{j c}$ and $\Delta x_{j c}$ allow general patterns of worker reallocation due to socioeconomic trends. ${ }^{14}$

Second, $\Delta T_{c}$ is a vector including changes in three measures of local trade exposure: changes in US tariffs $\left(\Delta \tau_{c}\right)$, changes in foreign tariffs $\left(\Delta \tau_{c}^{*}\right)$, and changes in Chinese import penetration $\left(\Delta I P_{c}\right)$. Whereas $\Delta \tau_{c}$ and $\Delta I P_{c}$ capture changes in local import competition, $\Delta \tau_{c}^{*}$ reflects changes in local access to export markets. Despite our primary interest being the impact of trade policy (via falling US and falling foreign tariffs), we control for the concurrent surge in Chinese IP given the strong empirical evidence of its adverse impact on US labor market outcomes. Moreover, by including trade policy and Chinese IP simultaneously, we make the novel contribution of investigating the relative importance of these alternative forms of trade exposure.

Our local (i.e., sub-national) labor markets approach follows the recent literature exploring the effects of trade exposure. As discussed in Goldberg and Pavcnik (2016), perfectly integrated national labor markets effectively imply a single observation during the period of study for each country-labor market pair. One solution to this degrees of freedom problem, as put in Autor et al. (2013), is using local labor markets as the geographic unit of analysis. This approach identifies the effects of trade exposure if worker geographic mobility is limited and local labor markets differ in trade exposure due to variation in industrial composition. ${ }^{15,16}$

\footnotetext{
${ }^{13}$ For time-varying variables in $x_{j c}$, we control for initial levels and changes over the sample period.

${ }^{14}$ Non-trade reasons may include changes in computerization leading to the disappearance of jobs that rely heavily on routine tasks (Autor et al. (2006); Goos and Manning (2007); Michaels et al. (2014)).

${ }^{15}$ One notable exception to the recent use of local labor markets is the national-level US study of Pierce and Schott (2016). They overcome the degrees of freedom problem by using annual data for the 28 year period between 1990 and 2007 and using more than 2006 -digit NAICS industries.

${ }^{16}$ As pointed out by Goldberg and Pavcnik (2016, p.11), if the indentifying assumption of limited gepographic mobility is violated in the data then the estimates will produce no systematic relationships. Thus, relying on geographic immobility is not inherently problematic.
} 
The local labor market approach to the assessment of trade policy originates in Topalova (2007) who analyzed the impact of unilateral tariff liberalization on poverty in India. While a number of subsequent studies take a similar approach in a developing country context, the only developed country study, according to Goldberg and Pavcnik (2016, p.37), is McLaren and Hakobyan (2016) who study the local wage impacts of tariff reductions granted by the US on Mexican imports under NAFTA. ${ }^{17}$ McLaren and Hakobyan (2016) find that workers in NAFTA vulnerable locations - locations with large employment shares in industries with high pre-NAFTA tariffs on Mexico experience slower wage growth relative to workers in locations not vulnerable to NAFTA. Within NAFTA vulnerable locations, these effects are strongest for low skill workers in importing-competing industries. While sharing natural similarities with McLaren and Hakobyan (2016), our analysis differs in important ways. First, we measure the employment reallocation effects of trade policy rather than wage effects. Second, we construct two measures of trade policy, one capturing changes in US tariffs (similar to McLaren and Hakobyan (2016)) and another capturing changes in foreign market access due to changes in foreign tariffs. Third, we allow the impact of trade on employment growth in a particular job to vary by initial job quality. Nevertheless, our results complement those in McLaren and Hakobyan (2016) by emphasizing the economic importance of trade policy for local labor market outcomes. ${ }^{18}$

We initially estimate (1) via Ordinary Least Squares (OLS) and cluster the standard errors at both the local labor market level and the job level (Cameron et al. (2011)). ${ }^{19}$ These two-way clustered standard errors are quite conservative, allowing correlation of employment growth shocks across all jobs within a local labor market and across all locations for a given job. Despite our sample size exceeding 784,000 observations, the clustering dramatically reduces the number of independent observations and, hence, substantially increases the standard errors relative to, say, only clustering at the local labor market or job level.

Our primary interest lies in the coefficients $\beta_{1}$ and $\beta_{2}$ and the vectors $\theta_{1}$ and $\theta_{2}$. But, several threats may undermine our ability to causally interpret $\theta_{1}$ and $\theta_{2}$. Moreover, the parameters in (1)

\footnotetext{
${ }^{17}$ For other studies in a developed country context, see, e.g., McCaig $(2011)$ who study the impact of the USVietnam Bilateral Investment Treaty on poverty in Vietnam and Kovak (2013) who analyzes the wage impact of unilateral liberalization in Brazil.

${ }^{18}$ Indeed, given the findings in McLaren and Hakobyan (2016), one would expect our analysis to reveal significant employment effects of US tariff policy given the observation in Goldberg and Pavcnik (2016, p.36) that national level studies in developed countries tend to find stronger employment responses than wage responses when industry-level tariff protection declines.

${ }^{19}$ Estimation is performed using -cgmreg- in Stata. See http://faculty.econ.ucdavis.edu/faculty/ dlmiller/statafiles/.
} 
may exhibit heterogeneity along interesting dimensions. Thus, we undertake numerous sensitivity analyses in Section 4 and the Supplemental Appendix.

First, changes in local trade exposure may be endogenous. Industry-, occupation- or locationspecific shocks to labor demand and/or import demand could endogenously affect tariffs through political economy channels or directly affect Chinese IP. Thus, following Autor et al. (2013), we instrument for Chinese IP using Chinese exports to high-income countries other than the US. The main idea is that the common component of Chinese exports across high income destinations is driven by productivity and other supply-side shocks in China rather than correlated import demand shocks across high-income countries. We instrument for US and foreign tariff variables using the share of imports sourced from countries having a Preferential Trade Agreement (PTA) with the US. The main idea is that PTA partners may, implicitly or explicitly, influence the tariffs that each imposes on non-members for goods heavily traded between the partners. Moreover, while industryor local-level shocks may affect the structure of the PTA (e.g. industry coverage and tariff phase out schedules), such shocks are unlikely to affect formation of the PTA itself.

Second, we augment the controls in (1) to further address endogeneity concerns. To address possible endogeneity arising from industry-specific shocks, we expand the set of industry fixed effects from 19 2-digit NAICS industries to 88 3-digit NAICS industries. We also add, at the most disaggregated industry level in our data, industry level controls (and their changes from 1990 to 2010) related to total factor productivity, the real price of investment goods, and the capital to labor ratio. To address possible endogeneity arising from occupation-specific shocks (e.g., shocks associated with skill-biased technological change), we replace the industry fixed effects in (1) with occupation fixed effects. To the extent that occupation fixed effects control for skills, variation across local labor markets within skill groups identifies the effects of trade exposure.

Additionally, our estimates $\theta_{1}$ and $\theta_{2}$ could reflect a spurious relationship between employment growth and trade exposure in the presence of secular industry- or location-specific trends in employment growth. Despite our inclusion of state and industry fixed effects, this will not account for industry-specific shocks that differentially affect locations or state-level shocks that differentially affect industries or locations within a state. Thus, we augment (1) to include the lag of $\Delta n_{j c}$ (specifically, employment growth between 1980 and 1990). The coefficient estimates then use variation conditional on location-job specific employment growth in the prior decade.

Third, we explore robustness to alternative definitions of job quality and local trade exposure. Fourth, we explore parameter heterogeneity across numerous dimensions: (i) age and cohort, (ii) 
sector (jobs in tradable goods industries, tradable services industries, or non-tradable industries), (iii) tariff types (intermediate versus non-intermediate goods and high versus low skill sectors), and (iv) occupation type (non-routine occupations, routine occupations, or abstract occupations). Also, because $\theta_{2}$ may itself vary with initial job quality, augment (1) with interactions between $q_{j}^{2}$ and $\Delta T_{c}$.

\subsection{Data}

Estimating (1) requires definitions of local labor markets $(c)$, jobs $(j)$, local job-specific employment growth $\left(\Delta n_{j c}\right)$, job quality $\left(q_{j}\right)$, changes in local trade exposure $\left(\Delta T_{c}\right)$, the vector of controls $\left(x_{j c}\right)$, and instruments for local trade exposure. The sample period spans 1990 to 2010. However, as part of the sensitivity analysis, we also utilize data from 1980. The non-trade data is obtained from the 1980 and 1990 Decennial Census (5\% sample), and the 2010 American Community Survey (ACS 1\% sample). ${ }^{20}$ The trade data are obtained from various sources: COMTRADE, TRAINS, the USITC, and the NBER-CES Manufacturing Database. Table A1 in the Supplemental Appendix provides summary statistics.

Local labor markets $(c)$ Following McLaren and Hakobyan (2016), we define local labor markets by the Census' Consistent Public Use Microdata Area (ConsPUMA; PUMA hereafter) definition. 543 PUMAs comprise the entire US, do not cross state lines, and are consistently defined over time. Overall, PUMAs are a more aggregate geographic unit than the 722 Commuting Zones (CZs) used in Autor et al. (2013) and related papers. Two reasons motivate our choice: (i) our primary motivation is investigating the effects of trade policy in the US and McLaren and Hakobyan (2016) is the only other study to do so using US local labor markets and (ii) Monte et al. (2015) find that, despite being designed to reflect commuting zone boundaries, a significant share of commuting by workers occurs between CZs. ${ }^{21}$ Nevertheless, we do not expect our choice of geographic unit to be consequential.

Job types $(j)$ Prior job polarization studies define jobs as the cross-product of industry and occupation codes. Using three-digit occupation codes and one-digit industry codes, Goos and Manning (2007) potentially have $370 \times 10=3700$ jobs and observe roughly 1600 in their data.

\footnotetext{
${ }^{20}$ See https://usa.ipums . org/usa/.

${ }^{21}$ Using 2006-2010 ACS data, Monte et al. (2015, p.15) find that $8.9 \%$ of residents in the median county commute to work outside of their $\mathrm{CZ}\left(41.9 \%\right.$ for the county at the $90^{\text {th }}$ percentile).
} 
We use 243 industries (1990 IPUMS Census industry codes) and the six occupation groups defined in Autor and Dorn (2013) (based on the 1990 IPUMS Census occupation codes), yielding 1458 possible jobs and 1444 that we observe in $1990 .^{22,23}$ Thus, our sample has $1444 \times 543=784,092$ location-job observations. Our job definition uses a wider array of industries, but more aggregate occupation groups, to help assess heterogeneity across jobs in the tradable goods sector versus all other sectors, and exploit variation in trade exposure across jobs in different detailed industries.

Local job-specific employment growth $\left(\Delta n_{j c}\right)$ The dependent variable captures changes in location-job specific employment shares between 1990 and 2010. To begin, we compute the population share (aged 25 to 64 and not currently enrolled in school, institutionalized, or listing their occupation as military) employed in job $j$ in location $c$ in year $t$. Denoting this count as $n_{j c t}$, where $t$ indexes the year, we define $\Delta n_{j c}=n_{j c, 2010}-n_{j c, 1990 \cdot{ }^{24}}$

Job quality $\left(q_{j}\right)$ To measure job quality and avoid confounding temporal labor reallocation across jobs with changes in the quality of jobs, we follow the existing job polarization literature. Specifically, we use a time invariant measure of job quality obtained from the initial period, $1990 .{ }^{25}$ Our primary measure of job quality is the Nam-Powers-Boyd (NPB) index of socioeconomic standing computed at the national level (i.e., the quality of a given job is constant across locations). We explore alternative measures in the sensitivity analysis.

The NPB index is a function of the median wage and median education level of a job, both of which have been used as measures of job quality (see, e.g., Autor et al. (2006); moreover, Acemoglu and Autor (2011, p.1046) describe job polarization as the "simultaneous rapid growth of both high education, high wage occupations and low education, low wage occupations"). The NPB index, which varies from 0 to 1 , is the approximate percentage of the labor force in jobs with a lower combination of median wage and median education (Nam and Boyd (2004)). ${ }^{26}$ Table A2 in the

\footnotetext{
${ }^{22}$ See the Supplemental Appendix for concordance issues.

${ }^{23}$ Note, we actually observe 1446 jobs in 1990. However, for two jobs there is missing data on job quality.

${ }^{24} \mathrm{As}$ is typical in the literature, our employment shares are employment to population ratios (as opposed to employment to total employment ratios). This accounts for the possibility that trade exposure may contribute to nonemployment (unemployment or other forms of nonemployment such as retirement or disability). It also avoids econometric complications arising from the fact that job invariant, location-specific attributes (i.e., any $x_{j c}$ that does not vary across $j$ such as economic and demographic attributes of local labor markets) cannot affect all employment shares in the same direction if the shares are restricted to sum to one.

${ }^{25}$ Note, this means that only jobs observed in 1990 can be included in the analysis. The quality of any new jobs appearing in later years have missing quality. However, as stated above, 1444 of the 1458 possible jobs are observed in 1990. Only one job appears in 2010 that did not appear in 1990; 134 jobs observed in 1990 are "extinct" in 2010.

${ }^{26}$ Specifically, we begin by computing the national median wage and national median education level for each
} 
Supplemental Appendix describes the so-called good jobs and bad jobs across broad occupation and industry groups by splitting the sample into the bottom $25 \%$, middle $50 \%$, and top $25 \%$ of jobs according to the NPB index. Table A2 shows the distribution of jobs and the distribution of workers across occupations or industries within each quality bin - low, middle, and high quality jobs, respectively.

Moving up the distribution of job quality, the data depict steady changes in the occupational and industrial composition. But, perhaps the most important take away is that jobs likely to be most affected by changes in trade exposure - those in tradable goods industries such as agriculture, mining, and manufacturing - are dispersed across the three job quality bins. Workers in these three industries comprise roughly $16 \%$ of employment in low quality jobs, $24 \%$ in middle quality jobs, and $20 \%$ in high quality jobs. This suggests trade could affect the allocation of workers to jobs throughout the distribution of job quality, rather than just in a particular segment.

Local measures of trade exposure $\left(\Delta T_{c}\right)$ Our measures of local trade exposure follow the approach popularized in Topalova (2007) and used recently elsewhere (e.g., Autor et al. (2013); Kovak (2013); McLaren and Hakobyan (2016)). Thus, we only briefly describe our measures here, relegating detailed discussion to the Supplemental Appendix. Local measures of trade exposure are computed by weighting industry-level measures of trade exposure by location-specific industrial composition.

The change in trade exposure faced by location $c$ between 1990 and 2010 is

$$
\Delta v_{c} \equiv \sum_{i} \omega_{i c} \Delta v_{i}, \text { where } \omega_{i c} \equiv \frac{L_{i c, 1990}}{L_{c, 1990}}
$$

Here, $\Delta v_{i}$ is the change in trade exposure faced by industry $i$ (i.e., $v_{i}$ represents either US tariffs $\tau_{i}$, foreign tariffs $\tau_{i}^{*}$, or Chinese import penetration $\left.I P_{i}\right)$ and $\omega_{i c}$ is the (time-invariant) employment share of industry $i$ in location $c$ in 1990 computed using the 1990 Census data described above. ${ }^{27}$ We aggregate over all Census industries in (2), consistent with much of the literature (Topalova (2007); Topalova (2010); McLaren and Hakobyan (2016)). However, Hasan et al. (2007) advocate only aggregating over traded industries; the theoretical model in Kovak (2013) provides additional

job in 1990. We then convert these into empirical cumulative density functions (CDFs) using employment shares as weights. Finally, $q_{j}$ is computed as the average percentile of job $j$ across the empirical CDF for the median wage and the empirical CDF for median education level.

${ }^{27}$ Using time-invariant industy-location employment shares mitigates endogeneity concerns due to local industrial composition responding to changes in trade exposure over the sample period. 
support. $^{28}$ Thus, we revisit this in the sensitivity analyses.

Computing changes in local US and foreign tariffs using (2) requires US and foreign tariffs by Census industry and year, $\tau_{i t}$ and $\tau_{i t}^{*}$ respectively. For US tariffs, we first use (time invariant) 1990 partner-specific US HS6 imports to weight US bilateral applied HS6 tariffs and obtain an average HS6 tariff imposed by the US. ${ }^{29,30}$ Again using time invariant 1990 US HS6 imports, we aggregate these 'average' HS6 tariffs imposed by the US to the Census industry level. Similarly for foreign tariffs, we first use (time invariant) 1990 partner-specific US HS6 exports to weight foreign HS6 tariffs imposed on the US. Again using time invariant 1990 US HS6 exports, we aggregate these 'average' HS6 tariffs faced by the US to the Census industry level. The only substantive difference in the computation of $\Delta \tau_{c}$ and $\Delta \tau_{c}^{*}$ is that many countries did not report HS tariffs until 1991, whereas the US reports HS tariffs for 1990. Thus, when a country's 1990 tariff is missing in TRAINS, we replace it with the average of, where available, its 1989 and 1991 tariffs.

Computing the change in local Chinese IP using (2) requires the change in Chinese IP by Census industry, $\Delta I P_{i}$. Following Acemoglu et al. (2015), we first define the change in Chinese IP in a 4-digit SIC industry $s$ as

$$
\Delta I P_{s} \equiv \frac{\Delta M_{s}}{Y_{s, 1991}+M_{s, 1991}-X_{s, 1991}}
$$

where the change in Chinese imports, $\Delta M_{s} \equiv M_{s, 2010}-M_{s, 1991}$, is normalized by domestic absorption in 1991 as proxied by domestic shipments, $Y_{s, 1991}$, plus net imports, $M_{s, 1991}-X_{s, 1991} \cdot{ }^{31,32}$ We then aggregate the individual variables in (3) to the Census industry level. ${ }^{33}$

The Supplemental Appendix details the magnitude of changes in trade exposure at the Census industry level (Table A3) and local level (Table A4). Ultimately, rather weak correlation across the

\footnotetext{
${ }^{28}$ The thoretical intuition for only aggregating over tradable industries in Kovak (2013) derives from the general equilibrium linkage between tradable and non-tradable goods prices. Nevertheless, the two approaches are identical (up to a positive factor of proportionality) when locations do not differ in the share of their workforce allocated to the traded sector (Kovak (2013, p.1964)).

${ }^{29}$ US bilateral tariffs can differ from the Most Favored Nation (MFN) tariff due to preferential tariffs (e.g., due to Preferential Trade Agreements or programs like the Generalized System of Preferences).

${ }^{30}$ For US tariffs and foreign tariffs, we use the tariff data from TRAINS and we also use the import data that accompanies the TRAINS tariff data.

${ }^{31}$ We obtain the necessary trade data from COMTRADE and the domestic shipments data from the NBER-CES Manufacturing Industry Database (Becker et al. (2013)).

${ }^{32}$ Shipments data are only available for manufacturing industries and not all tradable industries. However, we do not set $\Delta I P_{s}=0$ for non-manufacturing tradable industries. For these industries, we set $\Delta I P_{s}$ equal to the average $\Delta I P_{s}$ across all manufacturing industries.

${ }^{33}$ Note, $\Delta \tau_{c}$ includes changes in US tariffs imposed on China. Thus, to the extent that falling US tariffs on China are positively correlated with rising Chinese IP, one would expect the coefficients on Chinese IP in (1) to be attenuated by the inclusion of US tariffs (and vice versa). To this end, we will present separate results that, respectively, omit Chinese IP and omit tariffs.
} 
different trade exposure measures indicates there is sufficient variation in the data to separate the effects of each trade exposure measure. Moreover, the substantial increase in local trade exposure between 1990 and 2010, and the spatial variation in this increase, allows us to empirically identify the effects of local trade exposure (see Figure 1).

Covariates $\left(x_{j c}\right) \quad$ We control for numerous other attributes of locations and jobs including timevarying and location-specific variables related to the distribution of age, education, marital status, race, household size, language abilities, number of children less than age 18 within households, number of children under age five within households, nationality and home ownership. The only time invariant, location-specific variables are state fixed effects. Finally, the only time- and locationinvariant attributes are industry fixed effects. Our baseline specification includes 2-digit NAICS industry fixed effects (19 industries), but we later consider more disaggregated industry fixed effects at the 3-digit NAICS level (88 industries).

Instruments We use instrumental variables (IV) estimation to address the potential endogeneity of trade exposure. ${ }^{34}$ The Chinese import penetration related instrument follows Acemoglu et al. (2015), computed in three steps. First, the numerator is industry-level Chinese exports to eight non-US high income countries. ${ }^{35}$ Second, the denominator is industry-level US domestic absorption in the denominator of (3) in 1989. Third, (2) uses 1980 local employment weights when aggregating to the local level. As discussed in Acemoglu et al. (2015), the instrument is relevant if Chinese exports are correlated across high income countries and is valid if this correlation is driven by Chinese productivity and other supply-side shocks (rather than correlated import demand shocks among high income countries).

The two tariff related instruments are, to our knowledge, novel. Here, we briefly outline their construction. First, rather than aggregate bilateral US HS6 tariffs to the local level, we aggregate the share of US HS6 imports sourced from PTA partners (weighted by time invariant 1990 partnerspecific imports) to the local level and use the change between 1990 and 2010 as an instrument. Second, rather than aggregate foreign HS6 tariffs imposed on the US to the local level, we aggregate the share of foreign HS6 imports sourced from PTA partners (weighted by a foreign country's time invariant and partner-specific 1990 imports) to the local level and use the change between 1990 and 2010 as an instrument.

\footnotetext{
${ }^{34}$ A detailed discussion of the creation of the instruments is relegated to the Supplemental Appendix.

${ }^{35}$ Australia, Denmark, Finland, Germany, Japan, New Zealand, Spain, and Switzerland.
} 
The logic behind the tariff instruments is that PTAs afford preferential tariff access which creates incentives for PTA partners to politically influence each other's MFN tariffs after they have formed a PTA. Indeed, this is the key empirical finding in Limão (2006) for US MFN tariffs and Mai and Stoyanov (2015) for Canadian MFN tariffs. Hence, existing empirical evidence suggests relevance of the instruments. Validity rests on industry-level shocks not influencing formation of the PTA itself. Note, the instruments remain valid if such shocks affect the structure of PTAs. Indeed, PTAs routinely exclude certain sensitive sectors or phase out tariff protection over many years in certain sectors. Thus, industry-level shocks have ample scope to affect the structure of a PTA without affecting the formation of a PTA.

\section{Baseline results}

\subsection{OLS estimation}

Table 1 presents the baseline results. Column (1) regresses $\Delta n_{j c}$ on $q_{j}$ and $q_{j}^{2}$. Column (2) adds all local trade exposure measures: local US tariffs $\left(\Delta \tau_{c}\right)$, local foreign tariffs $\left(\Delta \tau_{c}^{*}\right)$, local Chinese IP $\left(\Delta I P_{c}\right)$, and interactions of each with job quality $q_{j}$. Column $(3)$ adds location-specific covariates. Column (4) adds state and industry fixed effects.

Column (1) confirms job polarization at the local labor market level in the US. ${ }^{36}$ Figure A1 (Panel A) in the Supplemental Appendix illustrates this polarization: positive employment growth in good and bad jobs for the average PUMA, but negative employment growth in middle quality jobs. Columns (2)-(10) show that adding the trade related variables does not qualitatively change the sign and significance of the estimates of $\beta_{1}$ and $\beta_{2}$. Thus, after controlling for changes in local trade exposure, job polarization persists when holding local trade exposure constant at its 1990 values. In terms of the magnitude of the employment effects, it is important to realize that, with 1444 jobs, the mean employment share across all location-jobs is $0.06 \%$ (or, less than $1 / 1444$ due to nonemployment; see footnote 24). As such, the magnitude of polarization is economically meaningful with predicted employment growth reaching about $33 \%(50 \%)$ of the average employment share when $q=0(q=1)$.

Our attention now turns to the impact of changes in local trade exposure on the distribution of employment across jobs of different quality. In equation (1), $\theta_{2}$ allows local trade exposure to

\footnotetext{
36 Autor and Dorn (2013) find a similar result via a reallocation of low-skill workers into the broad occupational category of low-skill services. In contrast, column (1) documents a reallocation of workers among 1444 different jobs.
} 
differentially affect employment growth by job quality. Formally, the coefficient vector on the local trade variables, $\theta_{1}$, represents the effect of a unit increase in $\Delta T_{c}$ when $q_{j}=0$. In contrast, $\theta_{1}+\theta_{2}$ represents the effect of a unit increase in $\Delta T_{c}$ when $q_{j}=1$. From a more heuristic perspective, $\theta_{1}$ gives a sense for how changes in local trade exposure affect employment growth of bad jobs, while $\theta_{1}+\theta_{2}$ gives a sense for how changes in local trade exposure affect employment growth of good jobs.

Columns (2)-(4) add all trade related variables. Several findings stand out. First, the estimates of $\beta_{1}, \beta_{2}, \theta_{1}$, and $\theta_{2}$ are virtually unchanged across the three specifications. This insensitivity suggests a lack of endogeneity concern; nonetheless, we revisit this below.

Second, declines in local US tariffs and increases in local Chinese IP, each of which reflect greater import competition, affect employment growth in the same direction. On one hand, falling local US tariff protection $\left(\Delta \tau_{c}<0\right)$ and rising Chinese IP $\left(\Delta I P_{c}>0\right)$ reduce employment growth of bad jobs as one might expect expect given recent empirical evidence in the literature. However, such changes also raise employment growth of good jobs. Thus, our results suggest that rising local exposure to import competition does not merely destroy jobs, but rather reallocates workers from bad jobs to good jobs.

Third, the statistical and economic significance is stronger for changes in local US tariffs than for changes in local Chinese IP. In column (4), the coefficients related to the former are individually statistically significant at the $5 \%$ level (jointly significant at the $10 \%$ level), but the coefficients related to the latter are statistically insignificant at conventional levels (individually and jointly). ${ }^{37}$ Moreover, the economic significance of the former is also substantially greater. This can be seen in two ways. To start, while the standard deviation of $\Delta I P_{c}$ is roughly seven times that of $\Delta \tau_{c}$ (see Table A1), the coefficient estimates on $\Delta \tau_{c}$ and $q_{j} \cdot \Delta \tau_{c}$ are roughly 18-20 times that for $\Delta I P_{c}$ and $q_{j} \cdot \Delta I P_{c}$. To be of equal economic magnitude, the point estimates should only be seven times larger.

In addition, the left hand column of Figure 2 illustrates the effects graphically by showing the estimated impact for an average PUMA of each trade exposure variable falling from the $75^{\text {th }}$ percentile of protection in its 1990 distribution to (i) the $75^{\text {th }}$ percentile in its 2010 distribution, (ii) the median of its 2010 distribution, and (ii) the $25^{\text {th }}$ percentile of its 2010 distribution. ${ }^{38}$ Panels A

\footnotetext{
${ }^{37}$ Throughout the analysis, it is important to remember that we use two-way clustered standard errors that are likely to be conservative. In contrast, standard errors based solely on (one-way) clustering at the PUMA level lead to coefficient estimates for the local tariff variables that are highly statistically significant $(p<0.01)$ and statistically significant for the local Chinese IP variables $(p<0.03)$.

${ }^{38}$ Since tariffs are declining over time, a local tariff at the $75^{\text {th }}$ percentile of its 1990 distribution is much higher than at the $75^{\text {th }}$ percentile of its 2010 distribution (see Figure 1).
} 
and $\mathrm{C}$ of Figure 2 clearly reveal a greater impact of falling local US tariffs relative to rising local Chinese IP. The effect of falling local US tariffs from the $75^{\text {th }}$ percentile in 1990 to the $25^{\text {th }}$ percentile in 2010 (i.e., comparing the dashed line relative to the solid line) on the employment growth of bad jobs when $q_{j}=0$ is about $0.02 \%$; the effect is about $0.01 \%$ if local US tariffs only decline to the $75^{\text {th }}$ percentile of its 2010 distribution. Given the average job size in our sample is $0.06 \%$, these effects represent about one-third and one-sixth, respectively, of the average job size. Moreover, these reductions in local US tariffs have similar quantitative effects on the employment growth of good jobs when $q_{j}=1$. In contrast, analogous increases in local Chinese IP have economic effects that are about one-third of those arising from falling local US tariffs.

Finally, our results indicate that rising local access to foreign markets via falling foreign tariffs also have heterogenous effects on local employment growth. However, in contrast to the effects of rising import competition, greater access to export markets reduces employment growth of good jobs and increases employment growth of bad jobs. These effects are economically significant and statistically significant at the $1 \%$ level (both individually and jointly). Again, this can be seen in two ways. To start, while the coefficient estimates on $\Delta \tau_{c}$ and $q_{j} \cdot \Delta \tau_{c}$ are roughly 3.5 times that on $\Delta \tau_{c}$ and $q_{j} \cdot \Delta \tau_{c}^{*}$, the standard deviation of $\Delta \tau_{c}^{*}$ is also about 3.5 times that of $\Delta \tau_{c}$ (see Table A1). That is, the economic significance of a change in local US tariffs is quantitatively similar to that of a change in local foreign tariffs. In addition, the left hand column in Figure 2 shows the quantitative effects of falling local foreign tariffs on employment growth in the average PUMA are very similar to that of falling local US tariff protection and, hence, substantially larger than the effects of rising local Chinese IP. In sum, greater export market access through falling foreign tariffs and greater import competition through falling US tariffs are economically significant determinants of, and have strong heterogenous effects on, local employment growth.

The relatively small effects of local Chinese IP contrast sharply with the recent literature on the labor market effects of Chinese IP growth. This may relate to the different focus of our study (namely, the impact of local trade exposure on the distribution of employment across the job quality spectrum), but this is not the entire explanation. Rather, the incorporation of local Chinese IP and local tariffs explains much of the difference.

To see this, we estimate equation (1) with either our local tariff measures or local Chinese IP. In Table 1, columns (5)-(7) are analogous to columns (2)-(4) except we omit local Chinese IP (and its interaction with $q$ ). Columns (4) and (7) reveal that omitting local Chinese IP barely affects the estimated effects of local foreign tariffs, but increases the estimated coefficients on local US tariffs (in 
absolute value) by about 30\%. Likewise, columns (8)-(10) are analogous to columns (2)-(4) except we omit the local tariff variables (and their interactions with $q$ ). Columns (4) and (10) reveal that omitting the local tariff variables substantially affects the estimated coefficients of local Chinese IP; the estimates increase by nearly $80 \%$ (in absolute value) and are now statistically significant at the $5 \%$ level (both individually and jointly). Comparing the left hand column of Figure 2 to Figure A2 in the appendix depicts these effects graphically. Together, these results have potentially important implications for future empirical studies by suggesting that the impacts of Chinese IP growth may be confounded with changes in tariff policy and, when controlling for both, the latter may be more important economically.

\subsection{IV estimation}

As stated above, including location-specific baseline attributes, changes in location-specific attributes, and state and industry fixed effects has virtually no effect on our coefficient estimates. While suggesting a lack of endogeneity, possible endogeneity of import penetration and trade policy is a common and valid concern in empirical analyses. Thus, we instrument for $\Delta T_{c}$ using the instruments described previously.

Table 2 presents the results. Exact identification of the model and our two-way clustered standard errors limit the possible diagnostics. However, we easily reject that our models are underidentified $(p<0.01)$. Moreover, the Anderson-Rubin Wald Test for the joint significance of the endogenous variables that is robust to weak instruments indicates that the local trade exposure variables are jointly statistically significant at conventional levels in all three models, indicating relevance of the instruments.

In terms of the point estimates, the primary finding is that IV estimation leaves our baseline results largely intact. Three additional findings standout. First, only including the tariff variables (column (1)) or only including Chinese IP (column (2)) magnifies the IV estimates relative to the corresponding OLS estimates in Table 1. Second, including all three trade exposure variables (column (3)) barely affects the point estimates on the local tariff variables relative to column (1). However, the standard errors are much larger. Third, including all three trade exposure variables (column (3)), reduces the local Chinese IP coefficient estimates to effectively zero. Again, though, the standard errors are much larger.

Figure 2 visually depicts these findings: the OLS and IV estimates suggest qualitatively similar 
effects of changes in local trade exposure. However, the economic magnitudes of the local tariff variables are greater using the IV estimates (middle column in Figure 2), whereas that of the local Chinese IP variable has diminished. ${ }^{39}$ Given the loss in precision with IV estimation, the magnitude changes should be viewed cautiously.

In sum, our baseline results are not substantially affected by treating local trade exposure as endogenous. Thus, due to the more conservative point estimates in our baseline analysis and the efficiency loss associated with IV in the presence of six endogenous regressors, we revert to OLS for the remainder of the paper.

\section{Sensitivity analyses}

We perform numerous sensitivity analyses to assess the robustness of the baseline results.

Alternative variable measurements The Supplemental Appendix investigates alternative definitions of job quality and local trade exposure, showing our results remain robust.

Alternative specifications Table 3 explores robustness of our results to alternative sets of covariates. Column (1) repeats the baseline results from column (4) of Table 1. Column (2) adds interactions between $\Delta T_{c}$ and $q_{j}^{2}$. Our baseline specification, by excluding this interaction, restricts the effect of $\Delta T_{c}$ on $\Delta n_{j c}$ to be linear in job quality. Graphically, the gap between any dashed line and the corresponding solid line in the left hand column in Figure 2 must vary linearly with job quality. This precludes the possibility that changes in local trade exposure may, say, exacerbate job polarization by increasing employment growth of both good and bad jobs while reducing employment growth of middle quality jobs. Column (2) allows this possibility. The right hand column in Figure 2 shows some indication of larger (smaller) effects of the local trade variables on bad (good) jobs relative to the baseline specification. Nevertheless, the continued asymmetric effects across the tails of the distribution of job quality leaves our baseline results qualitatively unaffected: local trade exposure neither exacerbates nor mitigates job polarization but rather reallocate workers upward or downward in the distribution of job quality.

\footnotetext{
${ }^{39}$ Note the scaling difference of the $y$-axis across the columns of Figure 2. Also, we normalize predicted employment growth when $q_{j}=0$ in the IV figures because, given our clustered standard errors, we partialled out the non-trade control variables prior to implementing IV estimation. Thus, we only have estimates for the coefficients on $q_{j}, q_{j}^{2}$, and the trade-related variables.
} 
While each measure of rising local trade exposure has not individually exacerbated or attenuated job polarization, could all three measures have jointly exacerbated or attenuated job polarization? The asymmetric effects of local US and foreign tariffs leave this possibility open. Figure 3 addresses this issue by using the estimates from column (2) to depict the joint impact of rising local trade exposure on cumulative employment growth (relative to holding local trade exposure constant at 1990 levels) across quartiles of the job quality distribution.

Specifically, Figure 3 shows the cumulative impact on employment growth for low, middle, and high quality jobs (respectively, the bottom 25\%, middle 50\%, and top 25\% of jobs) when local trade exposure falls from the $75^{\text {th }}$ percentile of protection in the 1990 distribution to the median in the 2010 distribution. For the individual trade exposure measures, the impacts across the quartiles confirm our interpretation: falling US tariffs and Chinese IP (foreign tariffs) reallocate workers from bad (good) to good (bad) jobs. Moreover, the joint impact of the trade exposure measures across the quartiles confirms no link with job polarization; rather, overall, rising local trade exposure reallocates workers from bad to good jobs. ${ }^{40}$

A common concern with trade and local labor market analyses is that, historically, declining locations may tend to specialize in import-competing goods. Thus, by construction, these locations may experience the greatest changes in local trade exposure. In turn, any relationship between local trade exposure and local labor market outcomes could be spurious due to location-specific secular trends. Column (3) addresses this concern by adding the lag of $\Delta n_{j c}$ defined as employment growth from 1980 to $1990 .{ }^{41}$ The results are virtually unchanged relative to column (1).

A potential concern with our baseline analysis is the presence of industry attributes, such as industry-specific technological change, that may be correlated with employment growth in certain jobs and industry trade exposure. Despite our use of 2-digit NAICS industry fixed effects, significant heterogeneity may exist within a 2-digit industry. Thus, columns (4) adds 3-digit NAICS industry fixed effects (88 industry dummy variables) and, additionally, column (5) adds Census industryspecific control variables. Motivated by Ebenstein et al. (2014), column (5) adds the following covariates (and their changes over the sample period): total factor productivity, the real price of investment goods, and the capital to labor ratio. ${ }^{42}$ Columns (4) and (5) show virtually unchanged

\footnotetext{
${ }^{40}$ See also Figure A1 (Panel B) in the Supplemental Appendix. It shows the cumulative impact of changes in all three trade exposure measures but without aggregagating jobs into quartiles according to job quality.

${ }^{41}$ We continue using OLS here. Despite using state and industry fixed effects, the absence of PUMA fixed effects means that the usual Nickell (1981) bias present in standard dynamic panel data models with a lagged dependent variable does not arise.

${ }^{42}$ Since these variables are taken from the 4-digit SIC version of the NBER-CES Manufacturing Industry Database,
} 
results relative to column (1).

Column (6) addresses another long-standing concern in the literature on trade and labor market outcomes: disentangling the role of trade and skill-biased technological change. Indeed, our results regarding rising local import competition resemble the effects of skill-biased technological change favoring high skill workers: less bad jobs and more good jobs. While our results concerning falling local foreign tariffs suggest opposite effects, thereby questioning the applicability of a skill-biased technological change explanation, we nonetheless investigate this issue further.

To do so, we remove industry fixed effects which, by construction, cannot control for skill-biased technological change since such technological change differentially affects workers (across skill levels) within a given industry. However, assuming skills are relatively homogenous within occupation groups, column (6) exploits our industry-occupation definition of a job by adding occupation fixed effects. Again, the results are virtually identical to the baseline results of column (1).

Heterogeneity by tariff type In the Supplemental Appendix, we investigate the possibility of heterogenous effects for different types of tariffs. In particular, we investigate (i) differential effects of falling US tariffs on intermediate goods versus non-intermediate goods and (ii) differential effects of falling foreign tariffs in high skill versus low skill industries. The former is partly motivated by the possibility that falling US tariffs on intermediate goods may proxy for the time-varying intensity of offshorability whereby lower US tariffs on intermediate goods induce US firms to offshore production of intermediate inputs and then import these inputs. The latter is motivated by the possibility that the extent to which the US takes advantage of greater access to export markets may depend on the skill intensity of the industries subject to falling foreign tariffs; as a skill abundant country, the US is presumably more likely to take advantage of falling foreign tariffs in high skill industries. Ultimately, while there is some evidence of differential effects, it is empirically difficult to separate the impacts with much statistical certainty.

Heterogeneity by sector Recent papers have emphasized local labor market linkages between trade-exposed sectors and other sectors. Mian and Sufi (2014) and McLaren and Hakobyan (2016) emphasize negative Keynesian-type aggregate demand spillovers when local shocks generate adverse local labor market outcomes. In addition, Acemoglu et al. (2015) emphasize a reallocation channel whereby, due to the tendency for balanced trade, labor flows into (out of) non-exposed tradable 
sectors should at least somewhat offset labor flows out of (into) exposed tradable sectors. ${ }^{43}$ We now investigate these linkages.

To do so, we split the 243 Census industries into three mutually exclusive groups: tradable goods, tradable services, and non-tradables. As previously described, construction of our local tariff variables begins by aggregating HS6 tariffs to the Census industry level. Thus, we classify a Census industry as belonging to the tradable goods sector if it is associated with at least one HS6 product. This produces 84 tradable goods Census industries. Since the HS classification does not cover services, we use the Bureau of Economic Analysis' (BEA) 1997 Import Matrix to examine imports. ${ }^{44}$ We classify a Census industry as belonging to the tradable services sector if it has positive imports according to the BEA but does not belong to the tradable goods sector. This produces 30 tradable services Census industries. ${ }^{45}$ We classify the remaining 129 Census industries as members of the non-tradable sector.

Our distinction between tradable goods and tradable service sectors may provide an improved means to investigate the reallocation channel laid out in Acemoglu et al. (2015) who, in fact, find little empirical evidence for the reallocation channel. First, our trade exposure variables are goods based as they stem from the HS classification of goods. Hence, by definition of our trade exposure measures, the tradable services sector is less exposed than the tradable goods sector. Second, despite running an overall trade deficit, the US runs a substantial trade surplus in services. Thus, combining tradable services with non-tradables as in Acemoglu et al. (2015) may miss an import aspect of any reallocation channel.

Table 4 presents the results. A few findings stand out. First, as one would expect, changes in local trade exposure have qualitatively identical effects in the tradable goods sector as in the full sample, but the magnitudes of the impacts of local US and local foreign tariffs are substantially larger when focusing solely on the tradable goods sector (see columns (1)-(3) in Table 4 and columns (2)-(4) in Table 1). The coefficient estimates on the local Chinese IP variables, however, are nearly identical to the full sample results.

These magnitudes can also be seen graphically. Comparing the left hand column of Panel A in Figure 2 and Figure 4 shows that the impact of falling local US tariffs in the tails of the job

\footnotetext{
${ }^{43}$ Indeed, Acemoglu et al. (2015) argue that the large US trade deficit may help explain their result that the negative aggregate demand effect appears to swamp any reallocation effect.

${ }^{44}$ We then use a concordance from the 1997 NAICS used by the BEA to Census industries.

${ }^{45}$ These industries include various transportation service industries (e.g., trucking, water, and air), professional service industries (e.g., savings institutions, insurance, advertising, computer and data processing, accounting, and legal), education service industries, and research and development service industries.
} 
quality distribution is about four times larger in the tradable goods sector relative to the full sample. Comparing the left hand column of Panel B in these figures shows that the impact of an increase in local foreign tariffs is about twice as large in the tradable goods sector. Comparing the left hand column of Panel $\mathrm{C}$ in these figures shows the impact of an increase in local Chinese IP is not noticeably different; however, comparing column (2) of Table 4 with column (10) of Table 1 shows that the impact is about three times as large when omitting the local tariff variables. In sum, there appears to be a direct linkage between changes in local trade exposure and local employment growth in the tradable goods sector.

Second, when analyzing the tradable services sector, there is no evidence supporting the reallocation channel in response to changes in local Chinese IP (as the coefficient estimates are not the opposite sign of those for the tradable goods sector). However, there is evidence supporting the reallocation channel in response to changes in local tariffs (as the coefficient estimates are the opposite sign of those for the tradable goods sector). Moreover, although the magnitude of the point estimates for the tradable services sector are similar to the baseline results, they are substantially smaller than the point estimates in the tradable goods sector. Thus, the results are consistent with the tradable service sector partially absorbing (accommodating) labor outflows (inflows) from (into) the tradable goods sector. Of course, given the size of the standard errors, these results must be interpreted cautiously.

Third, when analyzing the non-tradable sector, we find evidence consistent with non-trivial aggregate demand spillovers and, hence, the recent literature mentioned above. Specifically, the sign of the point estimates on all trade exposure variables for the non-tradable sector match those in the tradable goods sector (see columns (1)-(3) and columns (7)-(9)). Thus, job-specific employment growth in the non-tradable sector exacerbates (reinforces) any negative (positive) employment growth in the tradable goods sector. Moreover, these effects are always statistically significant at conventional levels and are also economically significant given that the magnitudes of these effects tend to be around 50-75\% of those in our baseline model. This can be seen visually by comparing the right hand column of Figure 4 with the left hand column of Figure 2.

Ultimately, the results in Table 4 are consistent with the tradable goods sector being the direct link between changes in local trade exposure and local employment growth. Nevertheless, we find evidence in line with (i) the reallocation effect outlined in Acemoglu et al. (2015) even though the authors find little supporting empirical evidence and (ii) aggregate demand spillover effects recently documented in the literature. 
Heterogeneity by age and cohort In the Supplemental Appendix, we explore whether the effects of local trade exposure differentially affect employment growth across three different cohorts of workers: (i) 'young' individuals aged 25-44, (ii) 'old' individuals aged 45-64, and (iii) the 'cohort' of individuals aged 25-44 in 1990 and 45-64 in 2010. Our results do not appear driven by particular age groups or cohorts.

\section{Occupational polarization and job polarization}

As discussed earlier, recent evidence indicates many developed countries have experienced job polarization - employment growth in middle quality jobs that is lower than employment growth in both high quality and low quality jobs - over the last 20-30 years. A prominent explanation is routine biased technological change displaces labor that predominantly performs routine tasks and these jobs tend to be middle quality jobs (e.g., Goos et al. (2009)). ${ }^{46}$ Offshoring and/or trade provide alternative explanations if they also displace labor predominantly performing routine tasks. Regardless, conceptualizing occupations involving routine tasks as concentrated in the middle of the job quality distribution and those involving non-routine or abstract tasks as concentrated in the tails of the job quality distribution, the idea of occupational polarization becomes synonymous with job polarization.

To this point, our focus has centered on the impact of rising local trade exposure on the relative local employment growth of good jobs and bad jobs. Thus, the occupation of a job has not been of intrinsic interest. However, we now assess whether changes in local trade exposure have heterogenous effects on local employment growth depending on the occupation of a job. In doing so, our analysis illuminates the fact that occupational polarization and job polarization are distinct features of labor markets.

Following Autor and Dorn (2013), we aggregate our six occupation groups into three mutually exclusive groups based on an occupation's routine task intensity. ${ }^{47}$ Abstract occupations include occupations in the occupation group of managers, professional, technology, finance, and public safety. Routine occupations lie in the occupation groups of (i) clerical, retail sales, (ii) production, craft, and (iii) machine operators, assemblers. Non-routine occupations lie in the occupation groups

\footnotetext{
${ }^{46} \mathrm{An}$ important finding in Autor et al. (2015) is that this routine biased technological change was driven by the automation of production activities within manufacturing during the 1980s and by the computerization of information processing tasks outside of manufacturing during the 2000s.

${ }^{47}$ See Table A2 for these six occupation groups.
} 
of (i) low skill services and (ii) transport, construction, mechanical, mining, and farm. ${ }^{48}$

Table 5 presents results estimating our baseline model separately for each of the three occupation groups. Column (1) displays the baseline results from column (4) of Table 1. Four points stand out. First, there is no evidence of job polarization within an occupation group when holding trade exposure constant at its 1990 levels. Rather, Figure 5 shows the job polarization observed in the full sample when holding trade exposure constant at 1990 levels stems from (i) positive employment growth in high quality abstract and low quality non-routine jobs and (ii) negative employment growth in middle quality routine jobs.

Second, the qualitative impacts of local trade exposure in the full sample hold for non-routine (column (2)) and routine occupations (column (3)). Falling local US tariffs or rising local Chinese IP reduce (increase) employment growth of bad (good) jobs. Falling local foreign tariffs increase (reduce) employment growth of bad (good) jobs. Comparing these results with column (1) indicates the economic significance of the effects in routine and non-routine occupations is similar to the full sample (see also the left and middle columns in Figure 5 and the left column in Figure 2). Moreover, it is noteworthy that effects of local Chinese IP are jointly statistically significant $(p=0.05)$ for the non-routine occupation group, while the effects of local US tariffs are not $(p=0.37)$. This pattern reverses for the routine occupation group ( $p=0.57$ and $p=0.10$, respectively). Third, all of the trade exposure coefficients are estimated imprecisely in the abstract occupation group.

In sum, acknowledging that the conservative nature of the standard errors associated with our two-way clustering becomes even more acute with the substantially smaller sample sizes in columns (2)-(4), Table 5 (and Figure 5) provides evidence that our baseline effects of changes in local trade exposure on employment growth of good and bad jobs hold for routine and non-routine occupations. But, how these findings relate to the existing literature on occupational polarization is not evident. The results in Table 5 (and Figure 5) provide insufficient information to infer the impacts of local trade exposure on occupational polarization because these impacts depend on the distribution of job quality within each occupation group.

That said, using the estimates from columns (2)-(4) in Table 5 along with the distribution of job quality within each occupation group, we can compute expected cumulative local employment growth across non-routine, routine, and abstract occupations when local trade exposure falls from

\footnotetext{
${ }^{48}$ In our Census classification of coccupations, the routine task intensity measure in Autor and Dorn (2013) has (i) a mean of 0.6 in abstract occupations, (ii) means of 3.3, 2.0, and 1.8 in the three occupation groups comprising routine occupations, and (iii) means of 0.8 and 0.4 in the occupation groups comprising non-routine occupations.
} 
the $75^{\text {th }}$ percentile of protection in the 1990 distribution to the median in the 2010 distribution. Figure 6 displays the results which are, perhaps, unexpected in light of Figure 5. For each occupation group, Figure 6 shows the expected impact from changes in local trade exposure on cumulative local employment growth in the average PUMA. It does this for each local trade exposure measure individually and for the combined impact of all trade exposure variables. Strikingly, rising local trade exposure via any of the three trade exposure variables generates occupational polarization: cumulative local employment growth is strongly negative in routine occupations, moderately positive in non-routine occupations, and negligible in abstract occupations. In routine occupations, the joint impact of rising trade exposure via simultaneous changes in all three trade measures is negative cumulative local employment growth of 3.7 percentage points. This is only partially offset by positive cumulative local employment growth of $1.8(0.3)$ percentage points in non-routine (abstract) occupations. Thus, consistent with Autor et al. (2015), rising local trade exposure generates occupational polarization of local labor markets and negative overall local employment growth.

While our three local trade exposure measures have differential effects on the employment growth of a job with given quality (i.e., local US tariffs and Chinese IP generally have the opposite effect of local foreign tariffs), the three measures have similar effects on occupational polarization. Two observations help understand the simultaneous occurrence of these results. First, the occupational polarization in Figure 6 depends on both (i) the heterogenous effects of changes in local trade exposure on the local employment growth of jobs across different initial qualities (from Figure 5) and (ii) the distribution of job quality within occupation groups. Knowledge of the former is insufficient to infer the impact of local trade exposure on occupational polarization. Second, despite the qualitatively different impacts of changes in local import competition (via changes in US tariffs or Chinese IP) and changes in local access to export markets (via changes in foreign tariffs) on the local employment growth of good and bad jobs, both predict negative local employment growth for some jobs and positive local employment growth for other jobs. Moreover, a sufficient mass of jobs in routine (non-routine) occupations lie in jobs where the impact on local employment growth is negative (positive) for both rising local exposure to import competition and rising local access to export markets. Ultimately, Figures 5 and 6 provide answers to two different questions that, while broadly related, are implicitly treated as synonymous in much of the current literature.

Stepping back, this section highlights two important points. First, the mapping from occupational polarization to job polarization is not necessarily straightforward. Despite Figure 6 indicating that rising local trade exposure generates occupational polarization, Figure 6 is based on the same 
coefficient estimates showing that rising local trade exposure does not exacerbate job polarization (rather, the qualitative effects of rising local trade exposure in Figure 5 are the same as those in Figure 2). Thus, one needs to pay very careful attention to the distribution of job quality within occupation types when mapping from occupational polarization to job polarization and vice versa. Second, rising local trade exposure, stemming from either Chinese IP or falling US or foreign tariffs, generates occupational polarization. This extends the findings in Autor et al. (2015) who focus on Chinese IP. Indeed, our results indicate falling local US tariffs generate even greater degrees of occupational polarization.

\section{Conclusion}

In this paper, we investigate the possible heterogenous effects of changes in local trade exposure on the employment growth of good versus bad jobs across US local labor markets between 1990 and 2010. We obtain several salient and robust findings.

First, and foremost, we find substantial heterogeneity in the effects of trade exposure on the employment growth of jobs of different initial quality. Moreover, the qualitative nature of these effects varies dramatically with the mode of trade exposure: rising local exposure to import competition reduces employment growth of bad jobs and increases employment growth of good jobs but rising local access to export markets increases employment growth of bad jobs and reduces employment growth of good jobs. Second, we document a pattern of job polarization at the US local labor market level that is not driven by rising local trade exposure. Holding local trade exposure constant at 1990 levels, jobs in the lower and upper tails of the job quality distribution experienced positive employment growth (in expectation), whereas the remainder experienced negative employment growth. Third, despite opposing results for changes in import competition and foreign market access, our results indicate that globalization - resulting in greater local import competition and local access to foreign markets - reallocates workers upwards in the distribution of job quality.

In addition, we uncover a number of interesting patterns that ought to spur future investigation and, if confirmed, guide future empirical research. First, declines in US tariffs matter substantially more than changes in Chinese import penetration. Second, we find important heterogeneities in the impact of trade exposure on jobs of a given quality across broad sectors of the economy (tradable goods, tradable services, and non-tradable). The presence of effects outside the tradable goods sector

is consistent with non-trivial spillover effects in sectors not directly affected by trade and trade 
policy. Finally, our finding that rising local trade exposure generates occupational polarization but not job polarization reveals important differences between these two phenomena. Because the now standard practice of dividing jobs into the broad categories of non-routine, routine, and abstract occupations implicitly pools jobs of varying quality, it is not obvious how determinants of occupational polarization affect job polarization absent further investigation.

Our results also ought to spur future research into richer theoretical models of trade exposure and labor market outcomes. Using a time invariant measure of job quality, standard trade theory does not help explain our pattern of results because it predicts that changes in trade exposure should not affect the distribution of workers across jobs of differing quality. Theoretical models that could potentially help explain our results require features such as wage dispersion for workers of a given type or the ability for a worker to choose between a diverse set of jobs. In these frameworks, tradeinduced resource reallocation can affect the dynamic matching of workers to jobs of differing (time invariant) quality.

\section{References}

Acemoglu, D., Autor, D., 2011. Skills, tasks and technologies: Implications for employment and earnings. Handbook of Labor Economics 4, 1043-1171.

Acemoglu, D., Autor, D., Dorn, D., Hanson, G. H., Price, B., 2015. Import competition and the great US employment sag of the 2000s. Journal of Labor Economics (forthcoming).

Autor, D. H., Dorn, D., 2013. The growth of low-skill service jobs and the polarization of the US labor market. The American Economic Review 103 (5), 1553-1597.

Autor, D. H., Dorn, D., Hanson, G. H., 2013. The China syndrome: Local labor market effects of import competition in the United States. The American Economic Review 103 (6), 2121-2168.

Autor, D. H., Katz, L. F., Kearney, M. S., 2006. The polarization of the US labor market. The American Economic Review, 189-194.

Autor, David, H., Dorn, D., Hanson, G. H., 2015. Untangling trade and technology: Evidence from local labour markets. The Economic Journal 125 (584), 621-646.

Balsvik, R., Jensen, S., Salvanes, K. G., 2015. Made in china, sold in norway: Local labor market effects of an import shock. Journal of Public Economics 127, 137-144.

Becker, R. A., Gray, W. B., Marvakov, J., 2013. NBER-CES manufacturing industry database: June 2013 revision. National Bureau of Economic Research.

Cameron, A. C., Gelbach, J. B., Miller, D. L., 2011. Robust inference with multiway clustering. Journal of Business \& Economic Statistics 29 (2), 238-249. 
Cozzi, G., Impullitti, G., 2016. Globalization and wage polarization. Review of Economics and Statistics (forthcoming).

Dauth, W., Findeisen, S., Suedekum, J., 2014. The rise of the east and the far east: German labor markets and trade integration. Journal of the European Economic Association 12 (6), 1643-1675.

Davis, D. R., Harrigan, J., 2011. Good jobs, bad jobs, and trade liberalization. Journal of International Economics 84 (1), 26-36.

Donoso, V., Martín, V., Minondo, A., 2015. Do differences in the exposure to Chinese imports lead to differences in local labour market outcomes? an analysis for Spanish provinces. Regional Studies 49 (10), 1746-1764.

Ebenstein, A., Harrison, A., McMillan, M., Phillips, S., 2014. Estimating the impact of trade and offshoring on American workers using the Current Population Surveys. Review of Economics and Statistics 96 (4), 581-595.

Goldberg, P. K., Pavcnik, N., 2016. The effects of trade policy. NBER Working Paper 21957.

Goos, M., Manning, A., 2007. Lousy and lovely jobs: The rising polarization of work in Britain. The Review of Economics and Statistics 89 (1), 118-133.

Goos, M., Manning, A., Salomons, A., 2009. Job polarization in Europe. The American Economic Review, 58-63.

Goos, M., Manning, A., Salomons, A., 2014. Explaining job polarization: Routine-biased technological change and offshoring. The American Economic Review 104 (8), 2509-2526.

Hasan, R., Mitra, D., Ural, B. P., 2007. Trade liberalization, labor-market institutions and poverty reduction: Evidence from Indian states. In: India Policy Forum. Vol. 3. pp. 71-122.

Helpman, E., Itskhoki, O., Redding, S., 2010. Inequality and unemployment in a global economy. Econometrica 78 (4), 1239-1283.

Keller, W., Utar, H., 2015. International trade and job polarization: Evidence at the worker level. Mimeo.

Kovak, B. K., 2013. Regional effects of trade reform: What is the correct measure of liberalization? The American Economic Review 103 (5), 1960-1976.

Limão, N., 2006. Preferential trade agreements as stumbling blocks for multilateral trade liberalization: Evidence for the United States. The American Economic Review 96 (3), 896-914.

Mai, J., Stoyanov, A., 2015. The effect of the Canada-US free trade agreement on Canadian multilateral trade liberalization. Canadian Journal of Economics (forthcoming).

McCaig, B., 2011. Exporting out of poverty: Provincial poverty in Vietnam and US market access. Journal of International Economics 85 (1), 102-113.

McLaren, J., Hakobyan, S., 2016. Looking for local labor market effects of NAFTA. Review of Economics and Statistics (forthcoming). 
Melitz, M., 2003. The impact of trade on intra-industry reallocations and aggregate industry productivity. Econometrica 71 (6), 1695-1725.

Mian, A., Sufi, A., 2014. What explains the 2007-2009 drop in employment? Econometrica 82 (6), $2197-2223$.

Michaels, G., Natraj, A., Van Reenen, J., 2014. Has ICT polarized skill demand? Evidence from eleven countries over twenty-five years. Review of Economics and Statistics 96 (1), 60-77.

Monte, F., Redding, S. J., Rossi-Hansberg, E., 2015. Commuting, migration and local employment elasticities. NBER Working Paper No.21706.

Nam, C. B., Boyd, M., 2004. Occupational status in 2000; over a century of Census-based measurement. Population Research and Policy Review 23 (4), 327-358.

Nickell, S., 1981. Biases in dynamic models with fixed effects. Econometrica, 1417-1426.

Pierce, J. R., Schott, P. K., 2016. The surprisingly swift decline of US manufacturing employment. The American Economic Review (forthcoming).

Samuel, L. R., 2013. The American Middle Class: A Cultural History. Vol. New York. Routledge.

Shapiro, C., Stiglitz, J. E., 1984. Equilibrium unemployment as a worker discipline device. The American Economic Review, 433-444.

Shen, L., Silva, P., 2014. Value added exports and US local labor markets: Does China really matter? Mimeo.

Spitz-Oener, A., 2006. Technical change, job tasks, and rising educational demands: looking outside the wage structure. Journal of Labor Economics 24 (2), 235-270.

Topalova, P., 2007. Trade liberalization, poverty and inequality: Evidence from Indian districts. In: Globalization and Poverty. University of Chicago Press, pp. 291-336.

Topalova, P., 2010. Factor immobility and regional impacts of trade liberalization: Evidence on poverty from India. American Economic Journal: Applied Economics 2 (4), 1-41. 
Table 1. Determinants of Changes in Local Job Shares.

\begin{tabular}{|c|c|c|c|c|c|c|c|c|c|c|}
\hline Variable & (1) & (2) & (3) & (4) & (5) & (6) & (7) & (8) & (9) & (10) \\
\hline Job Quality & $\begin{array}{l}-0.115 \wedge \\
(0.047)\end{array}$ & $\begin{array}{l}-0.129 * \\
(0.047)\end{array}$ & $\begin{array}{l}-0.129 * \\
(0.048)\end{array}$ & $\begin{array}{l}-0.077 \# \\
(0.042)\end{array}$ & $\begin{array}{l}-0.126 * \\
(0.046)\end{array}$ & $\begin{array}{l}-0.126 * \\
(0.047)\end{array}$ & $\begin{array}{l}-0.074 \# \\
(0.041)\end{array}$ & $\begin{array}{l}-0.130 * \\
(0.047)\end{array}$ & $\begin{array}{l}-0.130 * \\
(0.048)\end{array}$ & $\begin{array}{l}-0.078 \# \\
(0.043)\end{array}$ \\
\hline (Job Quality) $^{2}$ & $\begin{array}{l}0.126 \wedge \\
(0.050)\end{array}$ & $\begin{array}{l}0.126 \wedge \\
(0.050)\end{array}$ & $\begin{array}{l}0.126 \wedge \\
(0.052)\end{array}$ & $\begin{array}{l}0.101 \wedge \\
(0.045)\end{array}$ & $\begin{array}{l}0.126 \wedge \\
(0.050)\end{array}$ & $\begin{array}{l}0.126 \wedge \\
(0.051)\end{array}$ & $\begin{array}{l}0.101 \wedge \\
(0.045)\end{array}$ & $\begin{array}{l}0.126 \wedge \\
(0.050)\end{array}$ & $\begin{array}{l}0.126 \wedge \\
(0.051)\end{array}$ & $\begin{array}{l}0.101 \wedge \\
(0.046)\end{array}$ \\
\hline$\Delta$ Local US Tariff & & $\begin{array}{l}3.697 \wedge \\
(1.756)\end{array}$ & $\begin{array}{r}3.814 \wedge \\
(1.737)\end{array}$ & $\begin{array}{l}3.793 \wedge \\
(1.734)\end{array}$ & $\begin{array}{l}4.930 * \\
(1.647)\end{array}$ & $\begin{array}{l}5.013 * \\
(1.582)\end{array}$ & $\begin{array}{l}4.980 * \\
(1.577)\end{array}$ & & & \\
\hline $\begin{array}{c}\Delta \text { Local US Tariff } \\
\text { X Job Quality }\end{array}$ & & $\begin{array}{l}-7.154 \wedge \\
(3.204)\end{array}$ & $\begin{array}{l}-7.154 \wedge \\
(3.204)\end{array}$ & $\begin{array}{l}-7.154 \wedge \\
(3.221)\end{array}$ & $\begin{array}{l}-9.359 * \\
(2.863)\end{array}$ & $\begin{array}{l}-9.359 * \\
(2.863)\end{array}$ & $\begin{array}{l}-9.359 * \\
(2.873)\end{array}$ & & & \\
\hline$\Delta$ Local Foreign Tariff & & $\begin{array}{l}-0.936 * \\
(0.341)\end{array}$ & $\begin{array}{l}-0.971 * \\
(0.341)\end{array}$ & $\begin{array}{l}-0.962 * \\
(0.344)\end{array}$ & $\begin{array}{l}-1.018 * \\
(0.351)\end{array}$ & $\begin{array}{l}-1.047 * \\
(0.346)\end{array}$ & $\begin{array}{l}-1.038 * \\
(0.348)\end{array}$ & & & \\
\hline $\begin{array}{l}\Delta \text { Local Foreign Tariff } \\
\text { X Job Quality }\end{array}$ & & $\begin{array}{r}1.905 * \\
(0.629)\end{array}$ & $\begin{array}{c}1.905 * \\
(0.629)\end{array}$ & $\begin{array}{l}1.905 * \\
(0.632)\end{array}$ & $\begin{array}{r}2.051 * \\
(0.638)\end{array}$ & $\begin{array}{l}2.051 * \\
(0.638)\end{array}$ & $\begin{array}{l}2.051 * \\
(0.641)\end{array}$ & & & \\
\hline$\Delta$ Local Chinese Import & & -0.202 & -0.200 & -0.197 & & & & $-0.363 \wedge$ & $-0.363 *$ & $-0.359 \wedge$ \\
\hline Penetration & & $(0.139)$ & $(0.143)$ & $(0.144)$ & & & & $(0.147)$ & $(0.140)$ & $(0.140)$ \\
\hline$\Delta$ Local Chinese Import & & 0.361 & 0.361 & 0.361 & & & & $0.655 \wedge$ & $0.655 \wedge$ & $0.655^{\wedge}$ \\
\hline Pen. X Job Quality & & $(0.280)$ & $(0.281)$ & $(0.283)$ & & & & $(0.258)$ & $(0.258)$ & $(0.260)$ \\
\hline Baseline Covariates & $\mathrm{N}$ & $\mathrm{N}$ & $\mathrm{Y}$ & $\mathrm{Y}$ & $\mathrm{N}$ & $\mathrm{Y}$ & $\mathrm{Y}$ & $\mathrm{N}$ & $\mathrm{Y}$ & $\mathrm{Y}$ \\
\hline Change in Covariates & $\mathrm{N}$ & $\mathrm{N}$ & $\mathrm{Y}$ & $\mathrm{Y}$ & $\mathrm{N}$ & $\mathrm{Y}$ & $\mathrm{Y}$ & $\mathrm{N}$ & $\mathrm{Y}$ & $\mathrm{Y}$ \\
\hline Industry FEs & $\mathrm{N}$ & $\mathrm{N}$ & $\mathrm{N}$ & $\mathrm{Y}$ & $\mathrm{N}$ & $\mathrm{N}$ & $\mathrm{Y}$ & $\mathrm{N}$ & $\mathrm{N}$ & $\mathrm{Y}$ \\
\hline State FEs & $\mathrm{N}$ & $\mathrm{N}$ & $\mathrm{N}$ & $\mathrm{Y}$ & $\mathrm{N}$ & $\mathrm{N}$ & $\mathrm{Y}$ & $\mathrm{N}$ & $\mathrm{N}$ & $\mathrm{Y}$ \\
\hline $\mathrm{N}$ & 784092 & 784092 & 784092 & 784092 & 784092 & 784092 & 784092 & 784092 & 784092 & 784092 \\
\hline Joint Significance: & & & & & & & & & & \\
\hline US Tariff Variables & & $p=0.08$ & $\mathrm{p}=0.08$ & $\mathrm{p}=0.08$ & $\mathrm{p}=0.00$ & $\mathrm{p}=0.00$ & $\mathrm{p}=0.00$ & & & \\
\hline Foreign Tariff Variables & & $\mathrm{p}=0.01$ & $\mathrm{p}=0.01$ & $\mathrm{p}=0.00$ & $\mathrm{p}=0.00$ & $\mathrm{p}=0.00$ & $\mathrm{p}=0.00$ & & & \\
\hline China Variables & & $p=0.24$ & $p=0.31$ & $p=0.33$ & & & & $p=0.04$ & $p=0.04$ & $p=0.04$ \\
\hline All Trade Variables & & $p=0.02$ & $p=0.03$ & $p=0.02$ & $p=0.01$ & $p=0.01$ & $\mathrm{p}=0.01$ & & & \\
\hline
\end{tabular}

Notes: Dependent variable is the change in population share in a particular job and ConsPUMA from 1990-2010, where the shares in 1990 and 2010 are based on noninstitutionalized individuals aged 25-64, who are not self-employed, in school, or in the military. Estimation by OLS or Fixed Effects. For definitions of variables and list of other covariates not reported, see main text and Table A1 in the Supplemental Appendix. Regressions are weighted by ConsPUMA population in 1990. Two-way standard errors clustered by ConsPUMA and job in parentheses. $\# \mathrm{p}<0.10, \wedge \mathrm{p}<0.05$, and ${ }^{*} \mathrm{p}<0.01$. 
Table 2. Determinants of Changes in Local Job Shares: Instrumental Variables Estimation.

\begin{tabular}{lccc}
\hline Variable & $\mathbf{( 1 )}$ & $\mathbf{( 2 )}$ & $\mathbf{( 3 )}$ \\
\hline Job Quality & $-0.076 \wedge$ & $-0.082 \wedge$ & $-0.076 \#$ \\
& $(0.038)$ & $(0.040)$ & $(0.042)$ \\
$\left(\right.$ Job Quality) ${ }^{2}$ & $0.101 \wedge$ & $0.101 \wedge$ & $0.101 \wedge$ \\
& $(0.044)$ & $(0.044)$ & $(0.044)$ \\
$\Delta$ Local US Tariff & $9.100 *$ & & 8.393 \\
& $(3.184)$ & & $(5.914)$ \\
$\Delta$ Local US Tariff & $-15.887 *$ & & -15.668 \\
$\quad$ X Job Quality & $(5.390)$ & & $(11.300)$ \\
$\Delta$ Local Foreign Tariff & $-2.447 *$ & & $-2.267 \#$ \\
& $(0.856)$ & & $(1.310)$ \\
$\Delta$ Local Foreign Tariff & $4.203 *$ & & $4.160 \#$ \\
$\quad$ X Job Quality & $(1.394)$ & & $(2.414)$ \\
$\Delta$ Local Chinese Import & & $-0.449 \wedge$ & -0.048 \\
$\quad$ Penetration & & $(0.192)$ & $(0.384)$ \\
$\Delta$ Local Chinese Import & & $0.799 \wedge$ & 0.022 \\
$\quad$ Pen. X Job Quality & & $(0.340)$ & $(0.748)$ \\
& & & \\
N & & 784092 & 784092 \\
Underidentification & 11.802 & 43.726 & 11.283 \\
& $\mathrm{p}=0.00$ & $\mathrm{p}=0.00$ & $\mathrm{p}=0.00$
\end{tabular}

Joint Significance:

$\begin{array}{lccc}\text { US Tariff Variables } & \mathrm{p}=0.01 & & \mathrm{p}=0.35 \\ \text { Foreign Tariff Variables } & \mathrm{p}=0.01 & & \mathrm{p}=0.22 \\ \text { China Variables } & & \mathrm{p}=0.06 & \mathrm{p}=0.40 \\ \text { All Trade Variables } & \mathrm{p}=0.03 & & \mathrm{p}=0.00 \\ \text { All Trade Variables } & \mathrm{p}=0.03 & \mathrm{p}=0.05 & \mathrm{p}=0.02\end{array}$

(Anderson-Rubin Test)

Notes: Dependent variable is the change in population share in a particular job and ConsPUMA from 1990-2010, where the shares in 1990 and 2010 are based on non-institutionalized individuals aged 25-64, who are not self-employed, in school, or in the military. All specifications include baseline covariates, change in covariates, industry fixed effects, and state fixed effects. For definitions of variables and list of other covariates not reported, see main text and Table A1 in the Supplemental Appendix. Regressions are weighted by ConsPUMA population in 1990. Two-way standard errors clustered by ConsPUMA and job in parentheses. \# $\mathrm{p}<0.10, \wedge \mathrm{p}<0.05$, and $* \mathrm{p}<0.01$. 
Table 3. Determinants of Changes in Local Job Shares: Alternative Specifications.

\begin{tabular}{|c|c|c|c|c|c|c|}
\hline Variable & (1) & $(2)$ & (3) & (4) & (5) & (6) \\
\hline Job Quality & $\begin{array}{l}-0.077 \# \\
(0.042)\end{array}$ & $\begin{array}{l}-0.113 * \\
(0.043)\end{array}$ & $\begin{array}{l}-0.075 \# \\
(0.042)\end{array}$ & $\begin{array}{l}-0.084 \wedge \\
(0.041)\end{array}$ & $\begin{array}{l}-0.087 \wedge \\
(0.040)\end{array}$ & $\begin{array}{l}-0.077 \# \\
(0.046)\end{array}$ \\
\hline${\text { (Job Quality })^{2}}^{2}$ & $\begin{array}{l}0.101 \wedge \\
(0.045)\end{array}$ & $\begin{array}{l}0.132 * \\
(0.046)\end{array}$ & $\begin{array}{l}0.093 \wedge \\
(0.047)\end{array}$ & $\begin{array}{l}0.112 \wedge \\
(0.045)\end{array}$ & $\begin{array}{l}0.115 \wedge \\
(0.045)\end{array}$ & $\begin{array}{r}0.058 \\
(0.051)\end{array}$ \\
\hline$\Delta$ Local US Tariff & $\begin{array}{l}3.793 \wedge \\
(1.734)\end{array}$ & $\begin{array}{l}7.416 \wedge \\
(3.382)\end{array}$ & $\begin{array}{l}3.605 \wedge \\
(1.604)\end{array}$ & $\begin{array}{l}3.793 \wedge \\
(1.737)\end{array}$ & $\begin{array}{l}3.793 \wedge \\
(1.738)\end{array}$ & $\begin{array}{l}3.793 \wedge \\
(1.728)\end{array}$ \\
\hline $\begin{array}{c}\Delta \text { Local US Tariff } \\
\text { X Job Quality }\end{array}$ & $\begin{array}{l}-7.154 \wedge \\
(3.221)\end{array}$ & $\begin{array}{l}-21.805 \# \\
(12.649)\end{array}$ & $\begin{array}{l}-6.727 \wedge \\
(2.983)\end{array}$ & $\begin{array}{l}-7.154 \wedge \\
(3.227)\end{array}$ & $\begin{array}{l}-7.154 \wedge \\
(3.228)\end{array}$ & $\begin{array}{l}-7.154 \wedge \\
(3.206)\end{array}$ \\
\hline $\begin{array}{l}\Delta \text { Local US Tariff } \\
\quad \text { X (Job Quality) }{ }^{2}\end{array}$ & & $\begin{array}{r}13.137 \\
(11.525)\end{array}$ & & & & \\
\hline$\Delta$ Local Foreign Tariff & $\begin{array}{l}-0.962 * \\
(0.344)\end{array}$ & $\begin{array}{l}-2.135 * \\
(0.700)\end{array}$ & $\begin{array}{l}-0.875 * \\
(0.316)\end{array}$ & $\begin{array}{l}-0.962 * \\
(0.344)\end{array}$ & $\begin{array}{l}-0.962 * \\
(0.344)\end{array}$ & $\begin{array}{l}-0.962 * \\
(0.343)\end{array}$ \\
\hline $\begin{array}{l}\Delta \text { Local Foreign Tariff } \\
\quad \text { X Job Quality }\end{array}$ & $\begin{array}{r}1.905 * \\
(0.632)\end{array}$ & $\begin{array}{l}6.649 * \\
(2.450)\end{array}$ & $\begin{array}{c}1.735 * \\
(0.582)\end{array}$ & $\begin{array}{r}1.905 * \\
(0.633)\end{array}$ & $\begin{array}{r}1.905 * \\
(0.633)\end{array}$ & $\begin{array}{r}1.905 * \\
(0.630)\end{array}$ \\
\hline $\begin{array}{c}\Delta \text { Local Foreign Tariff } \\
\quad \text { X (Job Quality })^{2}\end{array}$ & & $\begin{array}{l}-4.254 \wedge \\
(2.090)\end{array}$ & & & & \\
\hline $\begin{array}{l}\Delta \text { Local Chinese Import } \\
\text { Penetration }\end{array}$ & $\begin{array}{r}-0.197 \\
(0.144)\end{array}$ & $\begin{array}{l}-0.526 \# \\
(0.316)\end{array}$ & $\begin{array}{r}-0.185 \\
(0.147)\end{array}$ & $\begin{array}{r}-0.197 \\
(0.145)\end{array}$ & $\begin{array}{r}-0.197 \\
(0.145)\end{array}$ & $\begin{array}{r}-0.197 \\
(0.143)\end{array}$ \\
\hline $\begin{array}{c}\Delta \text { Local Chinese Import } \\
\text { Pen. X Job Quality }\end{array}$ & $\begin{array}{r}0.361 \\
(0.283)\end{array}$ & $\begin{array}{r}1.690 \\
(1.290)\end{array}$ & $\begin{array}{r}0.332 \\
(0.290)\end{array}$ & $\begin{array}{r}0.361 \\
(0.284)\end{array}$ & $\begin{array}{r}0.361 \\
(0.285)\end{array}$ & $\begin{array}{r}0.361 \\
(0.281)\end{array}$ \\
\hline $\begin{array}{l}\Delta \text { Local Chinese Import } \\
\quad \text { Pen. X (Job Quality) }\end{array}$ & & $\begin{array}{r}-1.191 \\
(1.253)\end{array}$ & & & & \\
\hline $\begin{array}{l}\text { Specification Change } \\
\text { (relative to baseline } \\
\text { specification in (1)) }\end{array}$ & & $\begin{array}{l}\text { Add interactions } \\
\text { with quadratic } \\
\text { terms }\end{array}$ & $\begin{array}{c}\text { Add lagged } \\
\text { dependent } \\
\text { variable }\end{array}$ & $\begin{array}{l}\text { Add 3-digit } \\
\text { industry FEs }\end{array}$ & $\begin{array}{l}\text { Add 3-digit } \\
\text { industry FEs + } \\
\text { other industry } \\
\text { controls }\end{array}$ & $\begin{array}{c}\text { Replace } \\
\text { industry FEs } \\
\text { with occupation } \\
\text { FEs }\end{array}$ \\
\hline $\mathrm{N}$ & 784092 & 784092 & 784092 & 784092 & 784092 & 784092 \\
\hline Joint Significance: & & & & & & \\
\hline US Tariff Variables & $\mathrm{p}=0.08$ & $p=0.05$ & $p=0.08$ & $p=0.09$ & $p=0.09$ & $p=0.08$ \\
\hline Foreign Tariff Variables & $\mathrm{p}=0.00$ & $\mathrm{p}=0.00$ & $\mathrm{p}=0.00$ & $\mathrm{p}=0.00$ & $\mathrm{p}=0.00$ & $p=0.00$ \\
\hline China Variables & $\mathrm{p}=0.33$ & $\mathrm{p}=0.20$ & $\mathrm{p}=0.33$ & $\mathrm{p}=0.34$ & $\mathrm{p}=0.34$ & $\mathrm{p}=0.33$ \\
\hline All Trade Variables & $\mathrm{p}=0.02$ & $p=0.01$ & $\mathrm{p}=0.01$ & $\mathrm{p}=0.02$ & $\mathrm{p}=0.02$ & $\mathrm{p}=0.02$ \\
\hline
\end{tabular}

Notes: Dependent variable is the change in population share in a particular job and ConsPUMA from 1990-2010, where the shares in 1990 and 2010 are based on non-institutionalized individuals aged 25-64, who are not self-employed, in school, or in the military. All specifications include baseline covariates, change in covariates, industry fixed effects, and state fixed effects. For definitions of variables and list of other covariates not reported, see main text and Table A1 in the Supplemental Appendix. Regressions are weighted by ConsPUMA population in 1990. Two-way standard errors clustered by ConsPUMA and job in parentheses. \# $\mathrm{p}<0.10$, $\wedge \mathrm{p}<0.05$, and ${ }^{*} \mathrm{p}<0.01$. 
Table 4. Determinants of Changes in Local Job Shares: Heterogeneous Effects by Sector.

\begin{tabular}{|c|c|c|c|c|c|c|c|c|c|}
\hline \multirow[b]{2}{*}{ Variable } & \multicolumn{3}{|c|}{ Tradable Goods } & \multicolumn{3}{|c|}{ Tradable Services } & \multicolumn{3}{|c|}{ Non-Tradables } \\
\hline & (1) & (2) & (3) & (4) & (5) & (6) & (7) & (8) & (9) \\
\hline \multirow[t]{2}{*}{ Job Quality } & 0.032 & 0.035 & 0.029 & $-0.349 \wedge$ & $-0.359 \wedge$ & $-0.356 \wedge$ & -0.096 & -0.099 & -0.098 \\
\hline & $(0.055)$ & $(0.059)$ & $(0.056)$ & $(0.156)$ & $(0.164)$ & $(0.165)$ & $(0.073)$ & $(0.073)$ & $(0.073)$ \\
\hline \multirow[t]{2}{*}{ (Job Quality) $^{2}$} & -0.054 & -0.054 & -0.054 & $0.445 *$ & $0.445 *$ & $0.445 *$ & 0.134 & 0.134 & 0.134 \\
\hline & $(0.050)$ & $(0.050)$ & $(0.050)$ & $(0.161)$ & $(0.165)$ & $(0.168)$ & $(0.090)$ & $(0.090)$ & $(0.090)$ \\
\hline \multirow[t]{2}{*}{$\Delta$ Local US Tariff } & $16.017 *$ & & $14.796 *$ & -3.903 & & -6.144 & $3.110 *$ & & $2.198 \wedge$ \\
\hline & $(4.908)$ & & $(5.643)$ & $(4.475)$ & & $(5.115)$ & $(1.087)$ & & $(0.952)$ \\
\hline$\Delta$ Local US Tariff & $-26.085 *$ & & $-24.125 \wedge$ & 4.902 & & 9.754 & $-7.053 *$ & & $-5.386 *$ \\
\hline X Job Quality & $(8.090)$ & & (9.535) & $(8.122)$ & & (9.105) & (2.189) & & (1.859) \\
\hline \multirow[t]{2}{*}{$\Delta$ Local Foreign Tariff } & $-1.745 \wedge$ & & $-1.671 \#$ & 0.304 & & 0.482 & $-0.984 *$ & & $-0.931 *$ \\
\hline & $(0.854)$ & & $(0.872)$ & $(0.916)$ & & $(0.911)$ & $(0.358)$ & & $(0.345)$ \\
\hline$\Delta$ Local Foreign Tariff & $3.802 *$ & & $3.672 \wedge$ & -0.777 & & -1.099 & $1.648 \wedge$ & & $1.537 \wedge$ \\
\hline X Job Quality & $(1.418)$ & & $(1.458)$ & (1.661) & & $(1.591)$ & $(0.692)$ & & $(0.667)$ \\
\hline$\Delta$ Local Chinese Import & & $-1.223 \wedge$ & -0.207 & & 0.120 & -0.338 & & $-0.198 \wedge$ & $-0.157 \#$ \\
\hline Penetration & & $(0.516)$ & $(0.510)$ & & $(0.417)$ & $(0.484)$ & & $(0.095)$ & $(0.089)$ \\
\hline$\Delta$ Local Chinese Import & & $1.869 \wedge$ & 0.321 & & 0.090 & 0.794 & & $0.473 \wedge$ & $0.273 \#$ \\
\hline Pen. X Job Quality & & $(0.879)$ & $(0.918)$ & & $(0.738)$ & $(0.893)$ & & $(0.200)$ & $(0.159)$ \\
\hline Baseline Covariates & $\mathrm{N}$ & $\mathrm{Y}$ & $\mathrm{Y}$ & $\mathrm{N}$ & $\mathrm{Y}$ & $\mathrm{Y}$ & $\mathrm{N}$ & $\mathrm{Y}$ & $\mathrm{Y}$ \\
\hline Change in Covariates & $\mathrm{N}$ & $\mathrm{Y}$ & $\mathrm{Y}$ & $\mathrm{N}$ & $\mathrm{Y}$ & $\mathrm{Y}$ & $\mathrm{N}$ & $\mathrm{Y}$ & $\mathrm{Y}$ \\
\hline Industry FEs & $\mathrm{N}$ & $\mathrm{N}$ & $\mathrm{Y}$ & $\mathrm{N}$ & $\mathrm{N}$ & $\mathrm{Y}$ & $\mathrm{N}$ & $\mathrm{N}$ & $\mathrm{Y}$ \\
\hline State FEs & $\mathrm{N}$ & $\mathrm{N}$ & $\mathrm{Y}$ & $\mathrm{N}$ & $\mathrm{N}$ & $\mathrm{Y}$ & $\mathrm{N}$ & $\mathrm{N}$ & $\mathrm{Y}$ \\
\hline $\mathrm{N}$ & 273672 & 273672 & 273672 & 97740 & 97740 & 97740 & 412680 & 412680 & 412680 \\
\hline \multicolumn{10}{|l|}{ Joint Significance: } \\
\hline US Tariff Variables & $\mathrm{p}=0.01$ & & $\mathrm{p}=0.03$ & $\mathrm{p}=0.00$ & & $\mathrm{p}=0.06$ & $\mathrm{p}=0.00$ & & $\mathrm{p}=0.00$ \\
\hline Foreign Tariff Variables & $\mathrm{p}=0.00$ & & $\mathrm{p}=0.00$ & $p=0.62$ & & $\mathrm{p}=0.57$ & $\mathrm{p}=0.00$ & & $p=0.00$ \\
\hline China Variables & & $\mathrm{p}=0.01$ & $\mathrm{p}=0.86$ & & $\mathrm{p}=0.14$ & $\mathrm{p}=0.41$ & & $\mathrm{p}=0.02$ & $\mathrm{p}=0.21$ \\
\hline All Trade Variables & $\mathrm{p}=0.00$ & & $\mathrm{p}=0.00$ & $\mathrm{p}=0.00$ & & $\mathrm{p}=0.05$ & $\mathrm{p}=0.00$ & & $\mathrm{p}=0.00$ \\
\hline
\end{tabular}

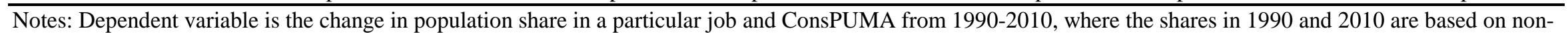
institutionalized individuals aged 25-64, who are not self-employed, in school, or in the military. All specifications include baseline covariates, change in covariates, industry fixed effects, and state fixed effects. For definitions of variables and list of other covariates not reported, see main text and Table A1 in the Supplemental Appendix. Regressions are weighted by ConsPUMA population in 1990 . Two-way standard errors clustered by ConsPUMA and job in parentheses. \# $\mathrm{p}<0.10, \wedge \mathrm{p}<$ 0.05 , and $* \mathrm{p}<0.01$. 
Table 5. Determinants of Changes in Local Job Shares: Heterogeneous Effects by Occupation Type.

\begin{tabular}{lccrr}
\hline Variable & $\mathbf{( 1 )}$ & $\mathbf{( 2 )}$ & $\mathbf{( 3 )}$ & $\mathbf{( 4 )}$ \\
\hline Job Quality & $-0.077 \#$ & 0.018 & 0.053 & 0.100 \\
& $(0.042)$ & $(0.040)$ & $(0.034)$ & $(0.235)$ \\
$\left(\right.$ Job Quality) ${ }^{2}$ & $0.101 \wedge$ & -0.067 & $-0.061 \#$ & 0.025 \\
& $(0.045)$ & $(0.043)$ & $(0.037)$ & $(0.163)$ \\
$\Delta$ Local US Tariff & $3.793 \wedge$ & 2.252 & $6.708 \wedge$ & -3.940 \\
& $(1.734)$ & $(1.705)$ & $(3.135)$ & $(5.755)$ \\
$\Delta$ Local US Tariff & $-7.154 \wedge$ & -5.714 & $-12.917 \wedge$ & 4.988 \\
$\quad$ X Job Quality & $(3.221)$ & $(4.108)$ & $(6.073)$ & $(7.795)$ \\
$\Delta$ Local Foreign Tariff & $-0.962 *$ & $-1.978 *$ & $-0.901 \wedge$ & 0.004 \\
& $(0.344)$ & $(0.757)$ & $(0.440)$ & $(0.935)$ \\
$\Delta$ Local Foreign Tariff & $1.905 *$ & $4.239 *$ & $2.177 \wedge$ & -0.139 \\
$\quad$ X Job Quality & $(0.632)$ & $(1.554)$ & $(0.934)$ & $(1.234)$ \\
$\Delta$ Local Chinese Import & -0.197 & $-0.421 \wedge$ & -0.218 & 0.131 \\
Penetration & $(0.144)$ & $(0.172)$ & $(0.205)$ & $(0.622)$ \\
$\Delta$ Local Chinese Import & 0.361 & $1.004 \wedge$ & 0.411 & -0.234 \\
Pen. X Job Quality & $(0.283)$ & $(0.407)$ & $(0.387)$ & $(0.904)$
\end{tabular}

Sample Selection:

Occupation Types
All

784092
Non-routine

262269
Routine

389874
Abstract

131949

Joint Significance:

US Tariff Variables

Foreign Tariff Variables

China Variables

All Trade Variables

$\begin{array}{llll}\mathrm{p}=0.08 & \mathrm{p}=0.37 & \mathrm{p}=0.10 & \mathrm{p}=0.06 \\ \mathrm{p}=0.00 & \mathrm{p}=0.02 & \mathrm{p}=0.01 & \mathrm{p}=0.67 \\ \mathrm{p}=0.33 & \mathrm{p}=0.05 & \mathrm{p}=0.57 & \mathrm{p}=0.77 \\ \mathrm{p}=0.02 & \mathrm{p}=0.03 & \mathrm{p}=0.01 & \mathrm{p}=0.22\end{array}$

Notes: Dependent variable is the change in population share in a particular job and ConsPUMA from 1990-2010, where the shares in 1990 and 2010 are based on non-institutionalized individuals with ages given in the table who are not self-employed, in school, or in the military. All specifications include baseline covariates, change in covariates, industry fixed effects, and state fixed effects. For definitions of variables and list of other covariates not reported, see main text and Table A1 in the Supplemental Appendix. Regressions are weighted by ConsPUMA population in 1990. Two-way standard errors clustered by ConsPUMA and job in parentheses. \# $\mathrm{p}<0.10, \wedge \mathrm{p}<0.05$, and ${ }^{*} \mathrm{p}<0.01$. 


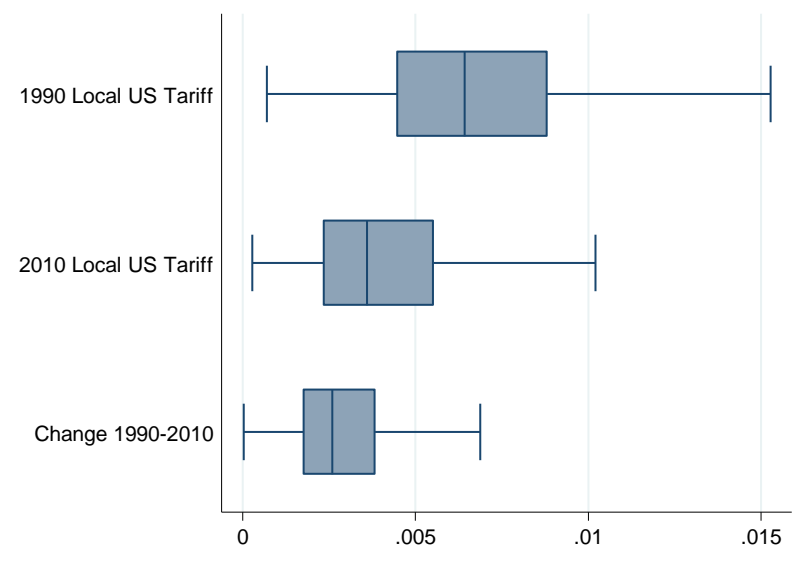

(A) Declining Local US Tariffs

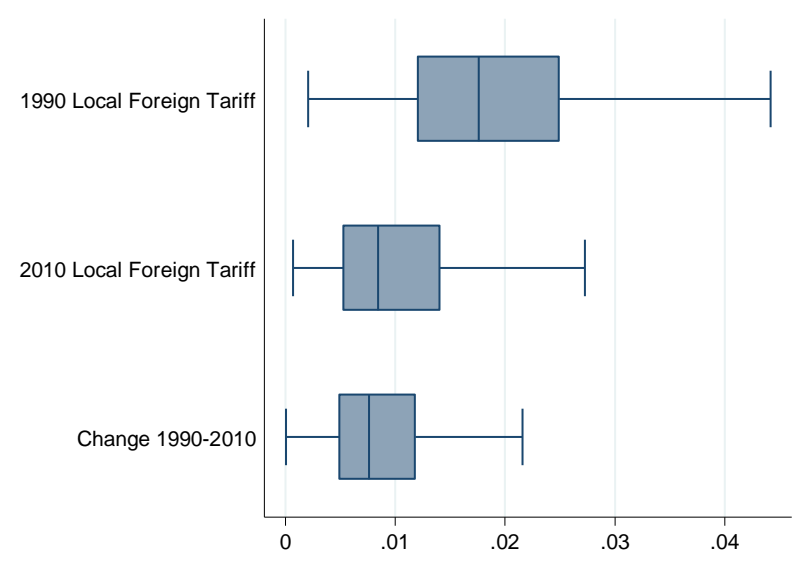

(B) Declining Local Foreign Tariffs

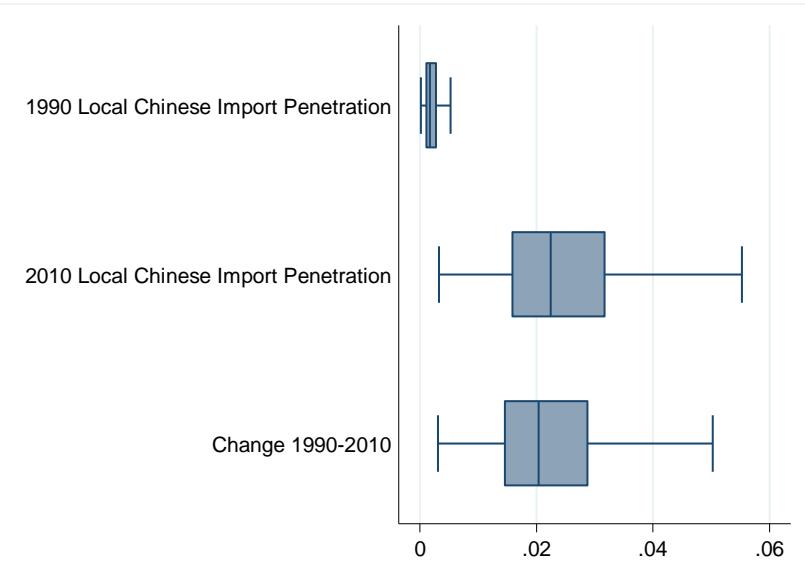

(C) Increasing Local Chinese Import Penetration

Figure 1. Rising Local Trade Exposure, 1990-2010.

Notes: Boxes represent the interquartile range, with the middle line corresponding to the median. The end lines correspond to the lower and upper adjacent values. See main text for definition of variables. 

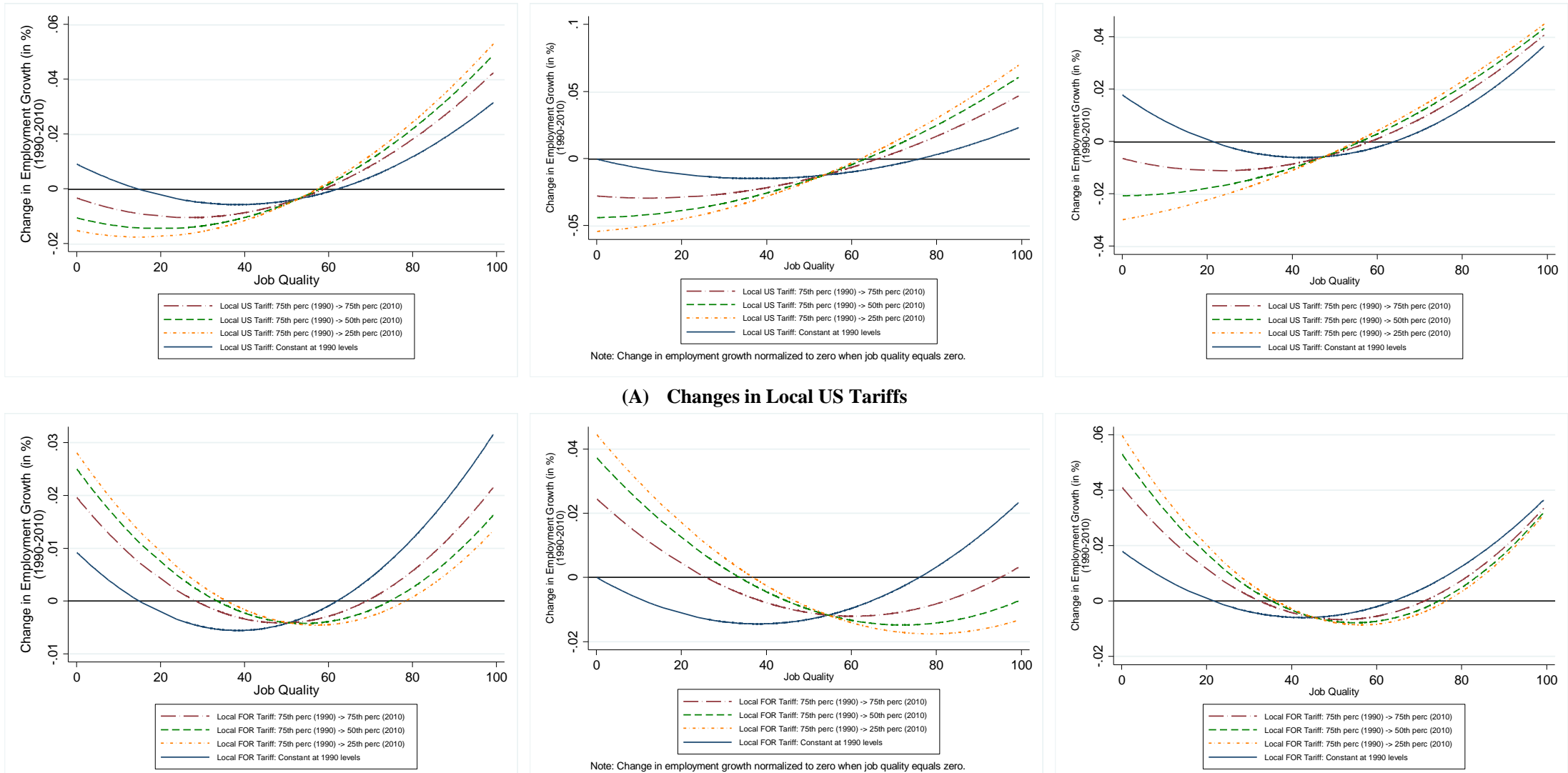

(A) Changes in Local US Tariffs
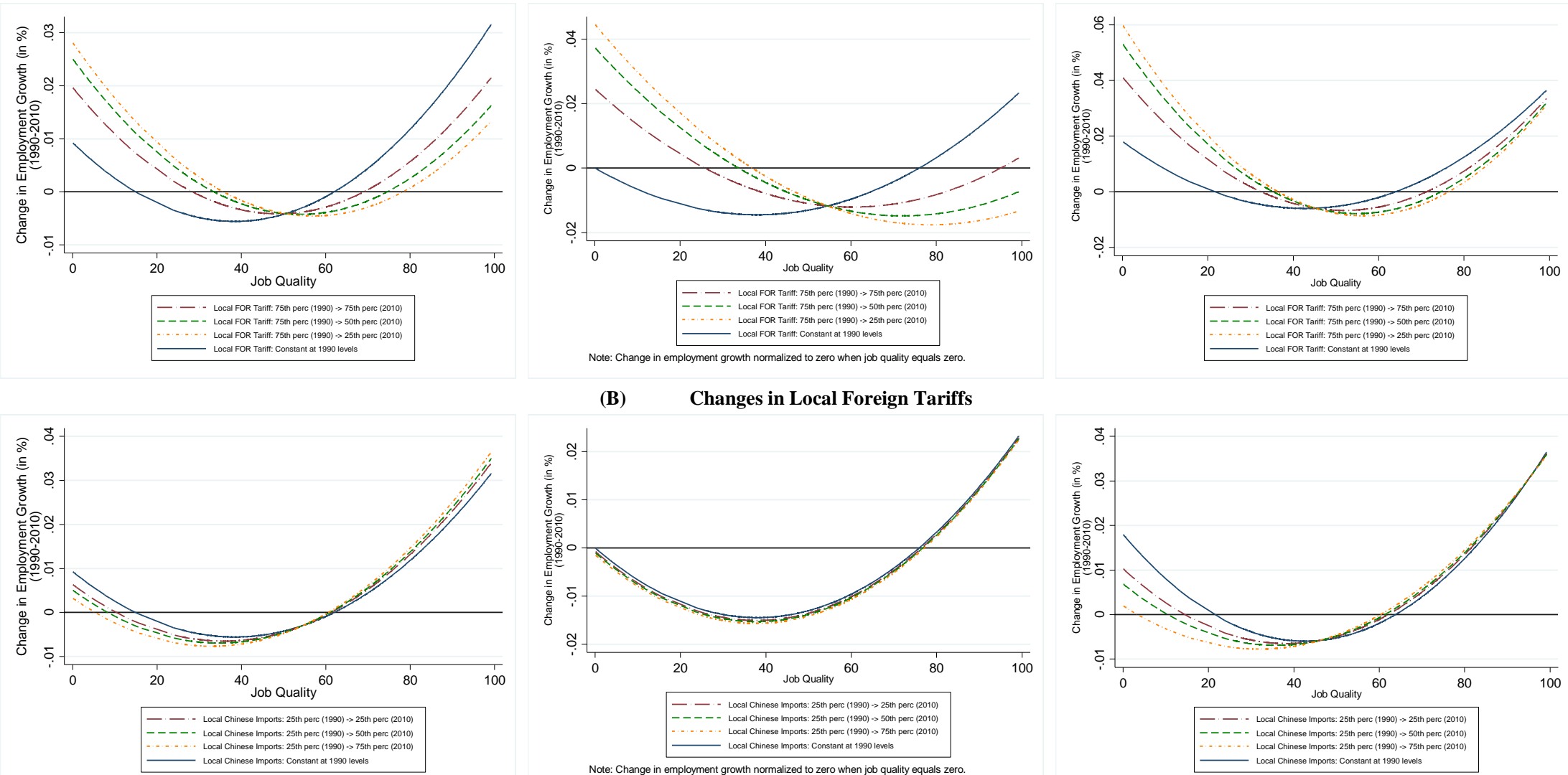

(B)
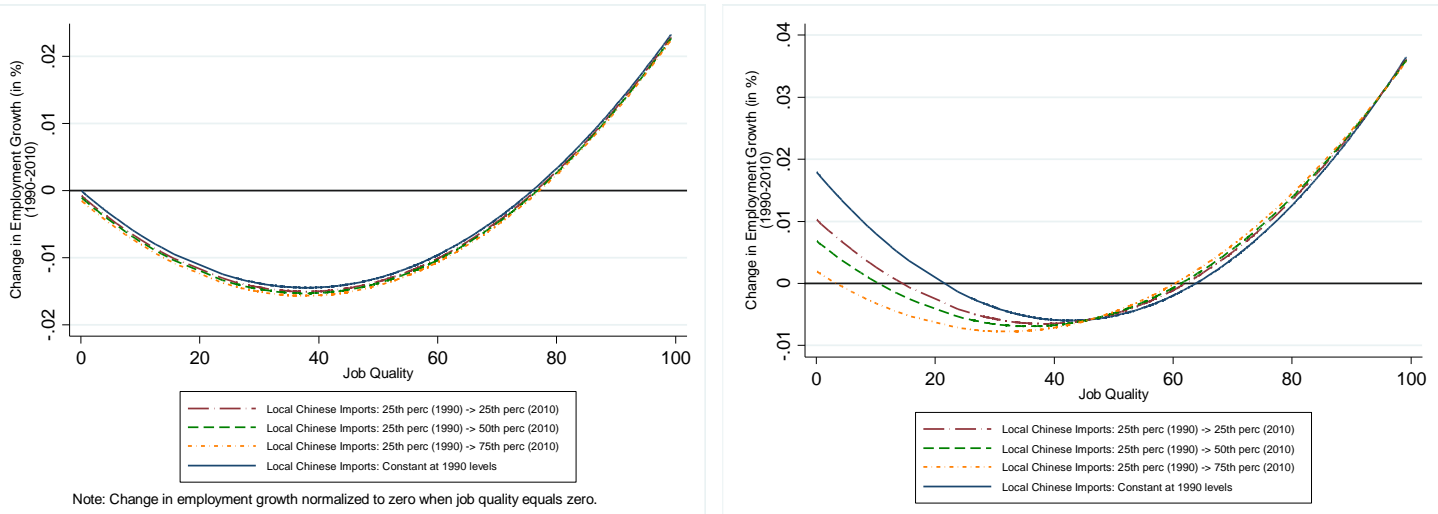

(C) Changes in Local Chinese Import Penetration

Figure 2. Impacts of Local Trade Variables on Changes in Local Employment Shares, 1990-2010.

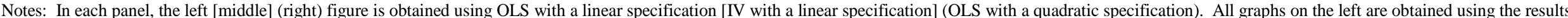

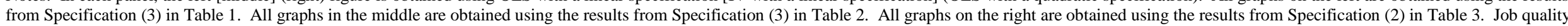
is measured as the NPB index (multiplied by 100). 


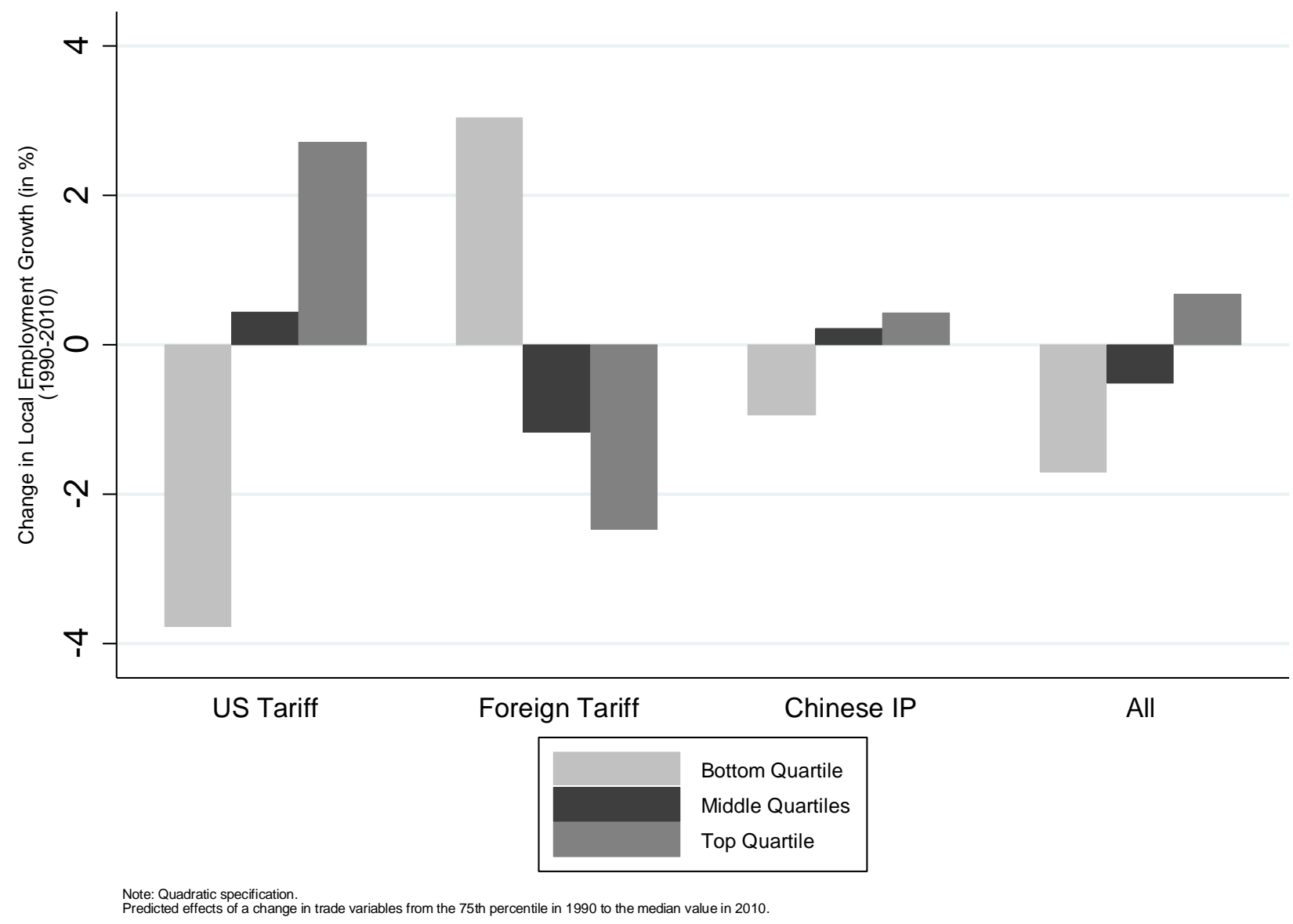

Figure 3. Cumulative Impacts of Local Trade Exposure Variables on Changes in Local Employment Shares by Quartiles of Job Quality, 1990-2010.

Notes: The figure is obtained using the results in Specification (2) in Table 3 and aggregating over jobs within each quartile (or combined quartile) of the job quality distribution. 

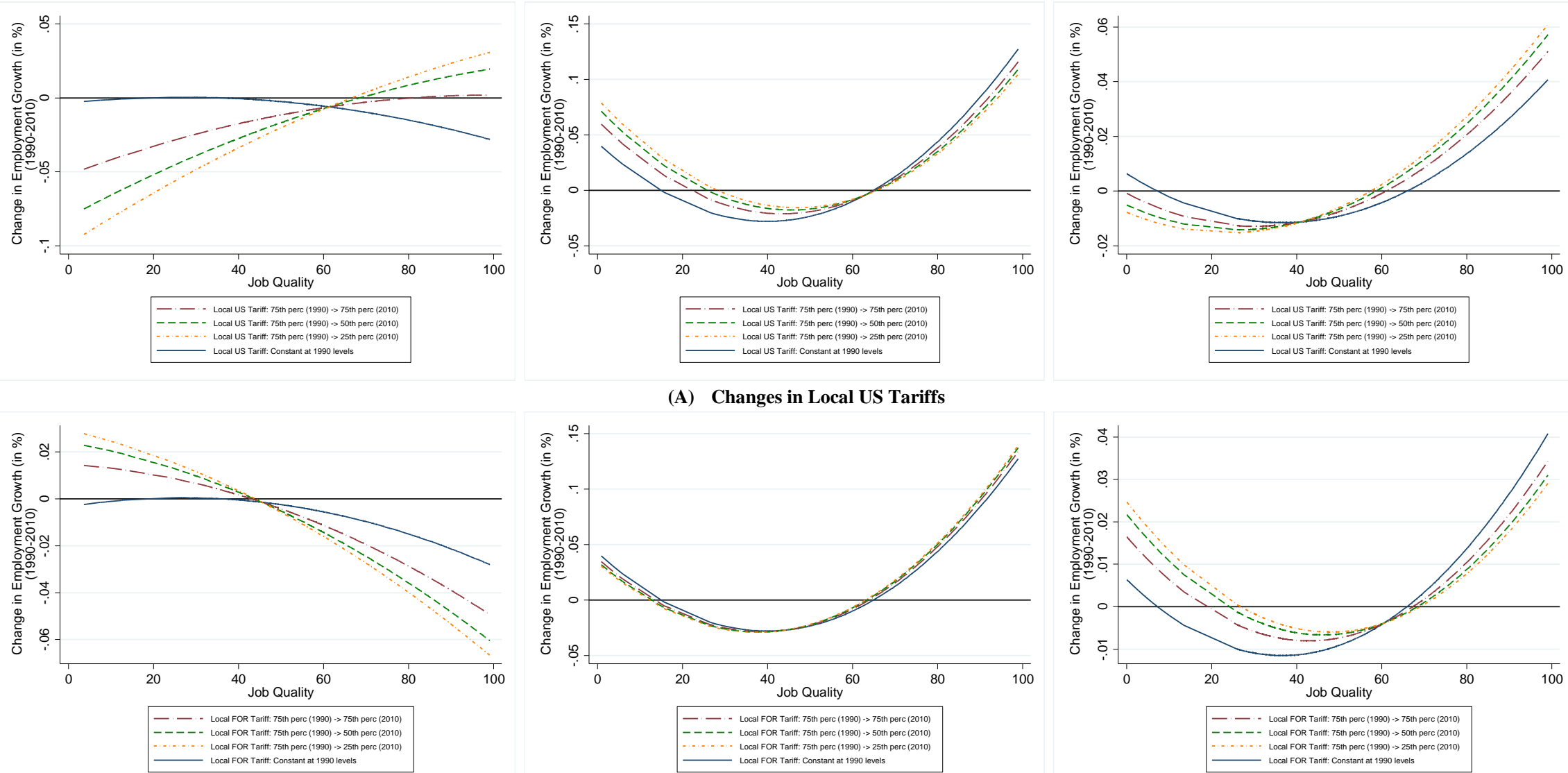

(A) Changes in Local US Tariffs
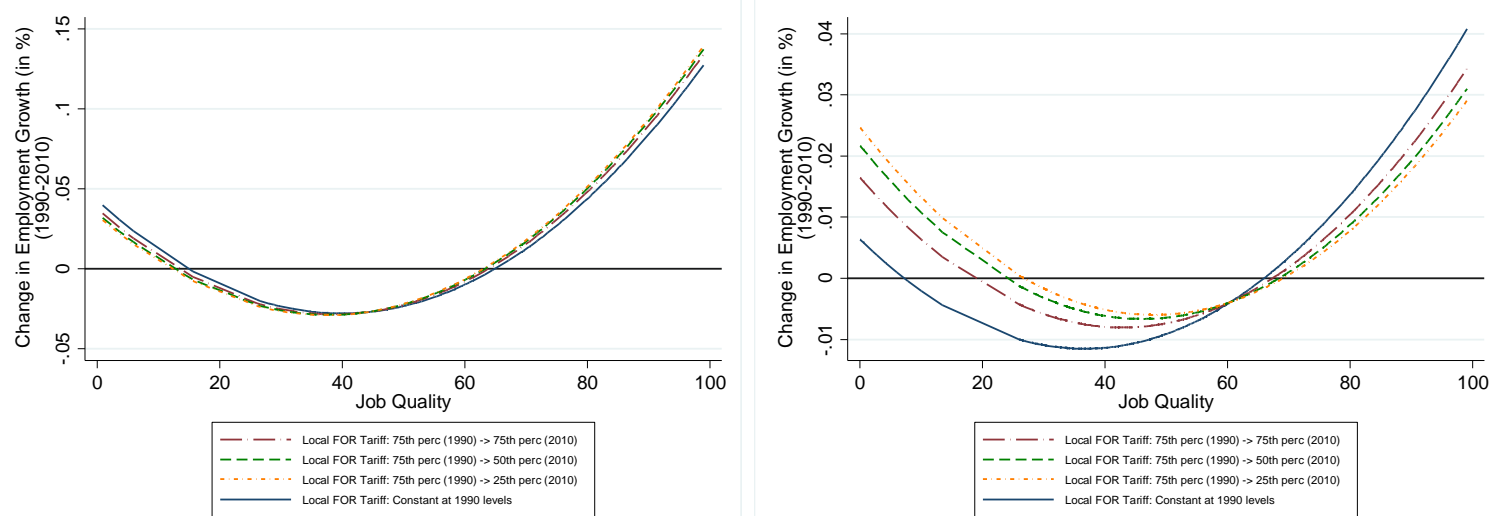

(B) Changes in Local Foreign Tariffs
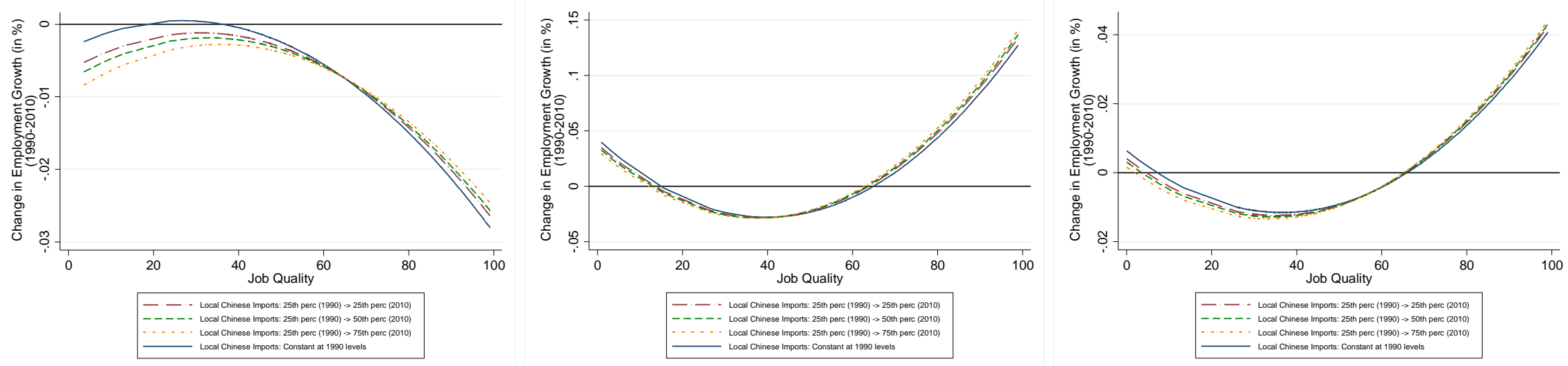

(C) Changes in Local Chinese Import Penetration

Figure 4. Impacts of Local Trade Variables on Changes in Local Employment Shares, 1990-2010: Heterogeneous Effects by Sector.

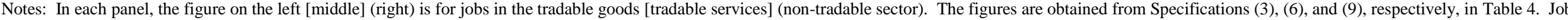
quality is measured as the NPB index (multiplied by 100). 

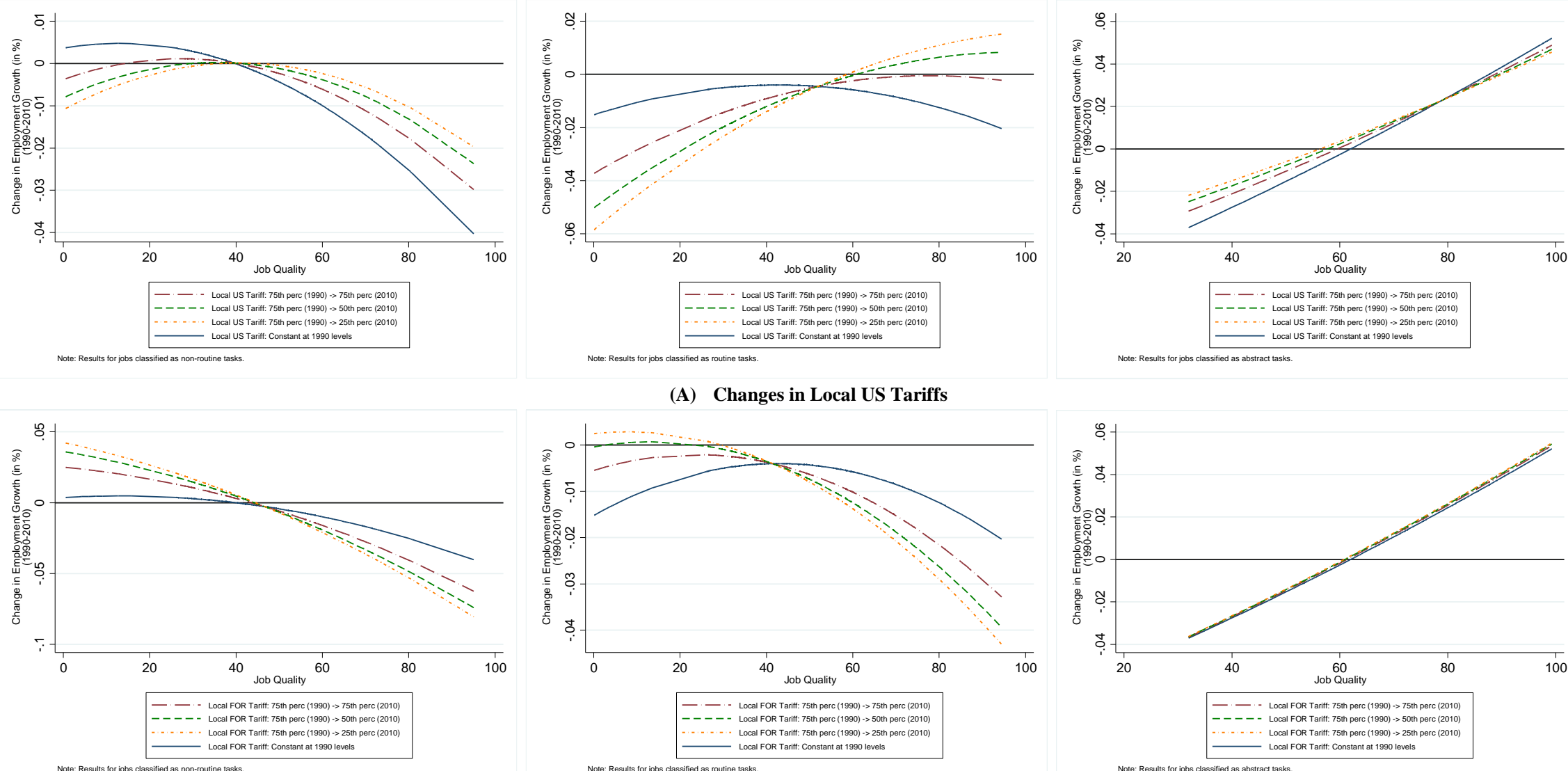

(A) Changes in Local US Tariffs
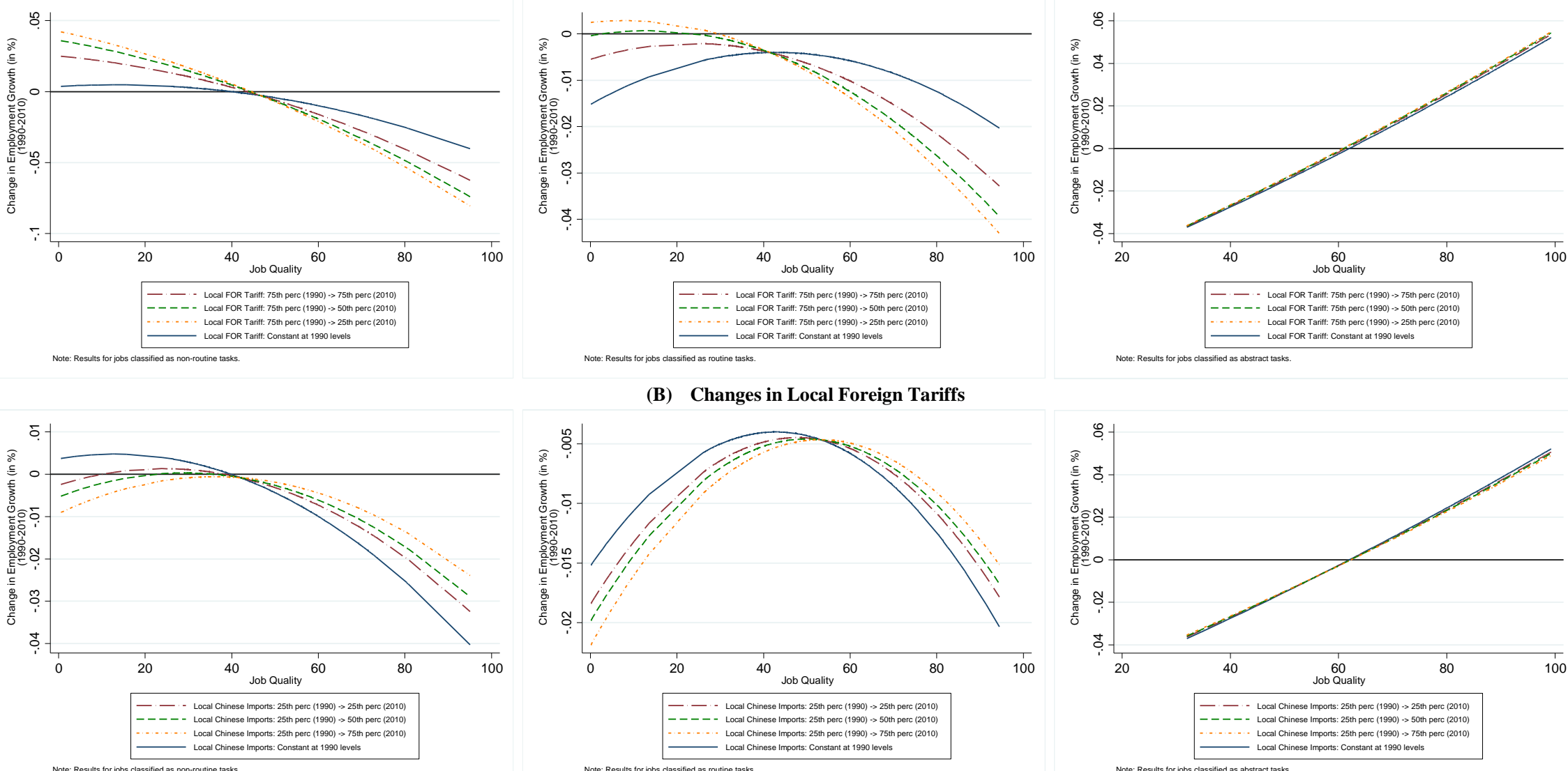

(B) Changes in Local Foreign Tariffs
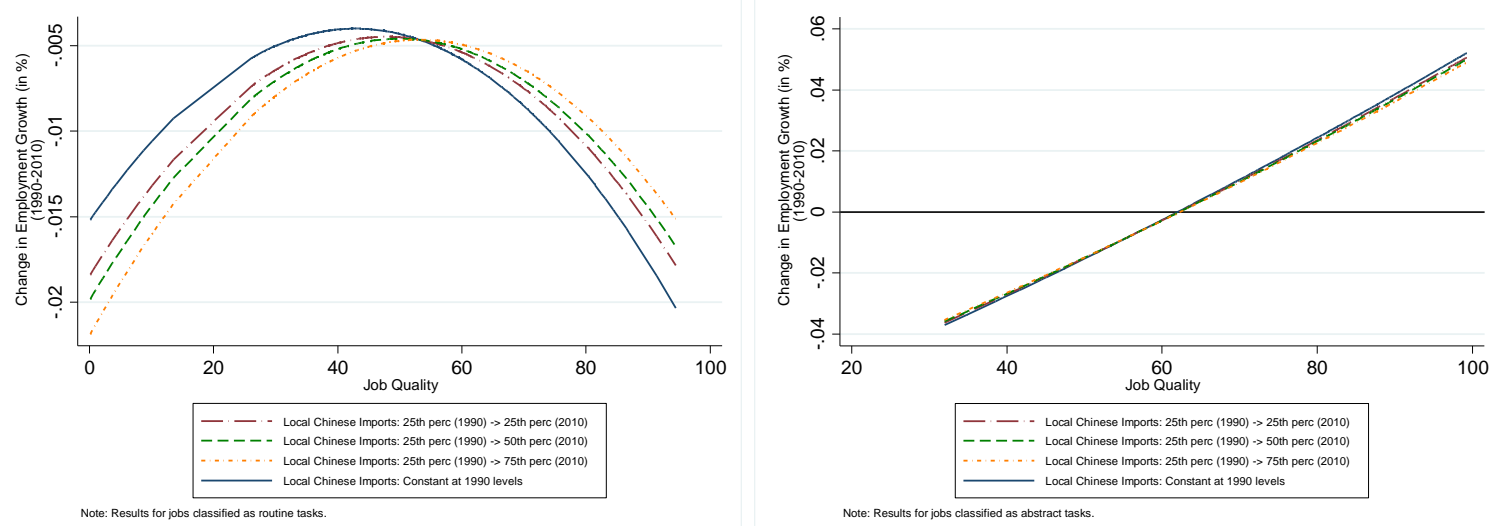

(C) Changes in Local Chinese Import Penetration

Figure 5. Impacts of Local Trade Variables on Changes in Local Employment Shares, 1990-2010: Heterogeneous Effects by Occupation Type.

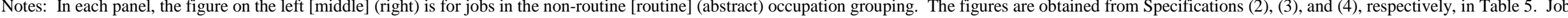
quality is measured as the NPB index (multiplied by 100). 


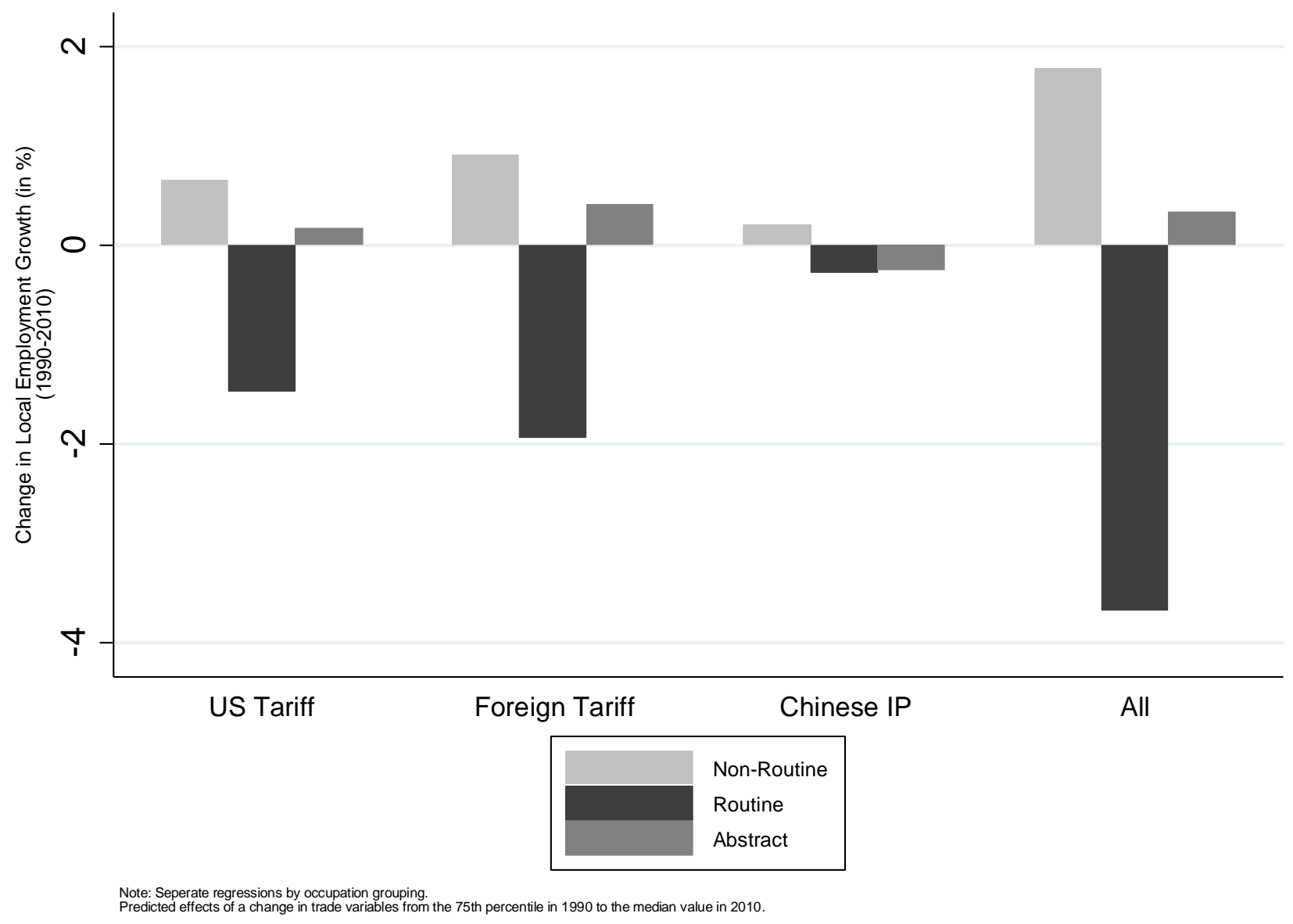

Figure 6. Cumulative Impacts of Local Trade Exposure Variables on Changes in Local Employment Shares of Occupations, 1990-2010.

Notes: The figures are obtained using the results in Specifications (2), (3), and (4) in Table 5 and aggregating over jobs within each occupational grouping. 


\title{
Supplemental Appendix
}

Good Jobs, Bad Jobs:

\section{What's Trade Got To Do With It?}

\author{
Jame Lake
}

Southern Methodist University

Daniel L. Millimet

Southern Methodist University \& IZA 


\section{Data}

Job types $(j)$ The six occupation groups defined by Autor and Dorn (2013) collapse their self-compiled occupation variable occ1990dd. However, we use the IPUMS Census variable occ1990. Thus, we concord the occupation groups based on occ1990dd to occupation groups based on occ1990. A further complication is that occ1990dd is based on the Census occupation variable occ1990 which differs from the IPUMS Census variable occ1990. Nevertheless, we carry out the concordance using David Dorn's concordance between the Census occ1990 variable and occ1990dd (http://www.ddorn.net/data.htm) and the IPUMS concordance between its own Census occ1990 variable and the Census occ1990 variable (https://usa.ipums.org/usa/ volii/occ_ind.shtml).

Constructing local measures of trade exposure $\left(\Delta T_{c}\right)$ Here we detail the construction of our measures of local trade exposure and discuss the industries and locations hardest hit by rising local trade exposure.

As discussed in the main text, we compute the change in trade exposure faced by location $c$ between 1990 and 2010 as

$$
\Delta v_{c} \equiv \sum_{i} \omega_{i c} \Delta v_{i}
$$

where $\Delta v_{i}$ is the change in trade exposure faced by industry $i$ (i.e., $v_{i}$ represents either US tariffs $\tau_{i}$, foreign tariffs $\tau_{i}^{*}$, or Chinese import penetration $\left.I P_{i}\right)$ and

$$
\omega_{i c} \equiv \frac{L_{i c, 1990}}{L_{c, 1990}}
$$

is the (time-invariant) employment share of industry $i$ in location $c$ in 1990 computed using the 1990 Census data described above.

To compute the change in local US tariffs, we need US tariffs by Census industry and year, $\tau_{i t}$. First, we use TRAINS to obtain the effectively applied tariff for each HS6 product $h$ that the US imposes on country $j$ in year $t$, denoted $\tau_{h j t}$. The effectively applied tariff is the minimum of the Most Favored Nation (MFN) tariff and any preferential tariff (e.g., due to PTAs or programs like the Generalized System of Preferences) levied by the US on country $j$. Second, we compute the average tariff imposed by the US on product $h$ in year $t$ as

$$
\tau_{h t}=\sum_{j} \alpha_{h j, 1990} \tau_{h j t}
$$

where $\alpha_{h j, 1990}$ is the (time invariant) share of 1990 US imports of product $h$ sourced from country $j$. Import shares are computed using the import data accompanying the TRAINS tariff data. Third, we compute the average tariff imposed by the US on products in Census industry $i$ and year $t$ as 


$$
\tau_{i t}=\sum_{h} \phi_{h(i), 1990} \tau_{h t}
$$

where $\phi_{h(i), 1990}$ is the (time invariant) share of 1990 US imports in Census industry $i$ attributable to HS6 product $h .{ }^{1}$ Finally, we compute $\Delta \tau_{i} \equiv \tau_{i, 2010}-\tau_{i, 1990}$ and obtain $\Delta \tau_{c}$ using (1) and (2).

To compute the change in local foreign tariffs applied to US exports, we follow a similar strategy. First, we compute the average foreign tariff faced by US exports of HS6 product $h$ as

$$
\tau_{h t}^{*}=\sum_{j} \alpha_{h j, 1990}^{*} \tau_{h j t}^{*}
$$

where $\tau_{h j t}^{*}$ is the effectively applied tariff for each HS6 product $h$ that country $j$ imposes on the US in year $t$ and $\alpha_{h j, 1990}^{*}$ is the (time invariant) share of 1990 US exports of product $h$ sent to partner country $j$. Second, we aggregate average product-level tariffs $\tau_{h t}^{*}$ to Census industry $i$ by

$$
\tau_{i t}^{*}=\sum_{h} \phi_{h(i), 1990}^{*} \tau_{h t}^{*}
$$

where $\phi_{h(i), 1990}^{*}$ is the (time invariant) share of 1990 US exports in Census industry $i$ attributable to HS6 product $h$. Finally, we compute $\Delta \tau_{i}^{*} \equiv \tau_{i, 2010}^{*}-\tau_{i, 1990}^{*}$ and, obtain $\Delta \tau_{c}^{*}$ using (1) and (2). The only substantive difference in the computation of $\Delta \tau_{c}$ and $\Delta \tau_{c}^{*}$ is that many countries did not report HS tariffs until 1991, whereas the US reports HS tariffs for 1990. Thus, when a country's 1990 tariff is missing in TRAINS, we replace it with the average of, where available, its 1989 and 1991 tariffs. $^{2}$

To compute the change in local Chinese IP, we follow the approach in Acemoglu et al. (2015). First, we define the change in Chinese IP in a 4-digit SIC industry $s$ as

$$
\Delta I P_{s} \equiv \frac{\Delta M_{s}}{Y_{s, 1991}+M_{s, 1991}-X_{s, 1991}}
$$

where the change in Chinese imports, $\Delta M_{s} \equiv M_{s, 2010}-M_{s, 1991}$, is normalized by domestic absorption in 1991 as proxied by domestic shipments, $Y_{s, 1991}$, plus net imports, $M_{s, 1991}-X_{s, 1991 .}{ }^{3}$ We obtain the necessary trade data from COMTRADE and the domestic shipments data from the NBER-CES Manufacturing

\footnotetext{
${ }^{1}$ To go from HS6 products and Census industries, we first use WITS concordances to move between HS6 and SIC classifications (http://wits.worldbank.org/product_concordance.html) and then use the Census concordance (see the discussion of $\left.\Delta I P_{c}\right)$ to go between SIC and Census classifications. We also use WITS concordances to concord the HS2007 tariffs in 2010 or the HS1996 tariffs in 2000 back to the HS1988/92 tariff classification of 1990.

${ }^{2}$ Most often, a missing 1990 tariff implies a missing 1989 tariff. If the 1991 tariff is available in this case, we use the 1991 tariff only. However, on some occasions, the 1990 and 1991 tariffs are missing, but the 1989 tariff is available. In this case, we use the 1989 tariff. In any case, $\alpha_{h j}^{*}$ is based on the year associated with the tariff and, because of the timing issue, all exports are converted into real US $\$ . \phi_{h(i), 1990}^{*}$ is then computed using all data underlying the $\alpha_{h j}^{*}$ terms.

${ }^{3}$ Shipments data are only available for manufacturing industries and not all tradable industries. However, we do not set $\Delta I P_{s}=0$ for non-manufacturing tradable industries. For these industries, we set $\Delta I P_{s}$ equal to the average $\Delta I P_{s}$ across all manufacturing industries.
} 
Industry Database $($ Becker et al. $(2013)){ }^{4,5}$ We then aggregate the individual variables in $(7)$ to Census industries $i$ and aggregate $\Delta I P_{i}$ to $\Delta I P_{c}$ using (1) and (2). ${ }^{6}$

To be clear, we aggregate over all Census industries in (1) rather than merely aggregating over tradable industries. This is consistent with much of the literature (Topalova (2007); Topalova (2010); McLaren and Hakobyan (2016)). However, Hasan et al. (2007) advocate only aggregating over traded industries; the theoretical model in Kovak (2013) provides additional support. ${ }^{7}$ Thus, we revisit this in the sensitivity analysis.

Industries most affected by rising trade exposure Before describing the magnitude of changes in local trade exposure, Table A3 describes the magnitude of changes in trade exposure at the Census industry level. Panels A, B, and C list the industries that experienced the largest decline in US tariffs, decline in foreign tariffs, and increase in Chinese IP, respectively. A few patterns stand out. First, as one would expect, the magnitude of US tariffs declines are substantially smaller than the magnitude of foreign tariff declines. ${ }^{8}$ Nevertheless, 20 out of the 84 traded Census industries experienced US tariff declines of at least 2.74 percentage points. Second, as the literature has documented, the rise in Chinese IP has been substantial. Across all 84 traded Census industries, the mean is an eleven percentage point increase and twelve Census industries experienced at least a 25 percentage point increase. Third, perhaps surprisingly, the correlation across the different measures of changing trade exposure is rather weak. That is, US tariff reductions tend to be concentrated in different industries than the main industries experiencing declining foreign tariffs or rising Chinese IP. This indicates that there is sufficient variation in the data to empirically separate the effects of each trade exposure measure.

Locations most affected by rising trade exposure Figure 1 from the main text illustrates the dramatic changes in local trade exposure between 1990 and 2010. Panel A illustrates that the median PUMA in terms of local US tariff protection in 2010 receives less protection than the PUMA at the $25^{\text {th }}$ percentile of local US tariff protection in 1990. Relative to the dispersion in 1990 local US tariffs, Panel

\footnotetext{
${ }^{4}$ Ideally, we would use 1990 values of the various variables, rather than their 1991 values, since our initial period is 1990 . However, because of changes to the HS classification of trade data in the late 1980s, COMTRADE only has cross-country trade for many countries beginning in 1991. While one can obtain pre-1991 US trade data from the USITC, we also need data on Chinese trade with other high income countries to compute the instrument for $\Delta I P_{c}$ (discussed later).

${ }^{5}$ All variables are converted to real US $\$$ since the variables in $\Delta I P_{i}$ cover different years.

${ }^{6}$ We use a Census concordance available at http://www.cdc.gov/niosh/soic/pdfs/PT19Y99AppB.pdf

${ }^{7}$ The thoretical intuition for only aggregating over tradable industries in Kovak (2013) derives from the general equilibrium linkage between tradable and non-tradable goods prices. Nevertheless, the two approaches are identical (up to a positive factor of proportionality) when locations do not differ in the share of their workforce allocated to the traded sector (Kovak (2013. p.1964)).

${ }^{8}$ The extreme fall in foreign tariffs in the Beverage industry is driven by non-trivial bilateral trade flows and the following bilateral HS6 tariffs: (i) Australia's tariffs of $492 \%$ on product 220410 and $1629 \%$ on product 220890, (ii) Singapore's tariff of $122 \%$ on product 220410 , (iii) Malaysia's tariff of $121 \%$ on product 220410 and (iv) Japan's tariff of $71 \%$ on product 220710 . The extreme fall in foreign tariffs in the Tobacco industry is driven by non-trivial bilateral trade flows and the bilateral HS6 tariffs on product 240220 of $2322 \%$ by Australia and $170 \%$ by Singapore.
} 
A also illustrates the substantial variation across locations in the magnitude of the decline in local tariff protection. Similar insights emerge from Panel B with regards to local foreign tariffs and Panel C with regards to local Chinese IP. The substantial increase in local trade exposure between 1990 and 2010, along with the spatial variation in this increase, allows us to empirically identify the effects of local trade exposure.

Table A4 illustrates the PUMAs facing the largest changes in trade exposure. ${ }^{9}$ In terms of local tariffs, Panels A and B reveal the PUMAs facing the steepest declines in average tariffs are heavily concentrated in North and South Carolina. These locations witnessed reductions in local US tariff protection of 0.8-1.5 percentage points and local foreign tariffs of 2.1-3.7 percentage points. ${ }^{10}$ While several PUMAs in North Carolina are also among those facing the largest increase in local Chinese IP, Panel C indicates the PUMAs most affected are more geographically diverse than those that faced the largest tariff reductions. Rising local exposure to Chinese IP ranges from 5.1-14.8 percentage points for the top 20 locations.

Instruments The first instrument, hypothesized to be related to $\Delta I P_{i}$, follows Acemoglu et al. (2015). The instrument is constructed in three steps. First, we replace industry-level US imports in 4-digit SIC industry $s$ in the numerator of (7) with Chinese exports to a set of eight high income countries that does not include the US. ${ }^{11}$ Second, 4-digit SIC industry-level domestic absorption in the denominator of (7) is taken from 1989 rather than $1991 .{ }^{12}$ This produces

$$
\Delta I P_{s}^{H I} \equiv \frac{\Delta M_{s}^{H I}}{Y_{s, 1989}+M_{s, 1989}-X_{s, 1989}}
$$

where $\Delta M_{s}^{H I}$ is the change in Chinese exports to the set of eight high income countries between 1991 and 2010. Third, after aggregating the individual variables in (8) to the Census industry level we use 1980 local employment weights to aggregate these Census industry-level measures to local measures using (1)-(2).

The tariff related instruments are based on the share of a country's imports stemming from countries with whom the importer shares a PTA. The share of US HS6 imports, weighted using time invariant 1990 partner-specific imports, sourced from PTA partners in year $t$ is

$$
P T A_{h t}^{U S}=\sum_{j} \alpha_{h j, 1990} P_{j t}^{U S}
$$

\footnotetext{
${ }^{9}$ Note, the mean change in rising trade exposure across all 543 PUMAs in Table A4 is roughly 15-20\% of the mean change across all 84 traded Census industries in Table A2 because, per Table A1, the share of workers in tradable goods industries is roughly $15-20 \%$.

${ }^{10}$ While the correlation between $\Delta \tau_{c}$ and $\Delta \tau_{c}^{*}$ is very strong for the locations most heavily affected by changing tariff exposure, this correlation subsides very quickly. For the 50 locations hardest hit by falling $\tau_{c}$, the correlation between $\Delta \tau_{c}$ and $\Delta \tau_{c}^{*}$ is 0.89 . For each subsequent set of 100 locations, the correlation varies between 0.02 and 0.35 .

${ }^{11}$ These countries are Australia, Denmark, Finland, Germany, Japan, New Zealand, Spain, and Switzerland.

${ }^{12}$ We use USITC data for 1989 US imports and exports because these are unavailable in WITS.
} 
where $P_{j t}^{U S}$ is an indicator variable that equals 1 if the US has a PTA with country $j$ in year $t$. The average PTA import share in Census industry $i$ and year $t$ is

$$
P T A_{i t}^{U S}=\sum_{h} \phi_{h(i), 1990} P T A_{h t}^{U S}
$$

After aggregating $P T A_{i t}^{U S}$ to the local level using (1) and (2) with 1980 employment weights, the first tariff related instrument is $\triangle P T A_{c}^{U S} \equiv P T A_{c, 2010}^{U S}-P T A_{c, 1990}^{U S}$.

The second instrument follows similarly. The share of HS6 imports for a foreign country $j$, weighted using country $j$ 's time invariant 1990 partner-specific imports, sourced from PTA partners in year $t$ is

$$
P T A_{h t}^{j}=\sum_{k} \alpha_{h k, 1990}^{j} P_{k t}^{j}
$$

where $P_{k t}^{j}$ is an indicator variable that equals 1 if country $j$ has a PTA with country $k$ in year $t$ and $\alpha_{h k, 1990}^{j}$ is the share of country $j$ 's 1990 HS6 imports for product $h$ sourced from country $k .{ }^{13}$ For HS6 product $h$ and year $t$, the average PTA import share of foreign countries is

$$
P T A_{h t}^{*}=\sum_{j} \alpha_{h j, 1990}^{*} P T A_{h t}^{j}
$$

For Census industry $i$ and year $t$, the average PTA import share of foreign countries is

$$
P T A_{i t}^{*}=\sum_{h} \phi_{h(i), 1990}^{*} P T A_{h t}^{*}
$$

After aggregating $P T A_{i t}^{*}$ to the local level using (1) and (2) with 1980 employment weights, the second tariff related instrument is $\triangle P T A_{c}^{*} \equiv P T A_{c, 2010}^{*}-P T A_{c, 1990}^{*}$.

\section{Additional sensitivity analyses}

Alternative variable measures Here, we explore the robustness of our results to alternative measures of job quality and local trade exposure.

In terms of job quality, we explore five alternative measures. First, rather than measuring job quality, $q_{j}$, at the national level, we allow for spatial variation in the quality of a job across regions. Specifically, we now compute job quality, denoted by $q_{j, r}$, separately for each of the nine US Census regions, indexed by $r .{ }^{14}$

\footnotetext{
${ }^{13}$ The same coverage caveat applies here as for foreign tariff coverage (see the discussion surrounding the construction of $\Delta \tau_{c}^{*}$ and footnote 2 ).

${ }^{14}$ We do not attempt to measure job quality at a more disaggregate level than Census regions since many jobs are not observed. For example, on average, each PUMA contains roughly 650 of the 1444 jobs. Even when computing regional measures of job quality, often a region does not contain a particular job. In these cases, we use the national measure of its quality for the region.
} 
This addresses concerns that a national measure of job quality may miss important regional variation in real wages due to price differences or important regional variation in educational attainment and nominal wages. Second, we revert back to a national measure of job quality, but instead use a time invariant measure based on the 2010 median wages and education levels observed in each job. This addresses the potential concern that the quality ranking of jobs may substantially change over our 20 year sample period and render our 1990 time-invariant notion of job quality misleading. Note, when doing so, our sample size shrinks as we only observe 1300 jobs in 2010. Third, we drop the education component of the NPB index and construct measures of job quality based solely on median wages. Here, we construct three such measures based on national median wages in 1990, national median wages in 2010, and regional median wages in 1990.

Table A5 presents the results. Column (1) of Table A5 presents the baseline results from column (4) of Table 1. The estimation results utilizing the alternative measures of job quality are shown in columns (2)-(6). Our qualitative results are invariant across these measures of job quality. However, we do find some attenuation of the effects of local US tariffs when using job quality measures based solely on median wages. The estimates are more precise in these specifications as well. In particular, the coefficients on the local Chinese IP variables are individually statistically significant in columns (4) and (6) at least at the $10 \%$ level (but, they remain jointly insignificant).

In terms of local trade exposure, we now revisit our construction of the local trade variables. As described previously, the literature has followed two approaches when aggregating industry-level trade exposure measures to location-specific measures of trade exposure: (i) aggregate over all industries using location-industry employment shares (e.g., Topalova (2007); Topalova (2010); McLaren and Hakobyan (2016)) or (ii) only aggregate over tradable sector industries using location-tradable industry employment shares (e.g., Hasan et al. (2007); Kovak (2013)). ${ }^{15}$ The analysis to this point follows the former approach. Column (7) in Table A5 follows the latter approach. While the qualitative results and the statistical significance remains mostly unchanged relative to the baseline results in column (1), the point estimates are substantially smaller. However, this is largely due to the different scale associated with the new local trade exposure variables. Indeed, the standard deviation of the modified versions of $\Delta \tau_{c}, \Delta \tau_{c}^{*}$ and $\Delta I P_{c}$ have increased about threefold. After scaling up the point estimates in column (7) by this factor, the economic magnitude of the estimated coefficients associated with $\Delta \tau_{c}, \Delta \tau_{c}^{*}$, and $\Delta I P_{c}$ are about $27 \%$, $22 \%$, and $48 \%$ smaller, respectively, relative to the baseline results in column (1).

Ultimately, our baseline results in the main text are robust to various measures of job quality and the method used when aggregating industry-level trade exposure to the local level.

\footnotetext{
${ }^{15}$ To be clear, the latter employment shares are normalized versions of the former where the normalization ensures the latter shares sum to unity.
} 
Heterogeneity by tariff type The main text described our motivation for (i) decomposing falling US tariffs into a component related to intermediate goods and a component related to non-intermediate goods and (ii) decomposing falling foreign tariffs into a component related to high skill industries and a component related to low skill industries. The new US tariff variables are constructed by defining $\phi_{h(i)}^{I n t}$ $\left(\phi_{h(i)}^{\text {NonInt }}\right)$ as the time invariant share of US intermediate (non-intermediate) imports in Census industry $i$ attributable to HS6 product $h$ and then applying (1)-(4) to compute $\Delta \tau_{c}^{I n t}$ and $\Delta \tau_{c}^{\text {NonInt }}$. The new foreign tariff variables are constructed in two steps. First, we compute the share of US workers with a Bachelor's degree or above in each Census industry and define high skill (low skill) industries as those whose share is above (below) the median. Second, we compute $\Delta \tau_{c}^{*, H S}\left(\Delta \tau_{c}^{*, L S}\right)$ using (1), but only aggregating over high skill (low skill) industries and using normalized location-industry employment shares that sum to unity.

Table A6 presents the results. Again, column (1) presents the baseline results from column (4) of Table 1. In column (2) the model now includes separate variables for local US intermediate tariffs and local US non-intermediate tariffs (along with their interactions with job quality). Interestingly, the effects of local US tariffs on intermediate goods are economically and statistically insignificant. That is, our baseline result that a decline in local US tariffs reduces (increases) employment growth of bad (good) jobs is completely driven by falling tariffs on HS6 non-intermediate goods. ${ }^{16}$ Moreover, to the extent that falling intermediate tariffs may proxy for rising offshorability, our results do not suggest that some locations are more vulnerable to offshoring due to cross-industry differences in the degree of rising offshorability. However, despite the differences in the point estimates, we are unable to reject equality of the effects of $\Delta \tau_{c}^{I n t}$ and $\Delta \tau_{c}^{\text {NonInt }}$ $(p=0.35)$.

In column (3), we now include separate variables for local foreign high skill tariffs and local foreign low skill tariffs (along with their interactions with job quality). Interestingly, while foreign high skill and low skill tariffs have similar qualitative effects, and we reject equality only at the $10 \%$ level $(p=0.10)$, the coefficient estimates on the foreign high skill tariffs variables are about three to four times larger.

Ultimately, while there is some evidence of a differential impact between different types of US tariffs (intermediate versus non-intermediate goods) and different types of foreign tariffs (skilled intensive versus unskilled intensive industries), it is empirically difficult to separate the differential impacts with much statistical certainty.

Heterogeneity by age and cohort Here, we explore whether the effects of local trade exposure differentially affect employment growth across different cohorts of workers. To do so, we define three alternative dependent variables: (i) employment growth for "young" individuals aged 25-44: $\Delta n_{j c}^{y g}=n_{j c, 2010}^{25-44}-n_{j c, 1990}^{25-44}$,

\footnotetext{
${ }^{16}$ This complements the results in Shen and Silva 2014 who find negative employment effects of rising local exposure to Chinese IP only when value added imports are measured as value added non-intermediate imports.
} 
(ii) employment growth for "old" individuals aged 45-64: $\Delta n_{j c}^{o l d}=n_{j c, 2010}^{45-64}-n_{j c, 1990}^{45-64}$ and (iii) "cohort" employment growth: $\Delta n_{j c}^{c o h}=n_{j c, 2010}^{45-64}-n_{j c, 1990}^{25-44}$. The young and old definitions allow us to explore the effects of local trade exposure on relatively new (potential) labor market participants versus experienced (potential) participants. ${ }^{17}$ The cohort definition allows us to effectively examine the effects of local trade exposure on the reallocation of a cohort using a pseudo-panel.

Table A7 presents the results where, again, column (1) presents the baseline results from column (4) in Table 5. Overall, our baseline results are quite robust across the three sub-samples. However, the effects of local trade exposure are generally statistically insignificant at conventional levels in the young sample. Nonetheless, the point estimates are qualitatively similar across the different specifications (see Figure A3). Thus, our results do not appear driven by particular age groups or cohorts.

\section{References}

Acemoglu, D., Autor, D., Dorn, D., Hanson, G. H., Price, B., 2015. Import competition and the great US employment sag of the 2000s. Journal of Labor Economics (forthcoming).

Autor, D. H., Dorn, D., 2013. The growth of low-skill service jobs and the polarization of the US labor market. The American Economic Review 103 (5), 1553-1597.

Becker, R. A., Gray, W. B., Marvakov, J., 2013. NBER-CES manufacturing industry database: June 2013 revision. National Bureau of Economic Research.

Hasan, R., Mitra, D., Ural, B. P., 2007. Trade liberalization, labor-market institutions and poverty reduction: Evidence from Indian states. In: India Policy Forum. Vol. 3. pp. 71-122.

Kovak, B. K., 2013. Regional effects of trade reform: What is the correct measure of liberalization? The American Economic Review 103 (5), 1960-1976.

McLaren, J., Hakobyan, S., 2016. Looking for local labor market effects of NAFTA. Review of Economics and Statistics (forthcoming).

Shen, L., Silva, P., 2014. Value added exports and US local labor markets: Does China really matter? Mimeo.

Topalova, P., 2007. Trade liberalization, poverty and inequality: Evidence from Indian districts. In: Globalization and Poverty. University of Chicago Press, pp. 291-336.

Topalova, P., 2010. Factor immobility and regional impacts of trade liberalization: Evidence on poverty from India. American Economic Journal: Applied Economics 2 (4), 1-41.

\footnotetext{
${ }^{17}$ We say "potential" participants since $n_{j c}$ is an empoyment to population ratio and thus include the nonemployed. See Section 2.2 of the main text.
} 
Table A1. Summary Statistics

\begin{tabular}{|c|c|c|c|c|}
\hline Variable & Mean & SD & Min & Max \\
\hline \multicolumn{5}{|l|}{ Job Variables } \\
\hline$\Delta$ Local Job Shares $(\mathrm{x} 100)$ & -0.001 & 0.143 & -9.372 & 5.650 \\
\hline Nam-Powers-Boyd Measure of Job Quality & 0.518 & 0.183 & 0.001 & 0.992 \\
\hline \multicolumn{5}{|l|}{ Trade Variables } \\
\hline$\Delta$ Local US Tariff $(x 100)$ & -0.305 & 0.204 & -1.482 & 0.136 \\
\hline$\Delta$ Local Foreign Tariff (x100) & -0.812 & 0.729 & -3.711 & 2.157 \\
\hline$\Delta$ Local Chinese Import Penetration (x100) & 0.023 & 0.014 & 0.003 & 0.147 \\
\hline \multicolumn{5}{|l|}{ Industry Controls } \\
\hline Real Price of Investment Goods & 1.094 & 0.014 & 1.002 & 1.124 \\
\hline Total Factor Productivity & 0.996 & 0.029 & 0.859 & 1.176 \\
\hline Capital-Labor Ratio & 0.086 & 0.053 & 0.010 & 0.734 \\
\hline Tradable Goods Sector & 0.349 & 0.477 & 0.000 & 1.000 \\
\hline Tradable Services Sector & 0.125 & 0.330 & 0.000 & 1.000 \\
\hline \multicolumn{5}{|l|}{ Local Controls } \\
\hline Age (mean) & 41.694 & 0.943 & 38.659 & 44.733 \\
\hline Born in US (\%) & 0.956 & 0.056 & 0.605 & 0.998 \\
\hline Homeownership (\%) & 0.737 & 0.094 & 0.218 & 0.936 \\
\hline \multicolumn{5}{|l|}{ Education } \\
\hline High School or Equivalent (\%) & 0.335 & 0.075 & 0.073 & 0.555 \\
\hline Some College, No Degree (\%) & 0.201 & 0.046 & 0.091 & 0.326 \\
\hline Associate's Degree (\%) & 0.071 & 0.020 & 0.022 & 0.134 \\
\hline Bachelor's Degree (\%) & 0.138 & 0.056 & 0.035 & 0.346 \\
\hline Master's Degree (\%) & 0.049 & 0.025 & 0.014 & 0.219 \\
\hline Professional Degree (\%) & 0.016 & 0.010 & 0.003 & 0.102 \\
\hline Doctoral Degree (\%) & 0.008 & 0.007 & 0.000 & 0.075 \\
\hline \multicolumn{5}{|l|}{ Marital Status } \\
\hline Separated/Divorced (\%) & 0.137 & 0.029 & 0.069 & 0.249 \\
\hline Widowed (\%) & 0.027 & 0.007 & 0.010 & 0.056 \\
\hline Never Married (\%) & 0.134 & 0.062 & 0.052 & 0.422 \\
\hline \multicolumn{5}{|l|}{ Race } \\
\hline Black, Non-Hispanic (\%) & 0.091 & 0.120 & 0.000 & 0.795 \\
\hline Hispanic (\%) & 0.042 & 0.087 & 0.000 & 0.805 \\
\hline American Indian, Alaskan (\%) & 0.008 & 0.029 & 0.000 & 0.584 \\
\hline Asian, Pacific Islander (\%) & 0.011 & 0.030 & 0.000 & 0.592 \\
\hline Other, Non-Hispanic (\%) & 0.000 & 0.001 & 0.000 & 0.011 \\
\hline \multicolumn{5}{|l|}{ English } \\
\hline Speaks English Well (\%) & 0.017 & 0.025 & 0.001 & 0.214 \\
\hline Speaks English Not Well or Not at All (\%) & 0.009 & 0.017 & 0.000 & 0.152 \\
\hline Speak Another Language and English (\%) & 0.076 & 0.092 & 0.009 & 0.745 \\
\hline \multicolumn{5}{|l|}{ Household Size } \\
\hline $2(\%)$ & 0.272 & 0.031 & 0.162 & 0.386 \\
\hline $3(\%)$ & 0.214 & 0.023 & 0.123 & 0.282 \\
\hline $4(\%)$ & 0.210 & 0.026 & 0.084 & 0.276 \\
\hline $5(\%)$ & 0.097 & 0.017 & 0.030 & 0.178 \\
\hline $6(\%)$ & 0.034 & 0.013 & 0.010 & 0.115 \\
\hline 7 (\%) & 0.013 & 0.008 & 0.002 & 0.073 \\
\hline $8+(\%)$ & 0.007 & 0.008 & 0.000 & 0.073 \\
\hline \multicolumn{5}{|l|}{ Own Children } \\
\hline $1(\%)$ & 0.213 & 0.022 & 0.128 & 0.276 \\
\hline $2(\%)$ & 0.211 & 0.027 & 0.087 & 0.281 \\
\hline $3(\%)$ & 0.088 & 0.018 & 0.020 & 0.154 \\
\hline $4(\%)$ & 0.025 & 0.011 & 0.006 & 0.106 \\
\hline $5+(\%)$ & 0.010 & 0.010 & 0.000 & 0.127 \\
\hline \multicolumn{5}{|l|}{ Own Children Under Age 5} \\
\hline $1(\%)$ & 0.113 & 0.013 & 0.066 & 0.154 \\
\hline $2(\%)$ & 0.033 & 0.008 & 0.014 & 0.068 \\
\hline $3+(\%)$ & 0.037 & 0.021 & 0.008 & 0.239 \\
\hline
\end{tabular}

Notes: Unit of observation is a ConsPUMA-job cell. There are 543 ConsPUMAs and 1444 jobs; 784092 total observations. All variables are from 1990 unless denoting the change from 1990 to 2010. 1990 data are from the Census 5\% sample. 2010 data are from the $1 \%$ American Community Survey. 
Table A2. Job Quality by Industry and Occupation

\begin{tabular}{ccccccc}
\multicolumn{3}{c}{ Job Shares } & & \multicolumn{3}{c}{ Employment Shares } \\
\cline { 1 - 1 } \cline { 5 - 7 } Low & Middle & High & & Low & Middle & High \\
Quality & Quality & Quality & & Quality & Quality & Quality
\end{tabular}

\begin{tabular}{|c|c|c|c|c|c|c|}
\hline \multicolumn{7}{|l|}{ Occupation Group } \\
\hline Managers, Professional, Technology, Finance, Public Safety & $0.83 \%$ & $6.36 \%$ & $53.89 \%$ & $0.57 \%$ & $9.70 \%$ & $79.85 \%$ \\
\hline Clerical, Retail Sales & $16.34 \%$ & $18.95 \%$ & $13.06 \%$ & $29.76 \%$ & $36.73 \%$ & $9.37 \%$ \\
\hline Low Skill Services & $33.80 \%$ & $15.49 \%$ & $2.22 \%$ & $47.41 \%$ & $2.62 \%$ & $0.46 \%$ \\
\hline Production, Craft & $11.08 \%$ & $18.95 \%$ & $16.67 \%$ & $0.86 \%$ & $6.32 \%$ & $2.26 \%$ \\
\hline Machine Operators, Assemblers & $21.88 \%$ & $19.23 \%$ & $5.56 \%$ & $11.87 \%$ & $11.65 \%$ & $2.45 \%$ \\
\hline Transport, Construction, Mechanical, Mining, Farm & $16.07 \%$ & $21.02 \%$ & $8.61 \%$ & $9.53 \%$ & $32.97 \%$ & $5.61 \%$ \\
\hline \multicolumn{7}{|l|}{ 2-Digit NAICS Industry } \\
\hline Agriculture, Forestry, Fishing and Hunting & $4.16 \%$ & $2.21 \%$ & $1.39 \%$ & $4.38 \%$ & $0.55 \%$ & $0.28 \%$ \\
\hline Mining, Quarrying, and Oil and Gas Extraction & $0.00 \%$ & $1.38 \%$ & $3.89 \%$ & $0.00 \%$ & $0.72 \%$ & $1.30 \%$ \\
\hline Utilities & $0.00 \%$ & $1.24 \%$ & $5.83 \%$ & $0.00 \%$ & $0.57 \%$ & $2.79 \%$ \\
\hline Construction & $0.28 \%$ & $0.55 \%$ & $0.28 \%$ & $0.32 \%$ & $13.06 \%$ & $2.27 \%$ \\
\hline Manufacturing & $12.74 \%$ & $39.83 \%$ & $40.56 \%$ & $11.80 \%$ & $22.37 \%$ & $18.50 \%$ \\
\hline Wholesale Trade & $8.86 \%$ & $7.75 \%$ & $8.89 \%$ & $1.80 \%$ & $4.56 \%$ & $5.82 \%$ \\
\hline Retail Trade & $32.69 \%$ & $10.37 \%$ & $3.06 \%$ & $24.62 \%$ & $11.82 \%$ & $1.85 \%$ \\
\hline Transportation and Warehousing & $1.66 \%$ & $2.77 \%$ & $7.78 \%$ & $0.38 \%$ & $5.67 \%$ & $5.90 \%$ \\
\hline Information & $0.55 \%$ & $3.04 \%$ & $5.00 \%$ & $0.79 \%$ & $4.69 \%$ & $4.66 \%$ \\
\hline Finance and Insurance & $0.28 \%$ & $3.04 \%$ & $1.94 \%$ & $0.19 \%$ & $6.52 \%$ & $7.16 \%$ \\
\hline Real Estate and Rental and Leasing & $1.66 \%$ & $1.38 \%$ & $0.56 \%$ & $1.17 \%$ & $1.24 \%$ & $2.47 \%$ \\
\hline Professional, Scientific and Technical Services & $1.66 \%$ & $3.60 \%$ & $6.11 \%$ & $0.17 \%$ & $2.91 \%$ & $6.72 \%$ \\
\hline Administrative and Support and Waste Management & $3.05 \%$ & $3.18 \%$ & $2.22 \%$ & $5.27 \%$ & $3.74 \%$ & $1.75 \%$ \\
\hline Educational Services & $1.66 \%$ & $1.80 \%$ & $1.39 \%$ & $9.01 \%$ & $2.09 \%$ & $14.91 \%$ \\
\hline Health Care and Social Assistance & $9.97 \%$ & $3.73 \%$ & $2.78 \%$ & $14.14 \%$ & $6.16 \%$ & $13.00 \%$ \\
\hline Arts, Entertainment, and Recreation & $1.66 \%$ & $1.52 \%$ & $0.28 \%$ & $2.22 \%$ & $0.99 \%$ & $0.11 \%$ \\
\hline Accommodation and Food Services & $3.32 \%$ & $0.83 \%$ & $0.00 \%$ & $15.69 \%$ & $2.74 \%$ & $0.00 \%$ \\
\hline Other Services, except Public Administration & $11.91 \%$ & $4.84 \%$ & $3.06 \%$ & $7.90 \%$ & $3.57 \%$ & $1.91 \%$ \\
\hline Public Administration & $3.88 \%$ & $6.92 \%$ & $5.00 \%$ & $0.16 \%$ & $6.02 \%$ & $8.60 \%$ \\
\hline
\end{tabular}

Notes: Low quality, middle quality, and high quality jobs correspond to the bottom $25 \%$, the middle $50 \%$ and the top $25 \%$, respectively, of jobs according to the 1990 Nam-Powers-Boyd Index. See main text for further details. 
Table A3. Census Industries Facing Largest Changes in Trade Exposure

Panel A. US Tariffs

US Rank Census Industry

Change FOR Rank CHN Rank

\begin{tabular}{clccc}
\hline 1 & Structural clay products & -0.0890 & 43 & 35 \\
2 & Other rubber products, and plastics footwear and belting & -0.0640 & 14 & 8 \\
3 & Knitting mills & -0.0507 & 3 & 30 \\
4 & Miscellaneous textile mill products & -0.0501 & 11 & 36 \\
5 & Medical, dental, and optical instruments and supplies & -0.0480 & 55 & 31 \\
6 & Blast furnaces, steelworks, rolling and finishing mills & -0.0451 & 22 & 54 \\
7 & Yarn, thread, and fabric mills & -0.0445 & 6 & 40 \\
8 & Canned, frozen, and preserved fruits and vegetables & -0.0426 & 25 & 56 \\
9 & Toys, amusement, and sporting goods & -0.0416 & 37 & 1 \\
10 & Scientific and controlling instruments & -0.0390 & 49 & 49 \\
11 & Drugs & -0.0380 & 45 & 48 \\
12 & Radio, TV, and communication equipment & -0.0331 & 41 & 4 \\
13 & Furniture and fixtures & -0.0325 & 29 & 6 \\
14 & Soaps and cosmetics & -0.0320 & 18 & 61 \\
15 & Pottery and related products & -0.0307 & 34 & 9 \\
16 & Carpets and rugs & -0.0305 & 4 & 60 \\
17 & Apparel and accessories, except knit & -0.0305 & 44 & 11 \\
18 & Glass and glass products & -0.0299 & 42 & 20 \\
19 & Beverage industries & -0.0285 & 1 & 81 \\
20 & Fabricated structural metal products & -0.0274 & 30 & 53 \\
\hline & Mean across all 84 traded Census industries & -0.0158 & & 5 \\
& & & & 4 \\
\end{tabular}

Panel B. Foreign Tariffs Faced by US

FOR Rank Census Industry

\begin{tabular}{clccc}
\hline 1 & Beverage industries & Change & US Rank CHN Rank \\
2 & Tobacco manufactures & -0.4874 & 19 & 81 \\
3 & Knitting mills & -0.3085 & 82 & 80 \\
4 & Carpets and rugs & -0.1540 & 3 & 30 \\
5 & Agricultural chemicals & -0.1288 & 16 & 60 \\
6 & Yarn, thread, and fabric mills & -0.1174 & 70 & 55 \\
7 & Miscellaneous fabricated textile products & -0.1155 & 7 & 40 \\
8 & Tires and inner tubes & -0.1094 & 26 & 10 \\
9 & Wood buildings and mobile homes & -0.1004 & 48 & 16 \\
10 & Metal forgings and stampings & -0.0965 & 23 & 82 \\
11 & Miscellaneous textile mill products & -0.0938 & 54 & 46 \\
12 & Watches, clocks, and clockwork operated devices & -0.0935 & 4 & 36 \\
13 & Miscellaneous plastics products & -0.0880 & 81 & 34 \\
14 & Other rubber products, and plastics footwear and belting & -0.0879 & 56 & 45 \\
15 & Miscellaneous paper and pulp products & -0.0862 & 2 & 8 \\
16 & Guided missiles, space vehicles, and parts & -0.0854 & 36 & 44 \\
17 & Railroad locomotives and equipment & -0.0833 & 69 & 84 \\
18 & Soaps and cosmetics & -0.0800 & 47 & 66 \\
19 & Footwear, except rubber and plastic & -0.0798 & 14 & 61 \\
20 & Paperboard containers and boxes & -0.0788 & 21 & 5 \\
\hline
\end{tabular}


Table A3 (cont.). Census Industries Facing Largest Changes in Trade Exposure

\section{Panel C. Chinese Import Penetration}

CHN Rank Census Industry

\begin{tabular}{ccc} 
Change & US Rank & FOR Rank \\
\hline 0.7815 & 9 & 37 \\
0.7411 & 35 & 58 \\
0.7160 & 27 & 61 \\
0.6116 & 12 & 41 \\
0.5580 & 21 & 19 \\
0.5485 & 13 & 29 \\
0.3034 & 30 & 24 \\
0.2815 & 2 & 14 \\
0.2777 & 15 & 34 \\
0.2676 & 26 & 7 \\
0.2623 & 17 & 44 \\
0.2552 & 63 & 51 \\
0.1851 & 39 & 33 \\
0.1454 & 80 & 47 \\
0.1383 & 34 & 48 \\
0.1345 & 48 & 8 \\
0.1316 & 42 & 23 \\
0.1303 & 33 & 39 \\
0.1268 & 37 & 35 \\
0.1123 & 18 & 42 \\
\hline 0.1101 & &
\end{tabular}

0.1101

Notes: See main text for definitions of US tariffs, foreign tariffs faced by US and Chinese import penetration. Each panel gives the ranking not only for the trade exposure variable in the panel title, but also for the other two trade exposure variables. 
Table A4. PUMAs Facing Largest Changes in Local Trade Exposure

Panel A. Local US Tariffs

US rank PUMA

1
2
3
4
5
6
7
8
9
1
1
1
1
1
1
1
1
1
1

$1 \quad 354$

2355

$3 \quad 342$

$4 \quad 353$

$5 \quad 357$

$6 \quad 432$

$7 \quad 488$

$8 \quad 429$

9425

$10 \quad 359$

$11 \quad 430$

$12 \quad 124$

$13 \quad 350$

$14 \quad 87$

15

16

17

18

19

20

402

428

122

120

431

State

State

North Carolina

North Carolina

North Carolina

North Carolina

North Carolina

South Carolina

Virginia

South Carolina

South Carolina

North Carolina

South Carolina

Indiana

North Carolina

$87 \quad$ Georgia

125 Indiana

Pennsylvania
Change FOR rank CHN rank

$-0.0148 \quad 2$

$-0.0137 \quad 6$

$-0.0133 \quad 1$

$-0.0131 \quad 4$

$-0.0116$

$-0.0114$

$-0.0113$

$-0.0108$

$-0.0097$

$-0.0096$

$-0.0094$

$-0.0090$

$-0.0090$

$-0.0086$

$-0.0084$

$-0.0081$

$-0.0080$

$-0.0079$

$-0.0077$

South Carolina $\quad-0.0076 \quad 17$

1

3

15

5

32

$11 \quad 67$

$5 \quad 12$

$9 \quad 59$

14

69

98

123

479

11

148

436

25

83

420

30

172
Counties

Alexander, Caldwell, Burke

Catawba

Randolph, Alamance

incl. Polk, McDowell, Rutherford

Davdison

incl. McCormick, Saluda, Edgefield

Dansville, Pittsylvania

Anderson

Oconee, Pickens

Cabarrus, Rowan

incl. Spartanburg, Greer

Gary

incl. Alleghany, Mitchell, Avery

Dade, Catoosa, Walker

Whiting, East Chicago, Hammond

Schuylkill

incl. Lee, Clarendon, Marlboro

Porter

Elkhart

York

\section{Panel B. Local Foreign Tariffs Faced by US}

\begin{tabular}{cccccll} 
FOR rank & PUMA & State & Change & US rank & CHN rank & \multicolumn{1}{c}{ Counties } \\
\hline 1 & 342 & North Carolina & -0.0371 & 3 & 5 & Randolph, Alamance \\
2 & 354 & North Carolina & -0.0362 & 1 & 1 & Alexander, Caldwell, Burke \\
3 & 357 & North Carolina & -0.0360 & 5 & 2 & Davdison \\
4 & 353 & North Carolina & -0.0341 & 4 & 13 & incl. Polk, McDowell, Rutherford \\
5 & 488 & Virginia & -0.0341 & 7 & 12 & Dansville, Pittsylvania \\
6 & 355 & North Carolina & -0.0340 & 2 & 3 & Catawba \\
7 & 356 & North Carolina & -0.0332 & 255 & 144 & incl. King, Forsyth, High Point \\
8 & 350 & North Carolina & -0.0304 & 13 & 11 & incl. Alleghany, Mitchell, Avery \\
9 & 429 & South Carolina & -0.0303 & 8 & 59 & Anderson \\
10 & 359 & North Carolina & -0.0299 & 10 & 98 & Cabarrus, Rowan \\
11 & 432 & South Carolina & -0.0274 & 6 & 67 & incl. McCormick, Saluda, Edgefield \\
12 & 430 & South Carolina & -0.0273 & 11 & 123 & incl. Spartanburg, Greer \\
13 & 87 & Georgia & -0.0272 & 14 & 148 & Dade, Catoosa, Walker \\
14 & 425 & South Carolina & -0.0261 & 9 & 69 & Oconee, Pickens \\
15 & 116 & Indiana & -0.0249 & 54 & 19 & incl. Ohio, Switzerland, Ripley \\
16 & 402 & Pennsylvania & -0.0223 & 16 & 25 & Schuylkill \\
17 & 431 & South Carolina & -0.0222 & 20 & 172 & York \\
18 & 490 & Virginia & -0.0210 & 472 & 492 & Chesterfield \\
19 & 112 & Indiana & -0.0210 & 37 & 24 & incl. Steuben, Lagrange, De Kalb \\
20 & 120 & Indiana & -0.0209 & 19 & 30 & Elkhart \\
\hline
\end{tabular}


Table A4 (cont.). PUMAs Facing Largest Changes in Local Trade Exposure

Panel C. Local Chinese Import Penetration

CHN rank PUMA

State

Change US rank FOR rank

Counties

$\begin{array}{lclcccl}1 & 354 & \text { North Carolina } & 0.1475 & 1 & 2 & \text { Alexander, Caldwell, Burke } \\ 2 & 357 & \text { North Carolina } & 0.1173 & 5 & 3 & \text { Davdison } \\ 3 & 355 & \text { North Carolina } & 0.1132 & 2 & 6 & \text { Catawba } \\ 4 & 38 & \text { California } & 0.0854 & 65 & 78 & \text { incl. Santa Clara, San Jose } \\ 5 & 342 & \text { North Carolina } & 0.0784 & 3 & 1 & \text { Randolph, Alamance } \\ 6 & 264 & \text { Missouri } & 0.0673 & 74 & 185 & \text { incl. Shannon, Ozark, Oregon } \\ 7 & 444 & \text { Tennessee } & 0.0664 & 25 & 27 & \text { incl. Pickett, Van Buren } \\ 8 & 16 & \text { Arkansas } & 0.0640 & 68 & 425 & \text { incl. Lee, Randolph, Lawrence } \\ 9 & 132 & \text { Iowa } & 0.0597 & 79 & 282 & \text { Linn } \\ 10 & 155 & \text { Kentucky } & 0.0585 & 26 & 159 & \text { incl. Cumberland, Clinton, Green } \\ 11 & 350 & \text { North Carolina } & 0.0574 & 13 & 8 & \text { incl. Alleghany, Mitchell, Avery } \\ 12 & 488 & \text { Virginia } & 0.0574 & 7 & 5 & \text { Dansville, Pittsylvania } \\ 13 & 353 & \text { North Carolina } & 0.0556 & 4 & 4 & \text { incl. Polk, McDowell, Rutherford } \\ 14 & 482 & \text { Virginia } & 0.0550 & 38 & 94 & \text { incl. Norton, Bland, Galax } \\ 15 & 258 & \text { Mississippi } & 0.0544 & 49 & 211 & \text { incl. Issaquena, Sharkey, Benton } \\ 16 & 534 & \text { Wisconsin } & 0.0542 & 215 & 276 & \text { Chippewa, Eau Claire } \\ 17 & 238 & \text { Michigan } & 0.0533 & 76 & 67 & \text { Ottawa } \\ 18 & 445 & \text { Tennessee } & 0.0528 & 30 & 64 & \text { incl. Moore, Perry, Houston } \\ 19 & 116 & \text { Indiana } & 0.0523 & 54 & 15 & \text { incl. Ohio, Switzerland, Ripley } \\ 20 & 265 & \text { Missouri } & 0.0511 & 90 & 217 & \text { Newton, Jasper }\end{array}$

Notes: PUMA and PUMA code refers to the Census consistent PUMA classification. Each panel gives the PUMA ranking not only for the trade exposure variable in the panel title, but also for the other two trade exposure variables. See main text for definitions of local US tariffs, local foreign tariffs faced by the US, and local Chinese import penetration. 
Table A5. Determinants of Changes in Local Job Shares: Alternative Variable Measures.

\begin{tabular}{|c|c|c|c|c|c|c|c|}
\hline Variable & (1) & (2) & (3) & (4) & (5) & (6) & (7) \\
\hline Job Quality & $\begin{array}{l}-0.077 \# \\
(0.042)\end{array}$ & $\begin{array}{l}-0.065 \wedge \\
(0.032)\end{array}$ & $\begin{array}{l}-0.138 * \\
(0.042)\end{array}$ & $\begin{array}{r}0.018 \\
(0.029)\end{array}$ & $\begin{array}{r}0.008 \\
(0.022)\end{array}$ & $\begin{array}{l}-0.045 \# \\
(0.026)\end{array}$ & $\begin{array}{l}-0.075 \\
(0.050)\end{array}$ \\
\hline (Job Quality) ${ }^{2}$ & $\begin{array}{l}0.101 \wedge \\
(0.045)\end{array}$ & $\begin{array}{l}0.088 \wedge \\
(0.039)\end{array}$ & $\begin{array}{c}0.150 * \\
(0.044)\end{array}$ & $\begin{array}{r}0.003 \\
(0.028)\end{array}$ & $\begin{array}{r}0.006 \\
(0.022)\end{array}$ & $\begin{array}{l}0.063 \wedge \\
(0.028)\end{array}$ & $\begin{array}{c}0.101 \wedge \\
(0.045)\end{array}$ \\
\hline$\Delta$ Local US Tariff & $\begin{array}{l}3.793 \wedge \\
(1.734)\end{array}$ & $\begin{array}{l}3.806 * \\
(1.374)\end{array}$ & $\begin{array}{c}3.032 \# \\
(1.634)\end{array}$ & $\begin{array}{c}2.190 \wedge \\
(1.088)\end{array}$ & $\begin{array}{r}2.046 \wedge \\
(0.924)\end{array}$ & $\begin{array}{c}1.902 \# \\
(1.138)\end{array}$ & $\begin{array}{r}0.918 \\
(0.391)\end{array}$ \\
\hline $\begin{array}{c}\Delta \text { Local US Tariff } \\
\text { X Job Quality }\end{array}$ & $\begin{array}{l}-7.154 \wedge \\
(3.221)\end{array}$ & $\begin{array}{l}-7.568 * \\
(2.638)\end{array}$ & $\begin{array}{l}-6.455 \wedge \\
(3.131)\end{array}$ & $\begin{array}{l}-4.717 \wedge \\
(2.304)\end{array}$ & $\begin{array}{l}-4.647 \wedge \\
(1.997)\end{array}$ & $\begin{array}{l}-4.420 \# \\
(2.271)\end{array}$ & $\begin{array}{l}-1.725 \wedge \\
(0.723)\end{array}$ \\
\hline$\Delta$ Local Foreign Tariff & $\begin{array}{l}-0.962 * \\
(0.344)\end{array}$ & $\begin{array}{l}-0.873 * \\
(0.335)\end{array}$ & $\begin{array}{l}-0.565 \# \\
(0.326)\end{array}$ & $\begin{array}{l}-0.712 * \\
(0.228)\end{array}$ & $\begin{array}{l}-0.607 * \\
(0.200)\end{array}$ & $\begin{array}{l}-0.529 \wedge \\
(0.231)\end{array}$ & $\begin{array}{l}-0.248 * \\
(0.091)\end{array}$ \\
\hline $\begin{array}{l}\Delta \text { Local Foreign Tariff } \\
\text { X Job Quality }\end{array}$ & $\begin{array}{c}1.905 * \\
(0.632)\end{array}$ & $\begin{array}{c}1.791 * \\
(0.624)\end{array}$ & $\begin{array}{l}1.268 \wedge \\
(0.620)\end{array}$ & $\begin{array}{l}1.654 * \\
(0.477)\end{array}$ & $\begin{array}{c}1.465 * \\
(0.430)\end{array}$ & $\begin{array}{l}1.287 * \\
(0.452)\end{array}$ & $\begin{array}{l}0.489 * \\
(0.167)\end{array}$ \\
\hline $\begin{array}{l}\Delta \text { Local Chinese Import } \\
\text { Penetration }\end{array}$ & $\begin{array}{r}-0.197 \\
(0.144)\end{array}$ & $\begin{array}{l}-0.130 \\
(0.125)\end{array}$ & $\begin{array}{l}-0.176 \\
(0.120)\end{array}$ & $\begin{array}{l}-0.156 \# \\
(0.082)\end{array}$ & $\begin{array}{r}-0.114 \\
(0.071)\end{array}$ & $\begin{array}{l}-0.159 \wedge \\
(0.080)\end{array}$ & $\begin{array}{l}-0.034 \\
(0.046)\end{array}$ \\
\hline $\begin{array}{c}\Delta \text { Local Chinese Import } \\
\text { Pen. X Job Quality }\end{array}$ & $\begin{array}{r}0.361 \\
(0.283)\end{array}$ & $\begin{array}{r}0.228 \\
(0.249)\end{array}$ & $\begin{array}{r}0.345 \\
(0.256)\end{array}$ & $\begin{array}{c}0.328 \# \\
(0.186)\end{array}$ & $\begin{array}{r}0.227 \\
(0.160)\end{array}$ & $\begin{array}{c}0.334 \# \\
(0.184)\end{array}$ & $\begin{array}{r}0.060 \\
(0.096)\end{array}$ \\
\hline \multicolumn{8}{|l|}{ Measure of: } \\
\hline Job Quality & $\begin{array}{c}\text { NPB } \\
\text { (national, } \\
1990)\end{array}$ & $\begin{array}{c}\text { NPB } \\
\text { (regional, } \\
1990)\end{array}$ & $\begin{array}{c}\text { NPB } \\
\text { (national, } \\
\text { 2010) }\end{array}$ & $\begin{array}{c}\text { Median } \\
\text { Wage } \\
\text { (national, } \\
\text { 1990) }\end{array}$ & $\begin{array}{c}\text { Median } \\
\text { Wage } \\
\text { (regional, } \\
1990 \text { ) }\end{array}$ & $\begin{array}{l}\text { Median } \\
\text { Wage } \\
\text { (national, } \\
\text { 2010) }\end{array}$ & $\begin{array}{c}\text { NPB } \\
\text { (national, } \\
1990)\end{array}$ \\
\hline Trade Variables & With Zeros & With Zeros & With Zeros & With Zeros & With Zeros & With Zeros & No Zeros \\
\hline $\mathrm{N}$ & 784092 & 784092 & 705900 & 784092 & 784092 & 705900 & 784092 \\
\hline \multicolumn{8}{|l|}{ Joint Significance: } \\
\hline US Tariff Variables & $\mathrm{p}=0.08$ & $\mathrm{p}=0.02$ & $\mathrm{p}=0.05$ & $\mathrm{p}=0.12$ & $\mathrm{p}=0.07$ & $\mathrm{p}=0.07$ & $\mathrm{p}=0.06$ \\
\hline Foreign Tariff Variables & $\mathrm{p}=0.00$ & $\mathrm{p}=0.00$ & $\mathrm{p}=0.01$ & $\mathrm{p}=0.00$ & $p=0.00$ & $\mathrm{p}=0.00$ & $\mathrm{p}=0.01$ \\
\hline China Variables & $\mathrm{p}=0.33$ & $\mathrm{p}=0.47$ & $\mathrm{p}=0.31$ & $p=0.16$ & $\mathrm{p}=0.24$ & $\mathrm{p}=0.13$ & $p=0.51$ \\
\hline All Trade Variables & $p=0.02$ & $p=0.01$ & $p=0.01$ & $p=0.01$ & $p=0.01$ & $p=0.00$ & $p=0.02$ \\
\hline
\end{tabular}

Notes: Dependent variable is the change in population share in a particular job and ConsPUMA from 1990-2010, where the shares in 1990 and 2010 are based on non-institutionalized individuals aged 25-64, who are not self-employed, in school, or in the military. All specifications include baseline covariates, change in covariates, industry fixed effects, and state fixed effects. NPB = Nam-Powers-Boyd measure of job quality. Regional measures of job quality are based on the nine US Census regions. Local trade variables either treat tariffs and Chinese imports as zero for non-traded sectors prior to aggregation ("With Zeros") or only aggregate over traded sectors ("No Zeros"). For definitions of variables and list of other covariates not reported, see main text and Table A1 in the Supplemental Appendix. Regressions are weighted by ConsPUMA population in 1990. Two-way standard errors clustered by ConsPUMA and job in parentheses. $\# \mathrm{p}<0.10, \wedge \mathrm{p}<0.05$, and ${ }^{*} \mathrm{p}<0.01$. 
Table A6. Determinants of Changes in Local Job Shares: Heterogeneous Effects by Tariff Types.

\begin{tabular}{|c|c|c|c|}
\hline Variable & (1) & (2) & (3) \\
\hline Job Quality & $\begin{array}{l}-0.077 \# \\
(0.042)\end{array}$ & $\begin{array}{l}-0.079 \# \\
(0.042)\end{array}$ & $\begin{array}{r}-0.069 \\
(0.043)\end{array}$ \\
\hline (Job Quality) $^{2}$ & $\begin{array}{l}0.101 \wedge \\
(0.045)\end{array}$ & $\begin{array}{l}0.101 \wedge \\
(0.046)\end{array}$ & $\begin{array}{l}0.101 \wedge \\
(0.045)\end{array}$ \\
\hline$\Delta$ Local US Tariff & $\begin{array}{l}3.793 \wedge \\
(1.734)\end{array}$ & & $\begin{array}{l}3.360 \wedge \\
(1.673)\end{array}$ \\
\hline $\begin{array}{c}\Delta \text { Local US Tariff } \\
\text { X Job Quality }\end{array}$ & $\begin{array}{l}-7.154 \wedge \\
(3.221)\end{array}$ & & $\begin{array}{l}-6.341 \wedge \\
(3.100)\end{array}$ \\
\hline$\Delta$ Local US Int. Tariff & & $\begin{array}{r}-0.026 \\
(1.324)\end{array}$ & \\
\hline $\begin{array}{l}\Delta \text { Local US Int. Tariff } \\
\text { X Job Quality }\end{array}$ & & $\begin{array}{r}-0.122 \\
(2.534)\end{array}$ & \\
\hline$\Delta$ Local US Non-Int. Tariff & & $\begin{array}{l}3.094 \# \\
(1.604)\end{array}$ & \\
\hline $\begin{array}{l}\Delta \text { Local US Non-Int. Tariff } \\
\text { X Job Quality }\end{array}$ & & $\begin{array}{l}-5.487 \# \\
(2.903)\end{array}$ & \\
\hline$\Delta$ Local Foreign Tariff & $\begin{array}{l}-0.962 * \\
(0.344)\end{array}$ & $\begin{array}{l}-0.665 \# \\
(0.396)\end{array}$ & \\
\hline $\begin{array}{l}\Delta \text { Local Foreign Tariff } \\
\quad \text { X Job Quality }\end{array}$ & $\begin{array}{l}1.905 * \\
(0.632)\end{array}$ & $\begin{array}{c}1.334 \# \\
(0.731)\end{array}$ & \\
\hline$\Delta$ Local Foreign HS Tariff & & & $\begin{array}{l}-1.378 * \\
(0.474)\end{array}$ \\
\hline $\begin{array}{l}\Delta \text { Local Foreign HS Tariff } \\
\text { X Job Quality }\end{array}$ & & & $\begin{array}{l}2.613 * \\
(0.895)\end{array}$ \\
\hline$\Delta$ Local Foreign LS Tariff & & & $\begin{array}{l}-0.387 \wedge \\
(0.189)\end{array}$ \\
\hline $\begin{array}{l}\Delta \text { Local Foreign LS Tariff } \\
\text { X Job Quality }\end{array}$ & & & $\begin{array}{l}0.792 \wedge \\
(0.347)\end{array}$ \\
\hline $\begin{array}{l}\Delta \text { Local Chinese Import } \\
\text { Penetration }\end{array}$ & $\begin{array}{r}-0.197 \\
(0.144)\end{array}$ & $\begin{array}{r}-0.168 \\
(0.159)\end{array}$ & $\begin{array}{l}-0.270 \wedge \\
(0.136)\end{array}$ \\
\hline $\begin{array}{c}\Delta \text { Local Chinese Import } \\
\text { Pen. X Job Quality }\end{array}$ & $\begin{array}{r}0.361 \\
(0.283)\end{array}$ & $\begin{array}{r}0.317 \\
(0.312)\end{array}$ & $\begin{array}{c}0.495 \# \\
(0.269)\end{array}$ \\
\hline $\mathrm{N}$ & 784092 & 784092 & 784092 \\
\hline \multicolumn{4}{|l|}{ Test of Equality: } \\
\hline $\begin{array}{l}\text { US Int./Non-Int. Tariffs } \\
\text { Foreign HS/LS Tariffs }\end{array}$ & & $p=0.35$ & $\mathrm{p}=0.10$ \\
\hline \multicolumn{4}{|l|}{ Joint Significance: } \\
\hline US Tariff Variables & $p=0.08$ & $p=0.18$ & $p=0.12$ \\
\hline Foreign Tariff Variables & $\mathrm{p}=0.00$ & $\mathrm{p}=0.07$ & $\mathrm{p}=0.01$ \\
\hline China Variables & $\mathrm{p}=0.33$ & $\mathrm{p}=0.56$ & $\mathrm{p}=0.10$ \\
\hline All Trade Variables & $\mathrm{p}=0.02$ & $p=0.04$ & $p=0.02$ \\
\hline
\end{tabular}

Notes: Dependent variable is the change in population share in a particular job and ConsPUMA from 1990-2010, where the shares in 1990 and 2010 are based on non-institutionalized individuals aged 25-64, who are not self-employed, in school, or in the military. All specifications include baseline covariates, change in covariates, industry fixed effects, and state fixed effects. For US tariffs, "Int." ("Non-Int.") refers to tariffs on intermediate (final) goods. For foreign tariffs, "HS" ("LS") refers to tariffs in high-skilled (low-skilled) industries. For definitions of variables and list of other covariates not reported, see main text and Table A1 in the Supplemental Appendix. Regressions are weighted by ConsPUMA population in 1990. Two-way standard errors clustered by ConsPUMA and job in parentheses. $\# \mathrm{p}<0.10, \wedge \mathrm{p}<0.05$, and ${ }^{*} \mathrm{p}<0.01$. 
Table A7. Determinants of Changes in Local Job Shares: Heterogeneous Effects by Cohort.

\begin{tabular}{|c|c|c|c|c|}
\hline Variable & (1) & (2) & (3) & (4) \\
\hline \multirow[t]{2}{*}{ Job Quality } & $-0.077 \#$ & $-0.103 \wedge$ & -0.048 & -0.071 \\
\hline & $(0.042)$ & $(0.051)$ & $(0.040)$ & $(0.045)$ \\
\hline \multirow[t]{2}{*}{$(\text { Job Quality })^{2}$} & $0.101 \wedge$ & $0.121 \wedge$ & $0.081 \#$ & 0.077 \\
\hline & $(0.045)$ & $(0.054)$ & $(0.043)$ & $(0.049)$ \\
\hline \multirow[t]{2}{*}{$\Delta$ Local US Tariff } & $3.793 \wedge$ & 3.114 & $4.445 \wedge$ & $4.302 \wedge$ \\
\hline & $(1.734)$ & $(1.957)$ & $(1.927)$ & $(1.975)$ \\
\hline$\Delta$ Local US Tariff & $-7.154 \wedge$ & -5.737 & $-8.433 \wedge$ & $-8.373 \wedge$ \\
\hline X Job Quality & (3.221) & (3.641) & (3.698) & (3.648) \\
\hline \multirow[t]{2}{*}{$\Delta$ Local Foreign Tariff } & $-0.962 *$ & $-0.890 \wedge$ & $-1.005 \wedge$ & $-1.044 *$ \\
\hline & $(0.344)$ & $(0.432)$ & $(0.394)$ & $(0.349)$ \\
\hline$\Delta$ Local Foreign Tariff & $1.905 *$ & $1.735 \wedge$ & $2.022 *$ & $2.114 *$ \\
\hline X Job Quality & $(0.632)$ & $(0.825)$ & $(0.750)$ & $(0.634)$ \\
\hline$\Delta$ Local Chinese Import & -0.197 & -0.228 & -0.196 & -0.209 \\
\hline Penetration & $(0.144)$ & $(0.139)$ & $(0.165)$ & $(0.200)$ \\
\hline$\Delta$ Local Chinese Import & 0.361 & 0.425 & 0.345 & 0.401 \\
\hline Pen. X Job Quality & $(0.283)$ & $(0.270)$ & $(0.320)$ & $(0.395)$ \\
\hline \multicolumn{5}{|l|}{ Sample Selection: } \\
\hline Age Range, 1990 & $25-64$ & $25-44$ & $45-64$ & $25-44$ \\
\hline Age Range, 2010 & $25-64$ & $25-44$ & $45-64$ & $45-64$ \\
\hline $\mathrm{N}$ & 784092 & 784092 & 784092 & 784092 \\
\hline \multicolumn{5}{|l|}{ Joint Significance: } \\
\hline US Tariff Variables & $\mathrm{p}=0.08$ & $p=0.28$ & $\mathrm{p}=0.07$ & $\mathrm{p}=0.04$ \\
\hline Foreign Tariff Variables & $p=0.00$ & $p=0.11$ & $\mathrm{p}=0.02$ & $\mathrm{p}=0.00$ \\
\hline China Variables & $p=0.33$ & $\mathrm{p}=0.25$ & $\mathrm{p}=0.38$ & $\mathrm{p}=0.57$ \\
\hline All Trade Variables & $\mathrm{p}=0.02$ & $p=0.26$ & $\mathrm{p}=0.01$ & $\mathrm{p}=0.00$ \\
\hline
\end{tabular}

Notes: Dependent variable is the change in population share in a particular job and ConsPUMA from 1990-2010, where the shares in 1990 and 2010 are based on non-institutionalized individuals with ages given in the table who are not self-employed, in school, or in the military. All specifications include baseline covariates, change in covariates, industry fixed effects, and state fixed effects. For definitions of variables and list of other covariates not reported, see main text and Table A1 in the Supplemental Appendix. Regressions are weighted by ConsPUMA population in 1990. Two-way standard errors clustered by ConsPUMA and job in parentheses. $\# \mathrm{p}<0.10, \wedge \mathrm{p}<0.05$, and $* \mathrm{p}<0.01$. 


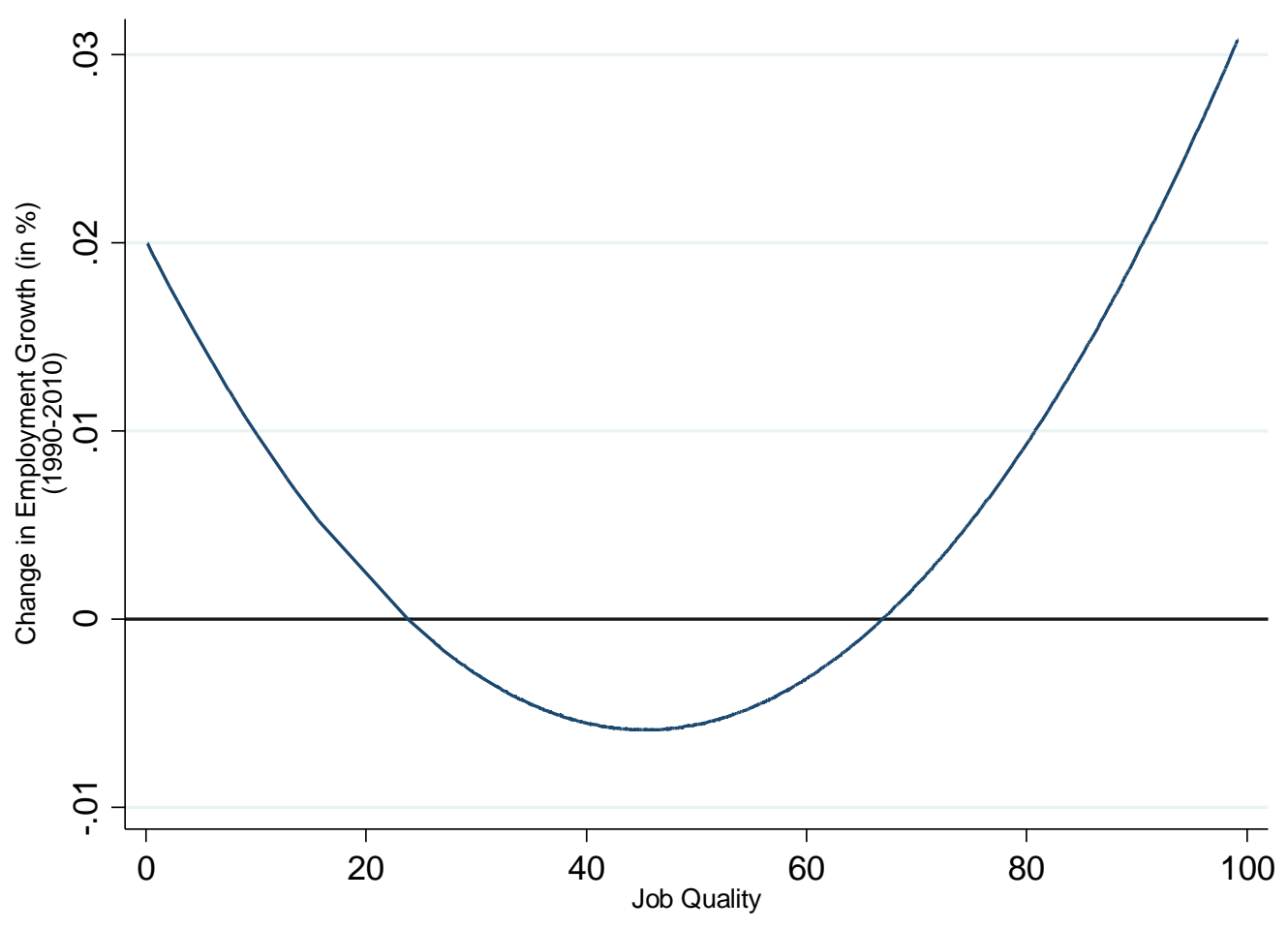

(A) Local Trade Measures Constant at 1990 Levels

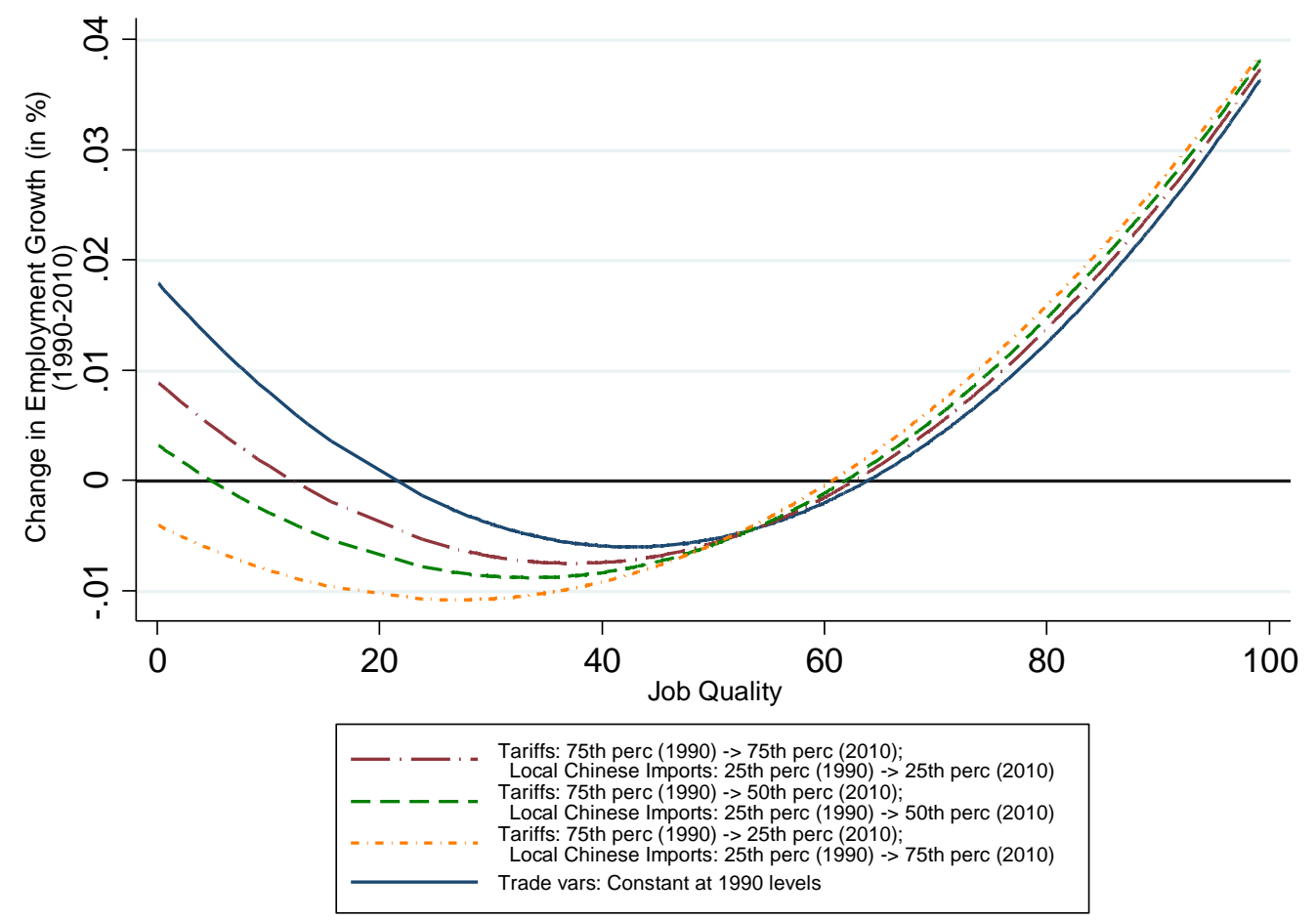

(B) Cumulative Effect of Changes in all Local Trade Measures

Figure A1. Job Polarization: 1990-2010.

Notes: Panel (A) is obtained using the results in Specification (1) in Table 1 setting all covariates other than job quality at their sample mean. Panel (B) is obtained using the results in Specification (2) in Table 3 setting all covariates other than job quality at their sample mean. Job quality is measured as the NPB index (multiplied by 100). 


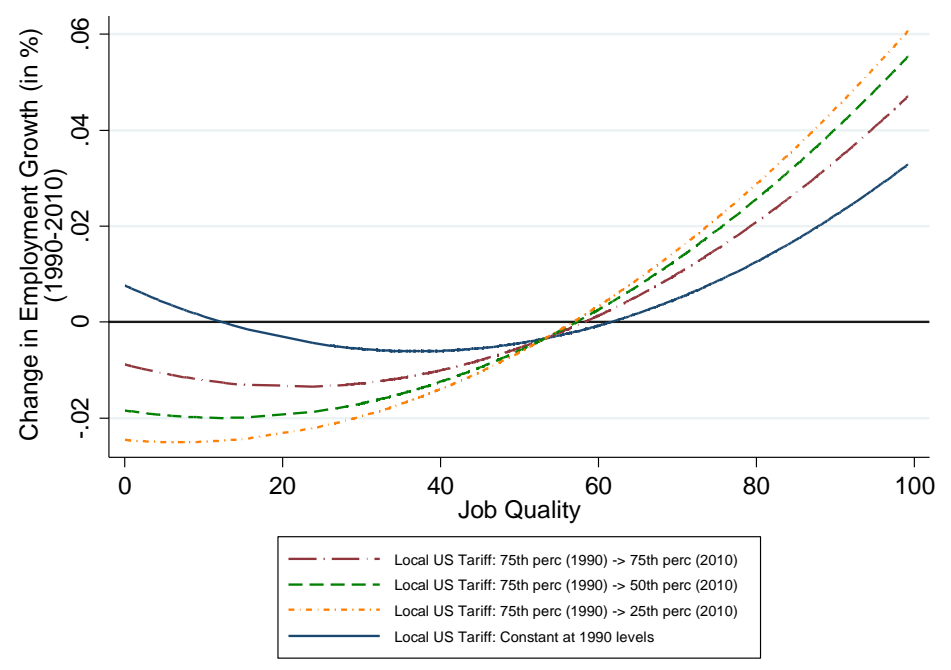

(A) Changes in Local US Tariffs

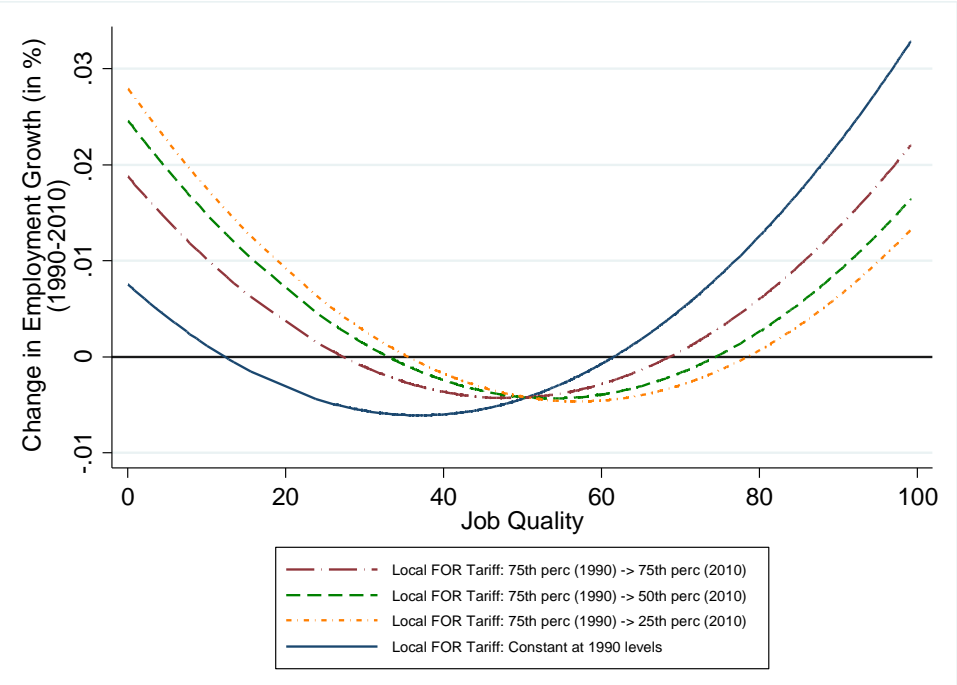

(B) Changes in Local Foreign Tariffs

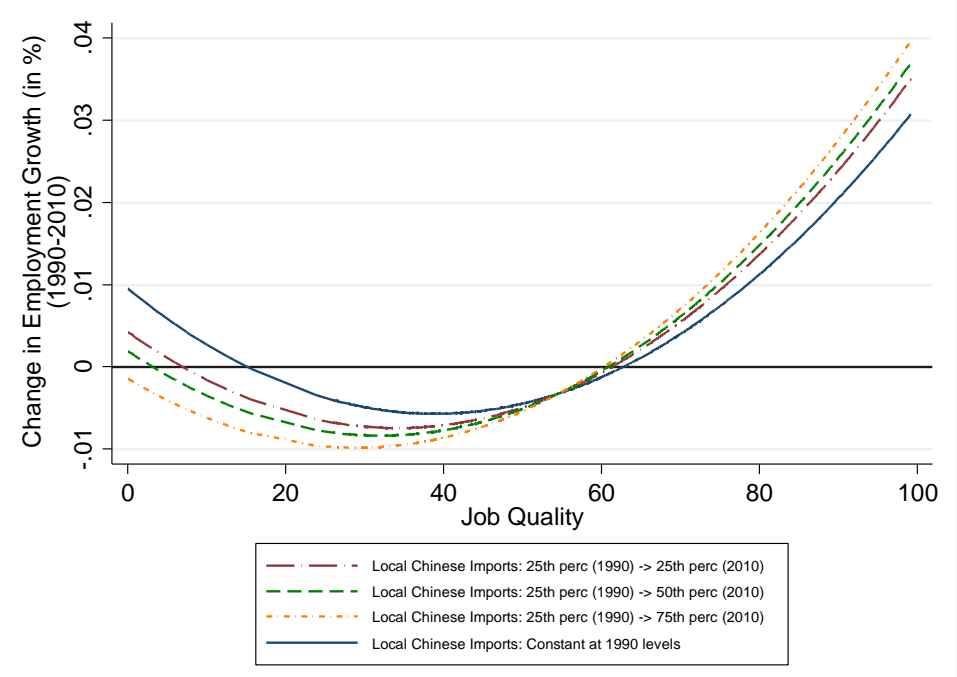

(C) Changes in Local Chinese Import Penetration

Figure A2. Impacts of Local Trade Variables on Changes in Local Employment Shares, 1990-2010.

Notes: The graphs in Panels A and B are obtained using the results from Specification (7) in Table 1. The graph in Panel C is obtained using the results from Specification (10) in Table 1. Job quality is measured as the NPB index (multiplied by 100). 

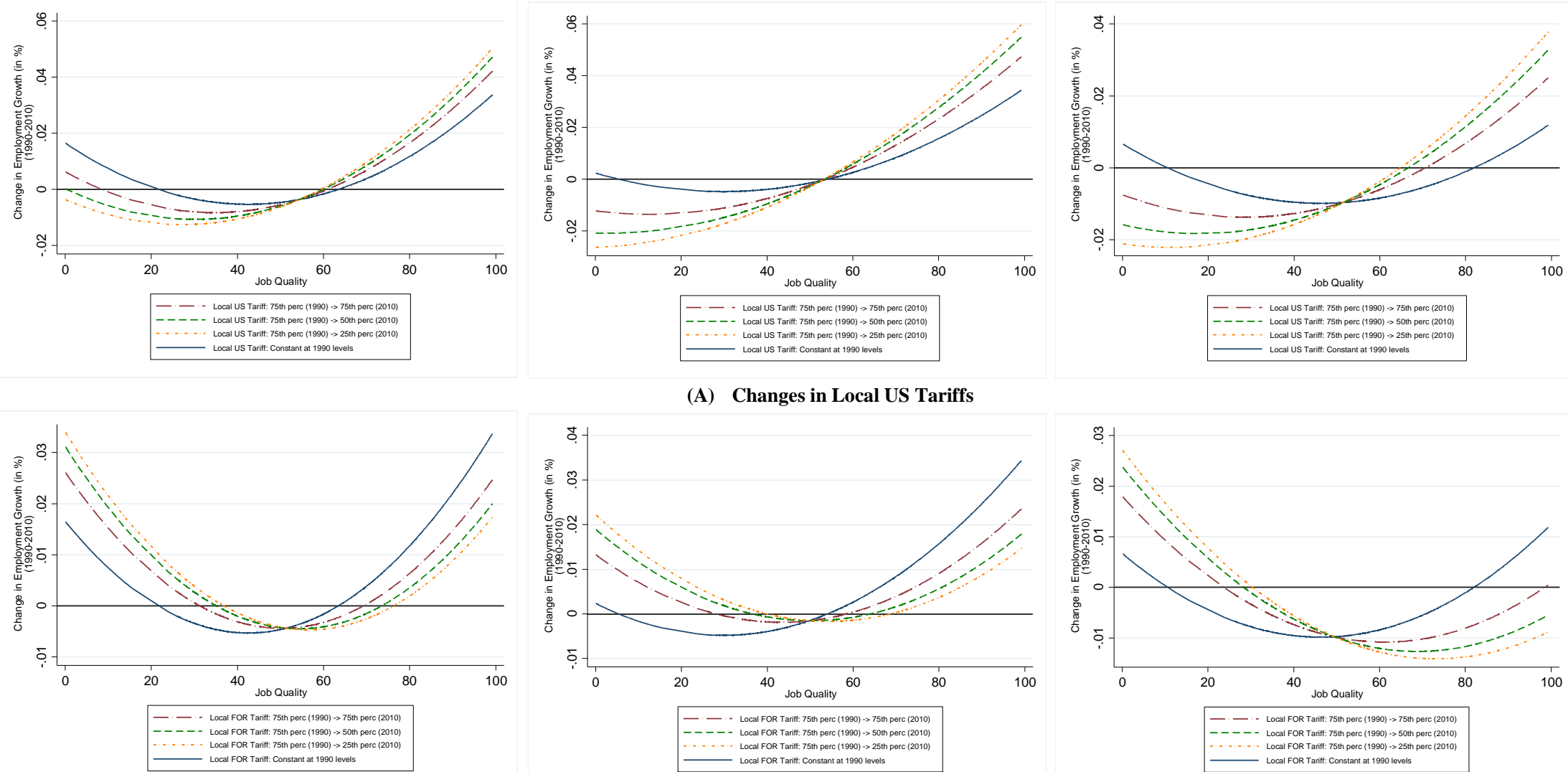

(A) Changes in Local US Tariffs
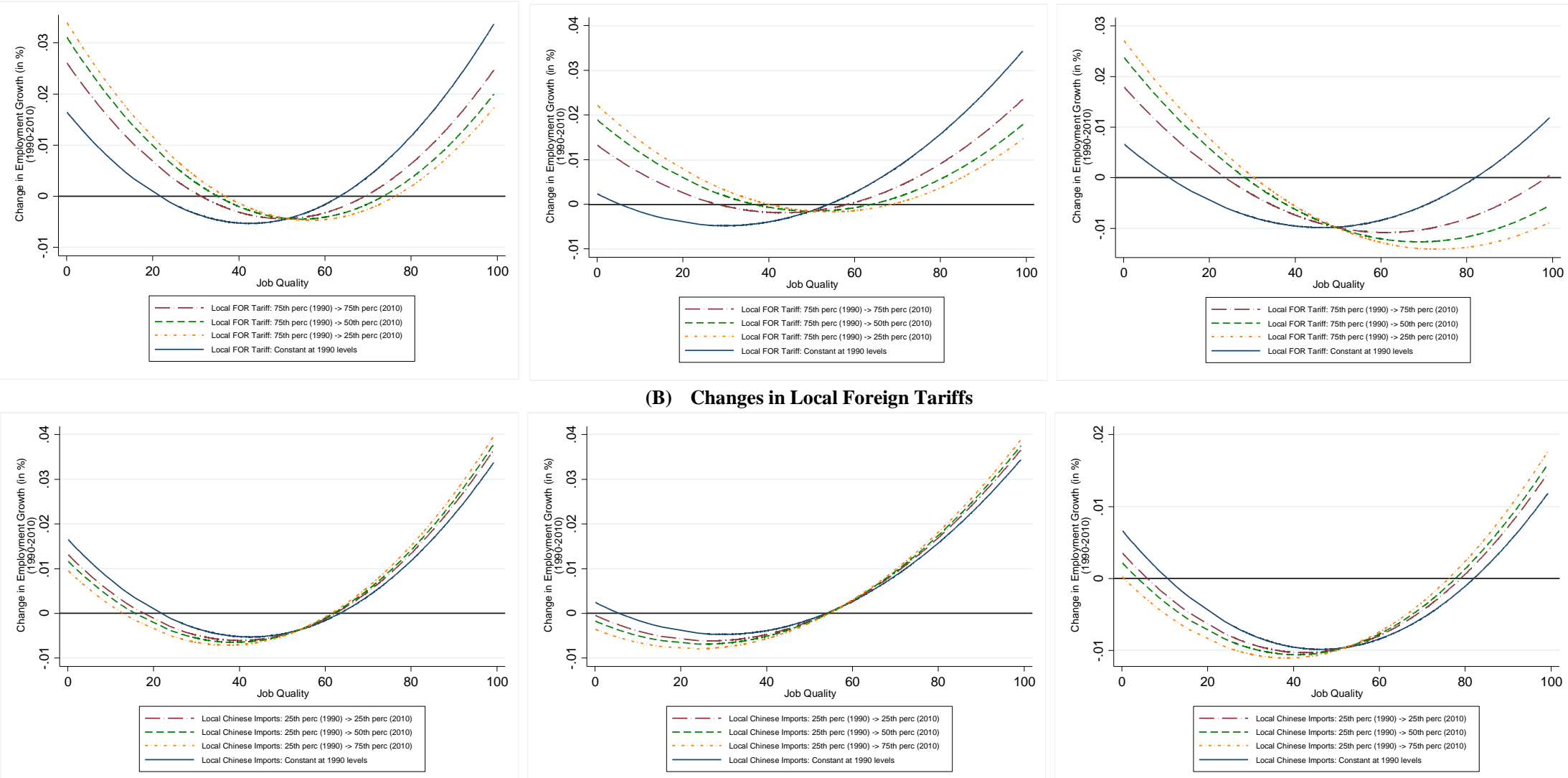

(C) Changes in Local Chinese Import Penetration

Figure A3. Impacts of Local Trade Variables on Changes in Local Employment Shares, 1990-2010: Heterogeneous Effects by Cohort.

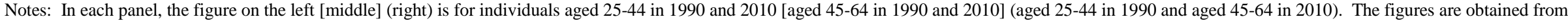
Specifications (2), (3), and (4), respectively, in Table A7. Job quality is measured as the NPB index (multiplied by 100). 